\title{
Static and Dynamic Strength Tests on Electrical Conductor Cables Specified for Airport Landing Structures
}

\author{
R. J.. Fields \\ S. R. Low, III \\ D. E. Harne
}

U.S. DEPARTMENT OF COMMERCE National Institute of Standards and Technology

Metallurgy Division

Gaithersburg, MD 20899

Propared for

Navigation and Landing Division

Federal Aviation Administration

Department of Transportation 

Static and Dynamic Strength Tests on Electrical Conductor Cables Specified for Aiport Landing Structures

\section{R. J.. Fields \\ S. R. Low, III \\ D. E. Harne}

U.S. DEPARTMENT OF COMMERCE National Institute of Standards and Technology Metallurgy Division Gaithersburg, MD 20899

\section{Prepared for}

Navigation and Landing Division Federal Aviation Administration Department of Transportation

October 1988

Issued September 1991

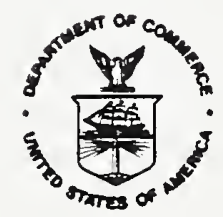

U.S. DEPARTMENT OF COMMERCE Robert A. Mosbacher, Secretary NATIONAL INSTITUTE OF STANDARDS AND TECHNOLOGY

John W. Lyone, Director 



\title{
Static and Dynamic Strength Tests on Electrical Conductor Cables Specified for Airport Landing Structures
}

R. J. Fields, S. R. Low, III, D. E. Harne

\author{
Metallurgy Division \\ National Bureau of Standards \\ Department of Commerce \\ Gaithersburg, MD \\ prepared for \\ Navigation and Landing Division \\ Federal Aviation Administration \\ Department of Transportation \\ Washington, DC
}




\section{Contents}

Administrative Information

Executive Summary

Background

Static Tests

Testing Procedure

Results

Discussion

Dynamic Tests

Design and Construction of Test Apparatus

Testing Procedure

Results

Discussion

Conclusions and Recommendations

List of Tables

List of Figures 


\section{ADMINISTRATIVE INFORMATION}

The research and measurements presented here were carried out under NBSFAA Interagency Agreement DTFA-01-85-Z-02007. The technical activities were monitored by Stephen A. Cannistra of the Federal Aviation. This report is the final report on conductor cables (one activity of several in the interagency agreement) and includes all details of experimental work, measurements, and conclusions relevant to the strength and impact behavior of certain conductor cables specified by the FAA for landing aids. The highspeed movies of the dynamic tests are in the possession of Stephen $A$. Cannistra.

\section{BACKGROUND}

In response to a National Transportation Safety Board Safety Recommendation (NTSB No. A-84-36), the Federal Aviation Administration authorized NBS to carry out a series of static and dynamic tests on electrical conductors specified for use in landing aids on airport runways. The structures are intended to be frangible so that they will break up readily if impacted, thus minimizing damage to the impacting aircraft. While the structures are frangible, they contain electrical cables which, due to the requirement of electrical conduction, are not frangible, In an actual impact, these cables do not break readily and tend to wrap around the aircraft. The tests authorized by the FAA were carried out to assess the force required to break through various types of FAA specified cables by a simulated aircraft impact. The types studies were:

14 AWG with type THW insulation 
12 AWG with type THW insulation

10 AWG with type THW insulation

10 AWG uninsulated

Furthermore, the effectiveness of using break-away connectors was evaluated to determine if they would reduce the total load on a impacting aircraft.

In order to correctly design the dynamic test apparatus, it was

necessary to know the approximate, expected load levels and cable elongations at fracture. Therefore a series of quasi-static tests were performed on the cables and break-away connectors. This report describes these quasi-static tests as well as the construction and application of the dynamic test apparatus .

\section{STATIC TESTS}

Test Procedure

Prior to testing each wire diameter was measured. The sheathing was removed at the gripped region and the diameter of the uninsulated copper cable was measured. The diameter of each individual strand was also measured prior to testing. These values were used in the determination of reductionof-area, true stress at fracture, and tension modulus.

Tension tests on the following electrical conductor cables were carried out:

(a) 7 stranded, 14 gage THW-type insulation

(b) 7 stranded, 12 gage THW-type insulation

(c) 7 stranded, 10 gage THW-type insulation

(d) 7 stranded, 10 gage bare

THW refers to an industry standard type of electrical insulation. These tests were carried out on a displacement-controlled, screw-driven testing 
machine at $21-23^{\circ} \mathrm{C}$ using displacement rates between 0.005 and $50 \mathrm{~cm} / \mathrm{min}$. Split capstan fixtures were used to grip the cables. These capstans allowed the wire to be wound around the capstan without crimping the wire in any manner. An initial gage length of $30.5 \mathrm{~cm}$ was used for each test and a minimum of three replicate tests were performed on each gage of wire at a given test rate. In no case did the results differ by more than $10 \%$ from the average value for a given cable type and testing condition. However, whenever failure of the cable occurred with $1 \mathrm{~cm}$ of the grip fixture, an additional test was performed. The load and specimen elongation were recorded digitally by a computer throughout each test. In general, at least 1000 data points were recorded per test. These data were stored on magnetic tape for post-test analyses.

From the tension tests, the ultimate tensile load, plastic yielding load, elongation to fracture, reduction in area, ultimate tensile strength, true stress at fracture, tension modulus, and total energy to failure were obtained. In addition, complete load-displacement and energy-displacement curves were generated from these tests.

NBS was able to obtain only one type of commercial break-away connector for these tests: Bussman ${ }^{1}$ type HEB-AW-RCL-A fuse holders. New connectors were tested each time in an identical fashion to that used for the copper conductor cables. However, only failure load, failure energy, loaddisplacement curves, and energy-displacement curves were recorded as results because no true deformation ever occurred in the tests on the break-away connectors.

${ }^{1}$ The use of trade names is only to fully document the research and does not imply endorsement by the NBS 
The results are given in Tables 1 to 5 . The ultimate tensile load ( $\mathrm{Pu}$ ) was the maximum load recorded during the test. The plastic yielding load was determined to be the load at which elastic or linear behavior ended. the elongation to fracture $\left(\epsilon_{f}\right)$ is given by

$$
\epsilon_{\mathrm{f}}=\frac{\ell-\ell_{0}}{\ell_{0}}
$$

where $l_{0}$ and $\ell$ are the initial and final gage lengths. Likewise, the reduction-in-area is defined as

$$
\text { R.A. }=\frac{A_{0}-A}{A_{0}}
$$

where $A_{0}$ and $A$ are the initial and final gage areas. These areas refer only to that of the copper strands and do not consider the area of the insulation. It is reasonable to ignore any contribution by the insulation because the insulation is so stretchable and soft compared to the copper that it contributes only a fraction of a percent to the strength. Nevertheless the insulation is somewhat important in that it tends to localize the fracture in the cable. More will be said about this in the discussion section.

The ultimate tensile strength and yield strength are calculated from

$$
\text { UTS }=P_{u} / A_{0}
$$

and

$$
\sigma_{\mathrm{y}}=\mathrm{P}_{\mathrm{y}} / \mathrm{A}_{0}
$$

where $P_{u}$ and $P_{y}$ are the ultimate tensile and load yielding load, respectively.

The true stress at fracture $\left(\sigma_{f}\right)$ is calculated from

$$
\sigma_{\mathrm{f}}=\frac{\mathrm{Pu}}{\mathrm{A}}
$$


since Pu usually occurred at the point of failure. The tension modulus (M) is determined as a function of the slope of the elastic line $\left(\frac{d P}{d l}\right)$.

$$
\mathrm{M}=\frac{\mathrm{dP}}{\mathrm{d} l} \frac{\ell_{0}}{\mathrm{~A}_{\mathrm{o}}}
$$

The load-displacement curves show the entire elastic, plastic, and fracture behavior. A representative selection of these curves are given in Figures 1-4. These curves may be integrated as follows to obtain the energy-displacement curves.

$$
E(\delta)=\int_{\Delta=0}^{\Delta} P d \Delta
$$

where $P$ is the load, $\Delta$ is the displacement, and $E(\Delta)$ is the energy expended to get to the displacement. Representative curves of energy versus displacement are shown in Figures 5-8. The total work of fracture $E\left(\Delta_{f}\right)$ is the energy expended to get to that displacement. Representative curves of energy versus displacement are shown in Figures 5-8. The total work of fracture $E\left(\Delta_{f}\right)$ is tabulated in Tables 1 to 5 .

Ultimate tensile loads and separation energy for the break-away connectors are listed in Table 6. Typical load versus displacement and energy versus displacement curves for the connectors are shown in Figures 9 and 10 .

\section{Discussion}

From the data presented in Tables 1 to 5 , it is clear that the ultimate tensile loads and the plastic yielding loads both increase with increasing rate for all the types of cable tested.

The ultimate tensile strength and plastic yield strength are fairly constant at a given rate. Therefore, this data may be used to predict the 
yielding and breaking loads of other gages of cable at these rates providing the initial area is known.

The reduction-in-area does not appear to depend on the gage of wire tested or the testing rate. Its average value is $85 \%$. The elongation-tofracture $\left(\epsilon_{\mathrm{f}}\right)$ also seems to be fairly independent of testing rate and wire gage.

The UTS and $\epsilon_{\mathrm{f}}$ seem to depend on whether the cable is insulated or not. The average $\epsilon_{f}$ for insulated cable is 448 while that for uninsulated cable is 20.98. The reason for this difference is due to a different failure mechanism in the uninsulated cable as compared to the insulated cable. Failure in both cases starts by the failure of one of the seven strands. If the cable is uninsulated, this strand unravels rapidly from the remaining strands, exposing the entire gage length to a 148 increase in average load. The next weakest strand breaks and unravels, raising the average stcess still further. In the insulated case, the failure of a strand is not followed by unravelling. Within a short distance of the failure, shear transfer permits the broken strand to support some load. As a consequence, the fracture of all seven strands occurs within a few millimeters of each other. This is in contrast to the uninsulated cable in which strands break anywhere along their $305 \mathrm{~mm}$ gage length. This presumably at their weakest cross-sections and results in a lower ultimate loads and shorter elongations-to-fracture.

The failure load for the bread-away connectors also depended on rate. This load level was much lower than that for any cable, requiring less than one tenth the force needed to break the smallest diameter cable tested here. DYNAMIC TESTS

Design and Construction of Test Apparatus 
The test apparatus design consisted of an impactor, simulating an aircraft wing, which was propelled along two guide rails to impact a test wire until the wire is broken. The impactor was propelled using a pull cable system, in which one end of a pull cable was attached to the impactor and the other was rapidly wound up on a rotating flywheel. The flywheel and guide rails were supported by a rigid steel frame which also housed the grips which supported the test wire in the position for testing. The transient load applied to the test wire was measured by strain gages affixed to the connecting rods for the grips; the strain signal being monitored through a high frequency bridge-amplifier system and recorded on a transient digital oscilloscope.

The apparatus for this test required a stiff test frame high enough to test both the $6.1 \mathrm{~m}(20 \mathrm{ft})$ and the 3.1 (10 ft) length test wires, and long enough to allow sufficient travel time, prior to impact, for the impactor to accelerate to the desired impact velocity and also to give an adequate run off for the test wire to stretch before breaking. To properly design the rigid test frame an approximate maximum load was needed. The rate dependence of the ultimate tensile load determined from the quasi-static tests was used to extrapolate the ultimate tensile load to rates expected during the dynamic tests. The form of equation used was

$$
\mathrm{UTL}=(\mathrm{A}=\mathrm{B} \log \ddot{\Sigma})^{-1}
$$

Where $" \dot{\Sigma}$ is the strain rate and $A$ and $B$ are fitting constraints. This approach predicted a maximum load of about 500 lbf. A safety factor was further employed to assure that the test frame did not significantly deflect, distort, or buckle during the test. The quasi-static elongation-to-failure was used to determine the size of the test frame. This approach assured that 
failure would occur before the impactor ran out of travel. Again a safety factor was employed in case the dynamic ductility was significantly greater than the quasi-static ductility.

A rectangular frame was thus designed and constructed having a height of $6.4 \mathrm{~m}(21 \mathrm{ft})$ and a length of $7.9 \mathrm{~m}(26 \mathrm{ft})$, with a vertical support in the center as shown in Figure 11. The frame was actually two identical parallel frames constructed of W4X13 steel beams measuring $10.5 \mathrm{~cm}$ by $10.2 \mathrm{~cm}(4.1$ in by 4 in) with a $0.63 \mathrm{~cm}(0.25 \mathrm{in})$ web and $0.95 \mathrm{~cm}(0.37$ in) flange thicknesses. The two frames are rigidly attached together having a $30 \mathrm{~cm}$ (12 in) separation for the impactor to travel between. The guide rails for the impactor are steel channels attached to the inside of the frames, and can be moved to the different testing heights required for various lengths of test wires.

The impactor, shown in Figure 12, was designed to travel within the guide rail channels on teflon sheets bolted to either side of its aluminum plate carriage. A $11.4 \mathrm{~cm}$ (4.5 in) diameter aluminum tube was affixed to the aluminum carriage to simulate the curvature of an aircraft wing. Edge stops were added to the ends of the tube to restrain the test cable from moving off the tube during impact with a test wire. A steel bolt was fastened through the impactor body for attaching the nylon drag line which was, in turn, pulled by the flywheel. A loop at the end of the drag line was attached to the impactor by placing it loosely around the steel bolt so that the impactor released from the drag line as it passed over the flywheel. This kept the impactor from being destroyed by being pulled into the rotating flywheel. The flywheel was powered by a $7 \mathrm{HP}$ electric motor and was constructed of a 20 $\mathrm{cm}$ (8 in) diameter steel cylinder, $58 \mathrm{~cm}(23 \mathrm{in})$ long. The two ends were 
reduced in diameter for insertion into pillow block bearings that were mounted on a steel support shelf below the impactor guide rails. For impact heights above the level of the support shelf, a $4.13 \mathrm{~cm}(1.62 \mathrm{in})$ diameter steel pipe was mounted to the test frame over and in line with the flywheel. This arrangement allowed the drag line to travel just below and parallel to the guide rails, over the pipe and turned at a right angle down to the flywheel.

During an actual test, when the flywheel achieved the proper rate of rotation, a lever mechanism (Figure 13) was pulled which attached a loop at the end of the drag line around one of two $1.3 \mathrm{~cm}(0.5 \mathrm{in})$ diameter bolts which were threaded into the center of the flywheel. Two bolts, diametrically opposed to each other, were used in order to retain balance in the flywheel. After the drag line attached, it was rapidly wound onto the rotating flywheel, pulling the impactor down the guide rails. Because the quantity of energy that was stored in a flywheel of this size and mass was large compared to the energy required to pull the impactor and break the test wire, very little reduction in impactor velocity occurred throughout the impact event.

The rotation frequency of the flywheel was constantly monitored from the initial start-up of the motor, until impact of the test wire occurred. This was accomplished with a light sensitive photo diode that sensed a light pulse reflected from a mirror mounted on the side of the flywheel (Figure 14). The photo diode produced a variation in voltage each time the light pulse struck it. The voltage change triggered a frequency meter. Knowing the rotation frequency and the diameter of the flywheel, an approximate value of the 
resultant impactor velocity could be computed. This was used as a guide for determining when to engage the drag line and start the test.

The actual velocity of the impactor was determined by using photodiodes placed at known positions along the path of the impactor and connected in series. As the impactor passed each photodiode, a voltage pulse was generated, and the signal was recorded on one channel of the oscilloscope. By measuring the time intervals between pulses, the impactor velocity was calculated at the positions of each of the photodiodes. A total of twelve photodiodes were mounted on the guide rails at positions ahead of the test cable, at the initial point where the impactor contacts test cable, and at positions after the impact point.

The test cable was held in the vertical position for testing by supporting each end of the cable with split capstan grips designed for holding wire and cable. Connecting rods were specially designed and constructed which exhibit a measurable elastic strain in response to the loads experienced by the test cable during an impact. This transient strain was measured by strain gages affixed to the surface of the rods. Two stacked, biaxial strain gages were positioned diametrically opposed to each other on each of the two rods such that the longitudinal and transverse strains were measured. Two gages were used on each rod, in this manner, to adjust for bending in the rod. The strain signals were monitored through a bridge-amplifier system (Figure 15) specifically designed to measure dynamic strain pulses. The strain levels were stored as voltage levels on separate channels of a transient digital oscilloscope (Figure 16). The strain level (or voltage level) was related to load by performing periodic calibrations of the instrumented pull rods. This was done by connecting the two pull rods 
with a chain hoist and dial dynamometer (a type of load measuring device). The chain hoist was tightened and the load indicated on the dynamometer was correlated with the output voltage of the strain gage-bridge-amplifier system. In general, the load was calibrated in this way beyond $2227 \mathrm{~N}$ (500 lbf) which was considerably above the forces observed during any test. The correlation between voltage level and load was linear and an example is shown in Figure 17.

Film records of the tests were made. Two high speed $16 \mathrm{~mm}$ film cameras were placed at $90^{\circ}$ apart viewing positions and recorded an unobstructed view of the impact event. One of these cameras is seen mounted on a tripod in Figure 11. Framing speeds of 500 to 2000 frames/sec were used.

The unique nature of this test has required that much of the test apparatus be specially designed for this program. This has resulted in a great deal of testing and redesign in order to meet the specified test criteria. The violent, high speed impact involved in this test also necessitated the rebuilding of some of the test apparatus components periodically or as often as each wire test. As a consequence, the dynamic tests took much longer than initially estimated.

\section{Results}

A typical output of the photodiode array is shown in Figure 18 . The photodiodes were positioned as follows:

\section{Diode \#}

1

2

3

4

5

6

7

8
Position w.r.t. Impact (mm)

$-1200$

$-900$

$-600$

$-300$

0

$+300$

$+600$

$+900$ 
Using the time at which the impactor passed a given diode (i.e., the peak voltage) and the position of that diode, the velocity at the time was calculated. This information is listed in Table 7. Three velocities were determined for each test: the maximum velocity of the impactor $\left(V_{m a x}\right)$, the minimum velocity $\left(V_{\min }\right)$, and the average velocity $\left(V_{a v e}\right)$.

Futhermore, the deflection of the cable at anytime (and especially at failure) was determined from the phtodiode record since the cable was always in contact with impactor. The original length $\left(l_{0}\right)$ of cable above $\left(l_{0}^{A}\right)$ and below $\left(\ell_{0}^{B}\right)$ the impactor was combined with the deflection at failure $\left(\Delta \mathrm{x}_{\mathrm{f}}\right)$ to calculate the elongation-to-failure:e

$$
\epsilon_{f} \quad=\frac{\left[\left(\ell_{0}^{A}\right)^{2}+\Delta x_{f}^{2}\right]^{t}+\left[\left(\ell_{0}^{B}\right)^{2}+\Delta x_{f}^{2}\right]^{\ddagger}}{\ell_{0}}-1
$$

The elongations-to-failure are tabulated in Table 7. Representative load records from the top and bottom pull-rods are shown in Figures 19-26. Due to the dynamic loading of the cable, an oscillation is set up which is clearly detected in these records. This oscillation makes it impossible to measure the tension modulus or the plastic yielding load. However, the ultimate tensile load (which is the most important design load) is easily determined. This quantity is listed in Table 8 for the top and bottom pull rods. The top and the bottom differ because the cable is being impacted above its middle in both the $10 \mathrm{ft}$ and $20 \mathrm{ft}$ tests. Furthermore, the fact that the forces are different in the top and bottom suggests that no slippage of the cable around the impactor occurs. Slippage would tend to equalize the force in the top and the bottom. Since the impact was always specified to be 
closer to the upper grip, the force in the cable above the impactor was always the greatest and failure always occurred in this part of the cable. Therefore, only the dynamic elongation-to-failure in the cable above the impactor should be compared to that obtained in the quasi-static tests.

Using the maximum forces in the upper ( $F_{\max }^{A}$ ) and lower portions ( $F_{\max }^{B}$ ) of the cable and the deflection at failure $\left(\Delta \mathrm{x}_{\mathrm{f}}\right)$, the resolved maximum force on the impactor was calculated as

$$
F_{\max }^{I m}=F_{\max }^{A} \frac{\Delta x_{f}}{\left[\left(l_{0}^{A}\right)^{2}+\Delta x_{f}^{2}\right]^{\frac{3}{2}}}+F_{\max }^{B} \frac{\Delta x_{f}}{\left[\left(l_{0}^{B}\right)^{2}+\Delta x_{f}^{2}\right]^{\frac{3}{2}}}
$$

where $\ell_{0}^{A}$ and $\ell_{0}^{B}$ are the initial lengths of cable above and below the impactor, respectively. This is the force that an aircraft wing would experience in a similar dynamic event. These forces are listed in Table 8 for the various cable types.

The energy expended in breaking these cables has also been calculated from the load and position data. The energy absorbed up to any time ( $t$ ) during the impact by the upper portion of cable is given by:

$$
E_{A}(t)=\int_{t=0}^{t} F_{A} d \Delta_{A}=\int_{t=0}^{t} \frac{F_{A} V^{2} t}{\left[(V t)^{2}+\left(1_{0}^{A}\right)^{2^{3 / 2}} d t\right.}
$$

where $\mathrm{V}$ is the average velocity (see Table 11). A similar expression may be written for the lower portion of cable. Representative curves of energy consumption are shown in Figures 27-34. The total energy expended is the sum of that absorbed by the upper and lower portions of the cable at failure. This quantity is listed in Table 8 and represents the amount of work an aircraft would have to do to break one of these cables. 
The break-away connectors were tested in two configurations: a single connector located in the middle of the upper portion of the cable and two connectors, one located in the upper and one in the lower portion of the cable. The two connector configuration was tried because, when only one was used, the remaining portion of cable would wrap itself around the impactor. To free itself, the impactor usually had to break the cable. Therefore, a single connector would not necessarily reduce the load in a dynamic impact situation. Typical load-time curves and energy-time curves are shown in Figures 35 to 42. The maximum load and energy-to-failure are listed in Table 9. Clearly, multiple connectors lead to considerably reduced failure loads and energies when compared to the cables without break-away connectors.

\section{Discussion}

The ultimate tensile strength for the four types of cables has been plotted against displacement rates ranging from the quasi-static to the dynamic in Figures 43-46. Curves have been drawn through these data points. The solid lines represent the best fit regression line using all the data. The dashed lines are the best fit regression line using only the quasi-static data and extrapolated to the dynamic rates. The equation of these lines are of the form

$$
\mathrm{UTS}=(\mathrm{A}+\mathrm{B} \log \Sigma)^{-1}
$$

where $\dot{\Sigma}$ is the strain rate and $A$ and $B$ are fitting parameters. The values of $A$ and $B$ determined using quasi-static data and quasi-static plus dynamic data are listed in Table 10. While there parameters are fairly similar, using only quasi-static data usually predicts dynamic strength which are $10-15 \%$ lower than the observed values. 
The elongation-to-failure in the upper portion of the cable, i.e., that part of the total cable that experienced failure, agrees tolerably well with that measured in quasi-static tests.

The break-away connectors require very little force or energy to separate when compared to the cables, even at the dynamic rates applied here. However, when the remaining cable wraps itself around the impactor, forces equal to that required to break the cable are observed. Clearly, wrapping of the cable around a wing could occur in actual applications. For this reason, two connector tests were carried out. In these tests, separation of connectors above and below the impactor took place at very low loads. If break-away connectors are used, two or more should be employed per cable to assure that, even in the event of cable wrapping very low forces are applied to the impacting aircraft and very little energy is required for complete separation.

\section{CONCLUSIONS AND RECOMMENDATIONS}

A series of quasi-static and dynamic strength tests on electrical conductor cables specified for airport landing structures have been carried out. The breaking loads, energies, and ductilities have been determined from four types of cables under conditions simulating impact by an aircraft wing. Additional quasi-static and dynamic breaking loads and energies were determined for a commercially available break-away connector. From these tests, the following conclusions may be drawn:

- The average 75 knot breaking loads for the 14 AWG THW, 12 AWG THW, 10 AWG THW, and 10 AWG uninsulated cable are 207, 334, 468, and 389 lbf, respectively. The energies expended breaking these cables were $234,318,262$, and $215 \mathrm{ft}-\mathrm{lbf}$, respectively. 
- The 75 knot breaking load for the connectors averages $50 \mathrm{lbf}$ regardless of the cable size or type. The breaking energy is less than $1 \mathrm{ft}-\mathrm{lbf}$.

- The dynamic strengths of the cables are higher by 10 to 15 \% than that predicted by extrapolation of quasi-static tests.

From the tests carried out, it appears that the break-away connectors provide for a significant reduction in loading while maintaining electrical continuity. However, use of only one connector can lead to the remaining cable wrapping around the impacting body. This occurrence results in breaking loads and energies equal to that required for cable failure. To realize the benefits of break-away connectors, at least two or more must be strategically placed on each conductor cable. 


\section{List of Tables}

Table 1. Results of tensile tests: testing rate $=0.005 \mathrm{~cm} / \mathrm{min}$.

Table 2. Results of tensile tests: testing rate $=0.05 \mathrm{~cm} / \mathrm{min}$.

Table 3. Results of tensile tests: testing rate $=0.5 \mathrm{~cm} / \mathrm{min}$.

Table 4. Results of tensile tests: testing rate $=5 \mathrm{~cm} / \mathrm{min}$.

Table 5. Results of tensile tests: testing rate $=50 \mathrm{~cm} / \mathrm{min}$.

Table 6. Results of tensile tests on break-away connectors.

Table 7. Impactor velocities, cable deflection, and elongation-to-failure determined from photodiode array

Table 8. Results of dynamic tests on conductor cables.

Table 9. Results of dynamic tests on break-away connectors

Table 10. Rate Dependent Strength Parameters 


\section{List of Figures}

Figure 1. Load-displacement curve of 14 gage insulated cable determined at displacement rate of $5 \mathrm{~cm} / \mathrm{min}$.

Figure 2. Load-displacement curve for 12 gage insulated cable determined at a displacement rate of $0.5 \mathrm{~cm} / \mathrm{min}$.

Figure 3. Load-displacement curve for 10 gage insulated cable determined at a displacement rate of $0.5 \mathrm{~cm} / \mathrm{min}$.

Figure 4. Load-displacement curve for 10 gage uninsulated cable determined at a displacement rate of $5 \mathrm{~cm} / \mathrm{min}$.

Figure 5. Energy-displacement curve for 14 gage insulated cable determined at a displacement rate of $5 \mathrm{~cm} / \mathrm{min}$.

Figure 6. Energy-displacement curve for 12 gage insulated cable tested at a displacement rate of $0.5 \mathrm{~cm} / \mathrm{min}$.

Figure 7. Energy-displacement curve for 10 gage insulated cable tested at a displacement rate of $0.5 \mathrm{~cm} / \mathrm{min}$.

Figure 8. Energy-displacement curve for 10 gage uninsulated cable tested at a displacement rate of $5 \mathrm{~cm} / \mathrm{min}$.

Figure 9. Load-displacement curve for a break-away connector tested at a displacement rate of $5 \mathrm{~cm} / \mathrm{min}$.

Figure 10. Energy-displacement curve for a break-away connector tested at a displacement rate of $5 \mathrm{~cm} / \mathrm{min}$.

Figure 11. Schematic of dynamic test apparatus and photograph showing a test cable being placed in the grips. A high speed camera can be seen on a tripod to the right of the test apparatus.

Figure 12. The impactor positioned in the guide rails prior to a test.

Figure 13. The pull cable or drag line is held in position by a lever mechanism ( $Y$-shaped arm) prior to attachment to the rotating flywheel.

Figure 14. The flywheel is the cylindrical object in the center of the photograph. The photodiode device for monitoring the flywheel rotation frequency is mounted to the right of the flywheel.

Figure 15. The bridge-amplifier system used to condition the strain signals from the grip connecting rods. A test cable split capstan grip, and connecting rod can be seen on the left between the two uprights of the test apparatus .

Figure 16. Electronic equipment used for the dynamic test. 
Figure 17. Correlation between voltage level from strain gage conditioners and actual load.

Figure 18. Typical electrical output of photodiode array during test. Bottom peaks occur when impactor leaves a photodiode unit.

Figure 19. Load-time records for a $10 \mathrm{ft}$ long, 14 gage, insulated cable.

Figure 20. Load-time records for a $10 \mathrm{ft}$ long, 12 gage, insulated cable.

Figure 21. Load-time records for a $10 \mathrm{ft}$ long, 10 gage, insulated cable.

Figure 22. Load-time records for a $10 \mathrm{ft}$ long, 10 gage, uninsulated cable.

Figure 23. Load-time records for a $20 \mathrm{ft}$ long, 14 gage, insulated cable.

Figure 24. Load-time records for a $20 \mathrm{ft}$ long, 12 gage, insulated cable.

Figure 25. Load-time records for a $20 \mathrm{ft}$ long, 10 gage, uninsulated cable.

Figure 27. Energy-time records for a $10 \mathrm{ft}$ long 14 gage, insulated cable.

Figure 28. Energy-time records for a $10 \mathrm{ft}$ long, 12 gage, insulated cable.

Figure 29. Energy-time records for a $10 \mathrm{ft}$ long, 10 gage, insulated cable.

Figure 30. Energy-time records for a $10 \mathrm{ft}$ long, 10 gage, uninsulated cable.

Figure 31. Energy-time records for a $20 \mathrm{ft}$ long, 14 gage, insulated cable.

Figure 32. Energy-time records for a $20 \mathrm{ft}$ long, 12 gage, insulated cable.

Figure 33. Energy-time records for a $20 \mathrm{ft}$ long, 10 gage, insulated cable.

Figure 34. Energy-time records for a $20 \mathrm{ft}$ long, 20 gage, uninsulated cable.

Figure 35. Load-time records for a $10 \mathrm{ft}$ long cable with one break-away connector located $8.5 \mathrm{ft}$. above lower grip, i.e., at midpoint of cable above impact point.

Figure 36. Energy-time records for test shown in Figure 35.

Figure 37. Load-time records

Figure 38. Energy-time records for test shown in Figure 37.

Figure 39. Load-time records for cable tested with break-away connectors located $1 \mathrm{ft}$ above and $1 \mathrm{ft}$ below impact point, i.e., $2 \mathrm{ft}$ span.

Figure 40. Energy-time records for test shown in Figure 39. 
Figure 41. Load-time records for cable tested with break-away connectors located $1 \mathrm{ft}$ above bottom grip and $1 \mathrm{ft}$ below top grip, i.e., $18 \mathrm{ft}$ span.

Figure 42. Energy-time records for test shown in Figure 41.

Figure 43. Ultimate tensile strength as a function of strain rate for 14 AWG/THW cable.

Figure 44. UTS as a function of strain rate for 12 AWG/THW cable.

Figure 45. UTS as a function of strain rate for 10 AWG/THW cable.

Figure 46. UTS as a function of strain rate for 10 AWG uninsulated cable. 
$\stackrel{0}{-1} \stackrel{0}{2} \stackrel{2}{=}$

ॠ

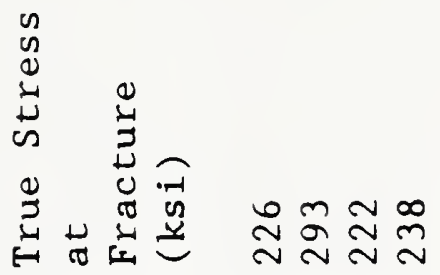

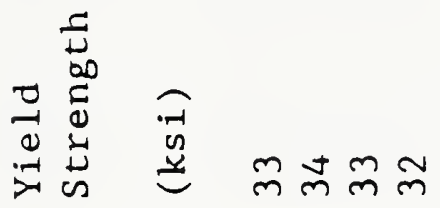

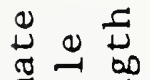

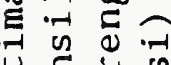

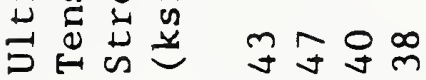

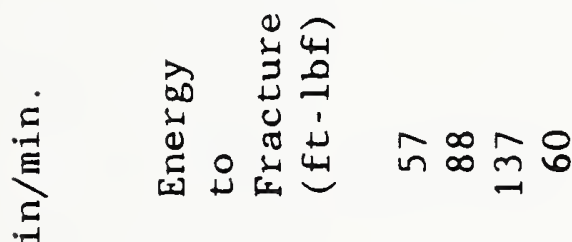

ช

4

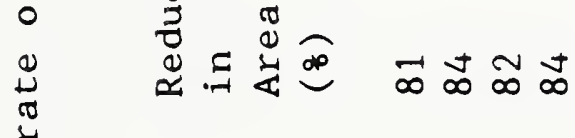

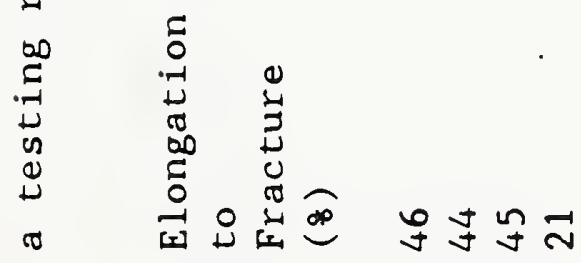

岁

焉

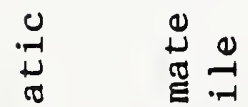

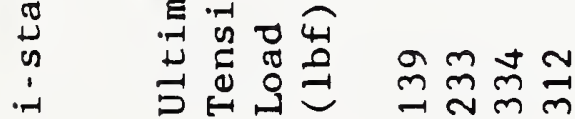

ज

$\stackrel{\text { o }}{3}$

$-$

$\stackrel{0}{\frac{0}{0}}$

$333 \stackrel{0}{3}$

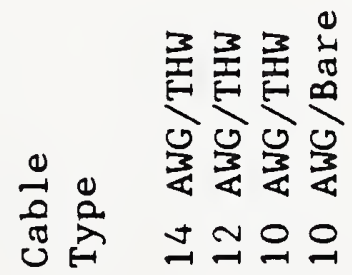


$\stackrel{0}{=} \cong$

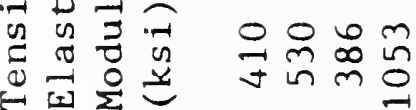

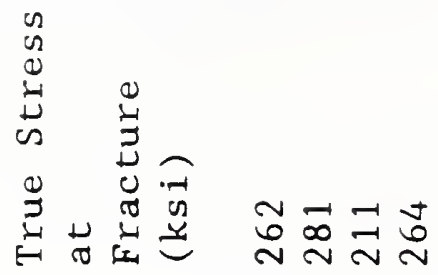

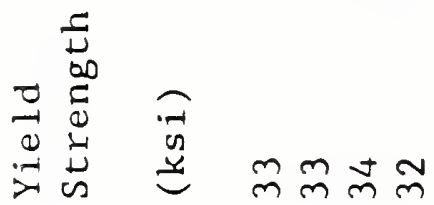

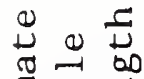

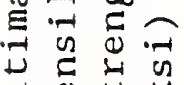

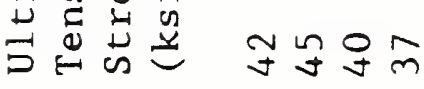

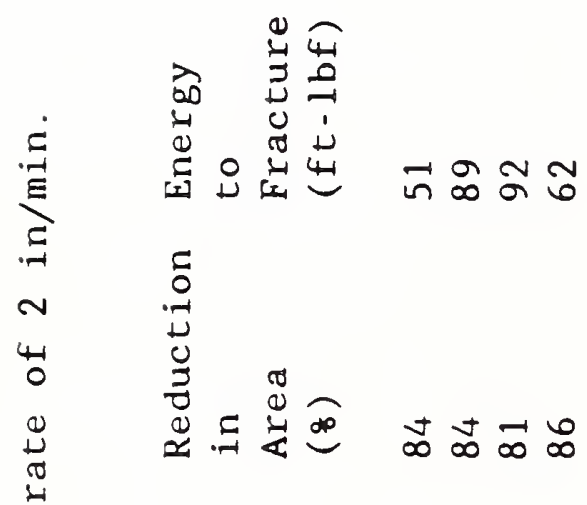

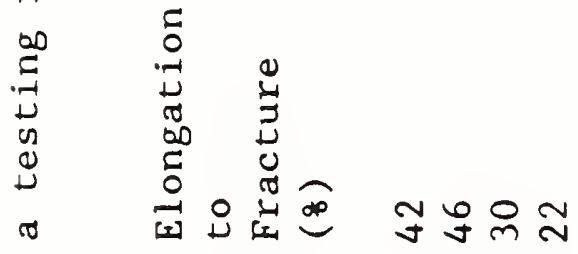

$\stackrel{\sim}{\sigma}$

o $\quad 0$.

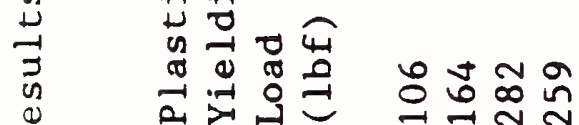

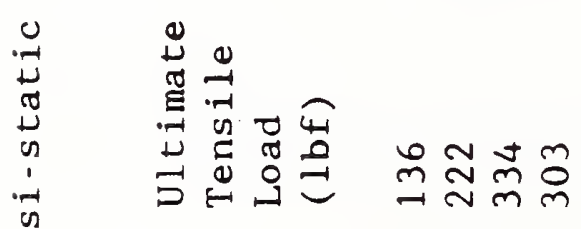

疋

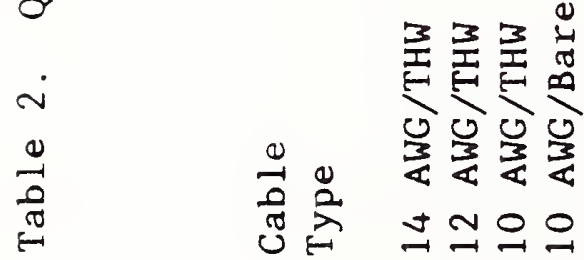




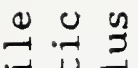

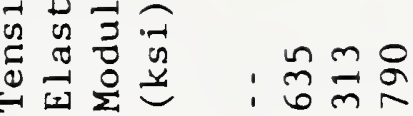

is

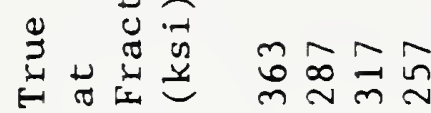

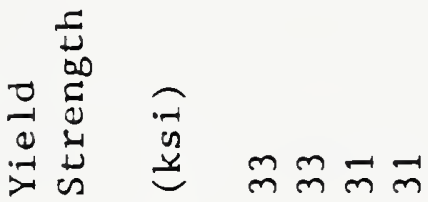

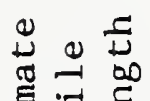

包可

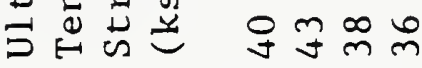

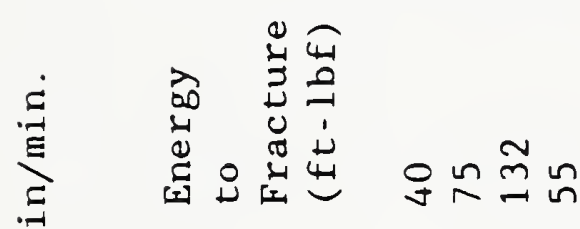

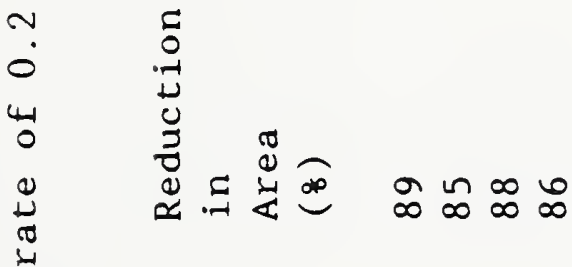

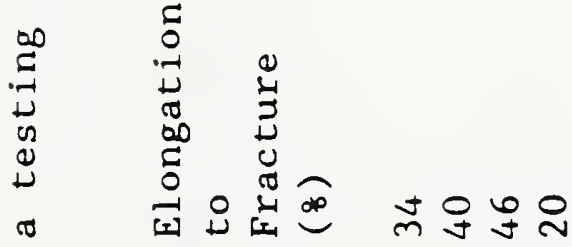

崩

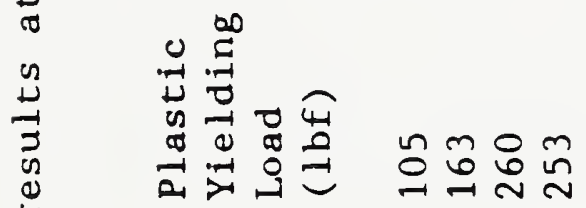

姜

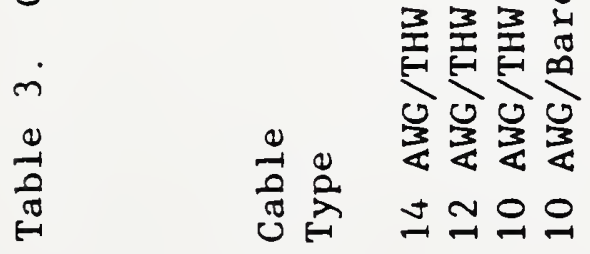




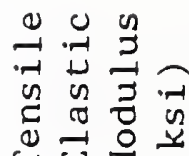

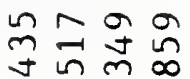

焉点

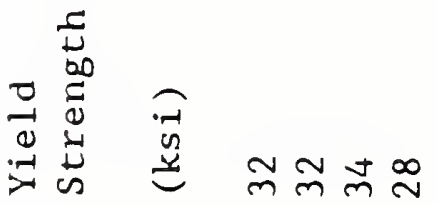

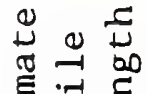

ज行

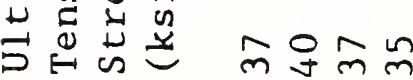

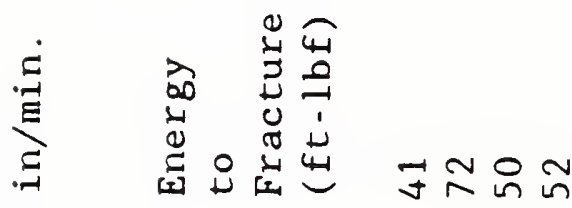

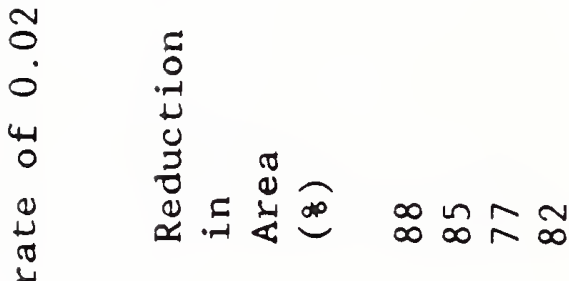

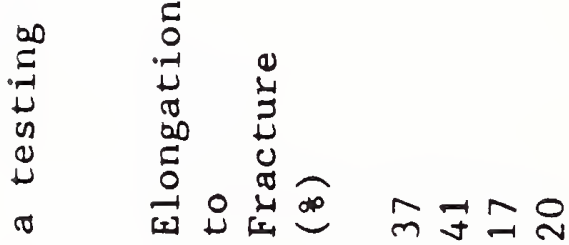

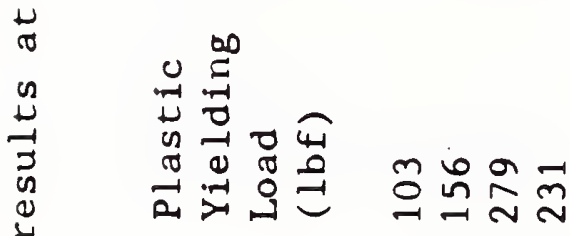

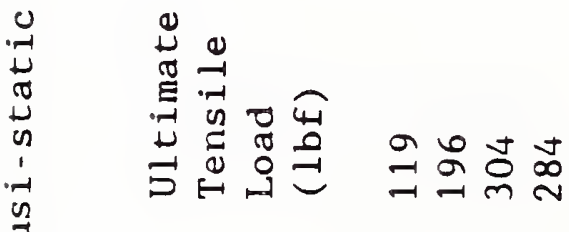

$\frac{5}{2}$

i

433

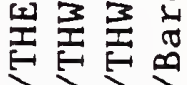

잉ำ

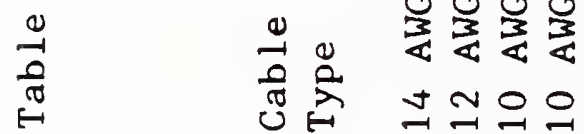




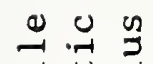

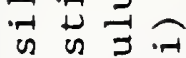

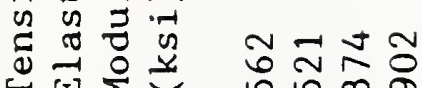

in

$\stackrel{Ð}{3}$

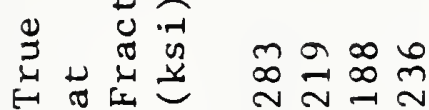

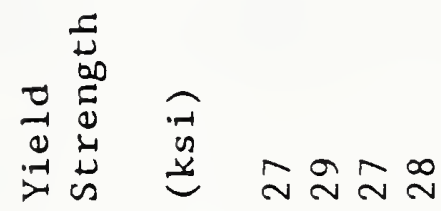

د

㐘: $=0$

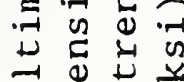

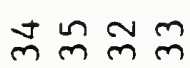

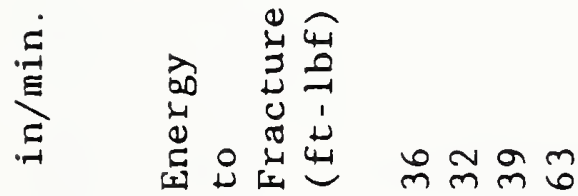

ชิ

:

๑5

㟧

(1)

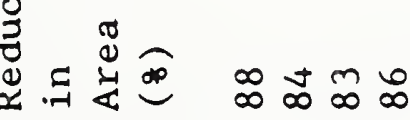

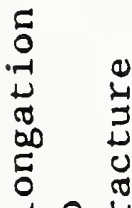

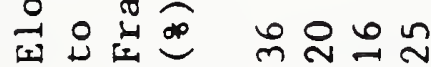

0 串

击

की

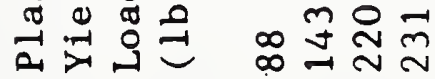

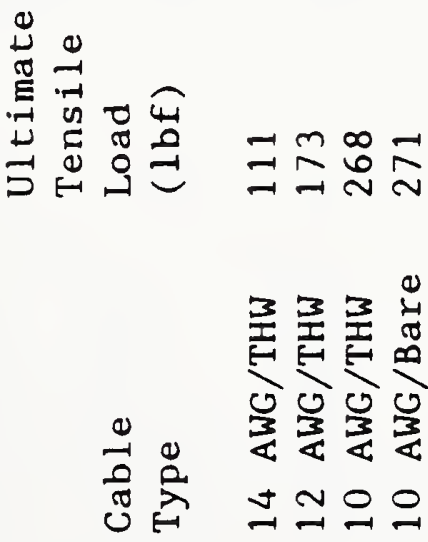


Table 6. Quasi-static results for break-away connectors.

$\begin{array}{lll}\begin{array}{l}\text { Testing Rate } \\ \text { (in/min) }\end{array} & \begin{array}{l}\text { Ultimate } \\ \text { Tensile } \\ \text { Load } \\ \text { (lbf) }\end{array} & \begin{array}{l}\text { Separation } \\ \text { Energy } \\ \text { (ft-lbf) }\end{array} \\ 20 & 9.8 & 0.60 \\ 2 & 8.0 & 0.50 \\ 0.2 & 7.3 & 0.40 \\ 0.02 & 6.1 & 0.39 \\ 0.002 & 7.9 & 0.44\end{array}$




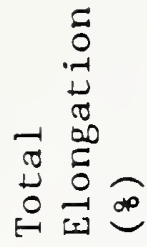

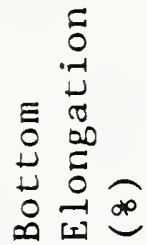

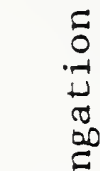

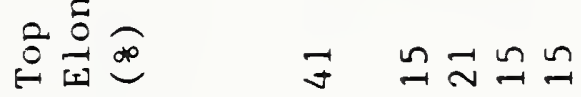

$\checkmark \sim m$ कंषं

ง $a$ no $\infty$ in

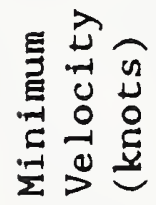

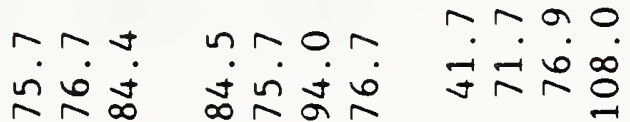

$\infty \sim \infty$

$\operatorname{nin}$

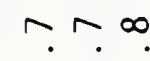
ำก 요요

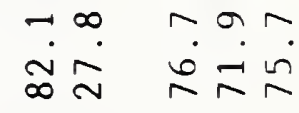<smiles>[CH-]=[SnH2]</smiles>
HNm HNm

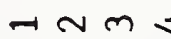

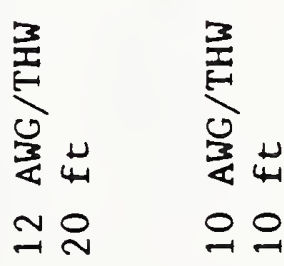
$\simeq$ 오

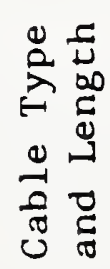

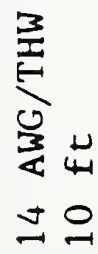

3
$\substack{3 \\ 0}$
30
祍

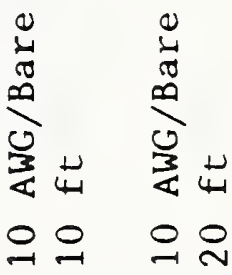




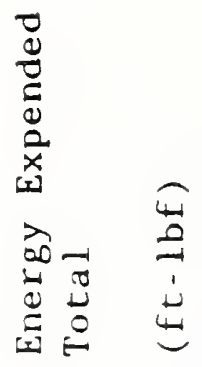

윷요욤

ก๐

을ํำ

$\stackrel{\sim}{\Xi} \underset{\sim}{=} \stackrel{m}{=}$

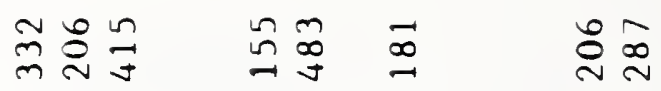

ร๐ป

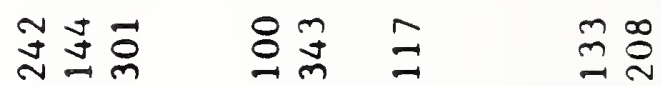

$\infty$

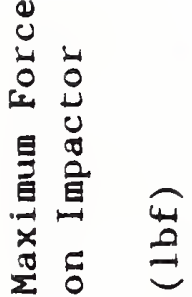

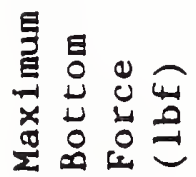

递

至

离

苋

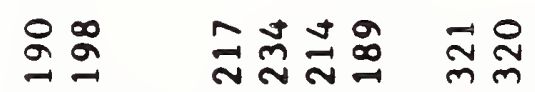

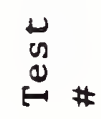

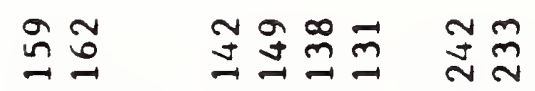

Nलतन mm

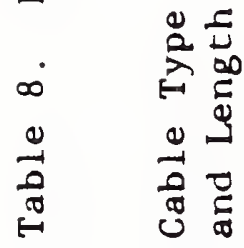

守永声

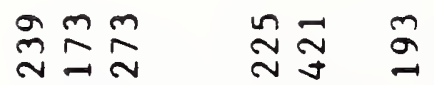

$\stackrel{ฐ}{2}$

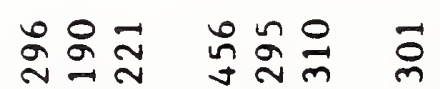

$\stackrel{\infty}{\sim} \quad \stackrel{n}{m} \stackrel{\infty}{m} \stackrel{m}{=}$

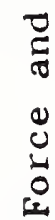

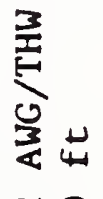

$\simeq 0$

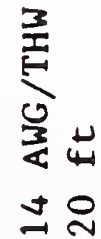

蛋

疍
군 으으 은
命 $\quad \stackrel{n}{\Xi} \quad \stackrel{m}{m}$

出

0

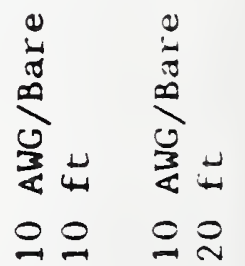




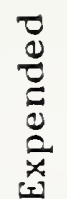

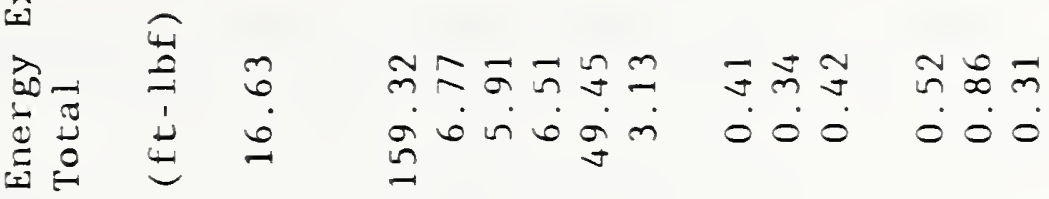

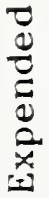

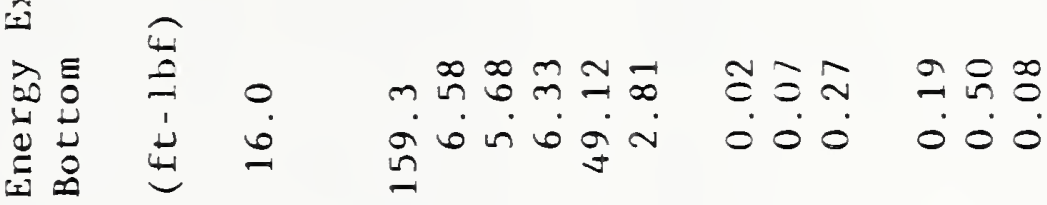

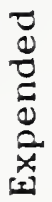

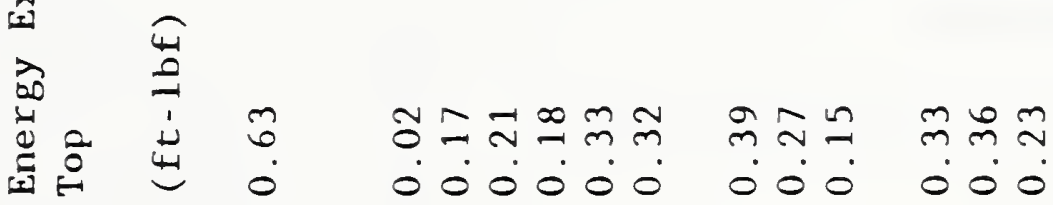

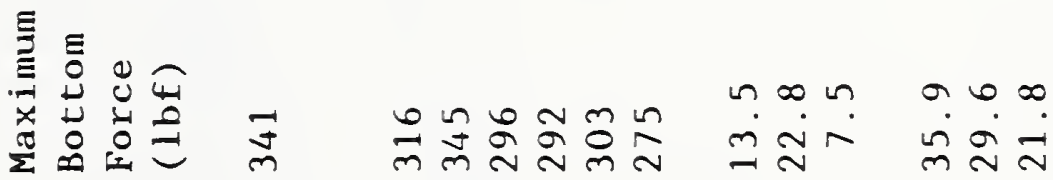

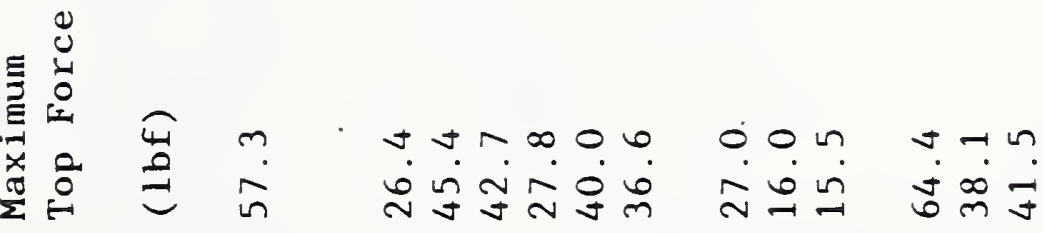

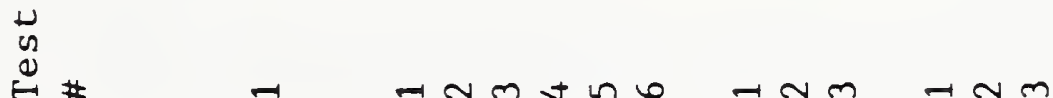

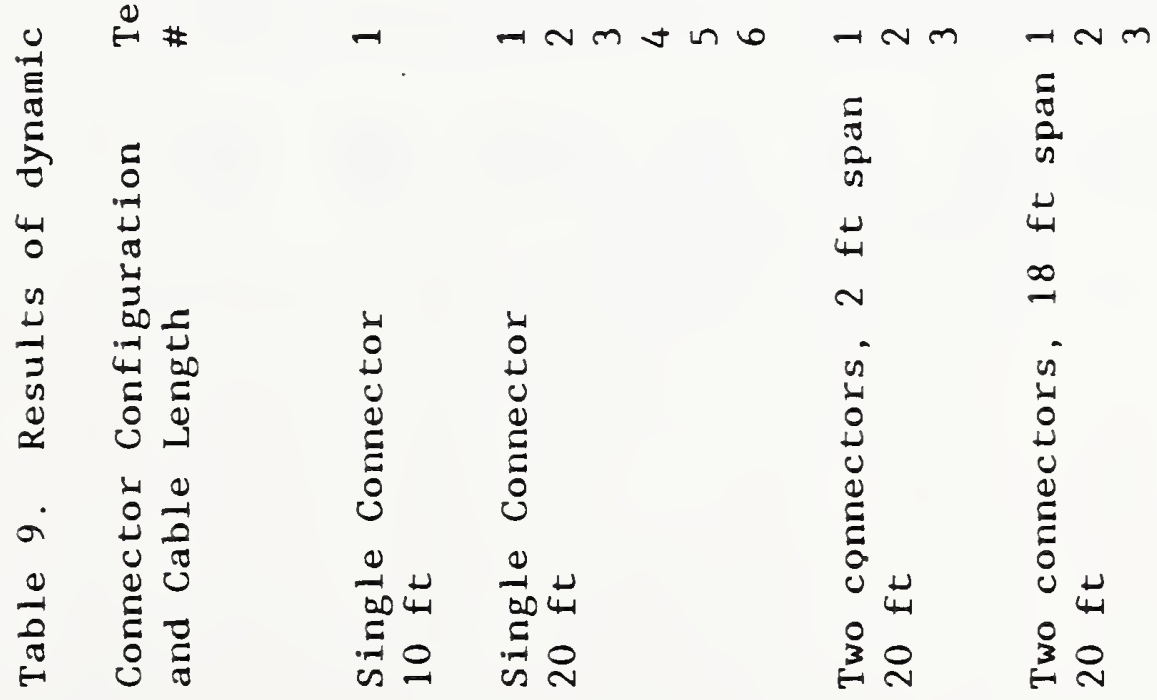




\section{Table 10. Rate Dependent Strength Parameters}

Cable Type

14 AWG/THW
12 AWG/THW
10 AWG/THW
10 AWG/THW

* Fitted to all data

** Fitted only to quasi-static data

\section{Predicted Parameters}

A

B

$0.0246 \quad-0.00155$

$0.0229-0.00174$

$1.0254 .-0.00187$

$0.0268 \quad-0.00143$ 


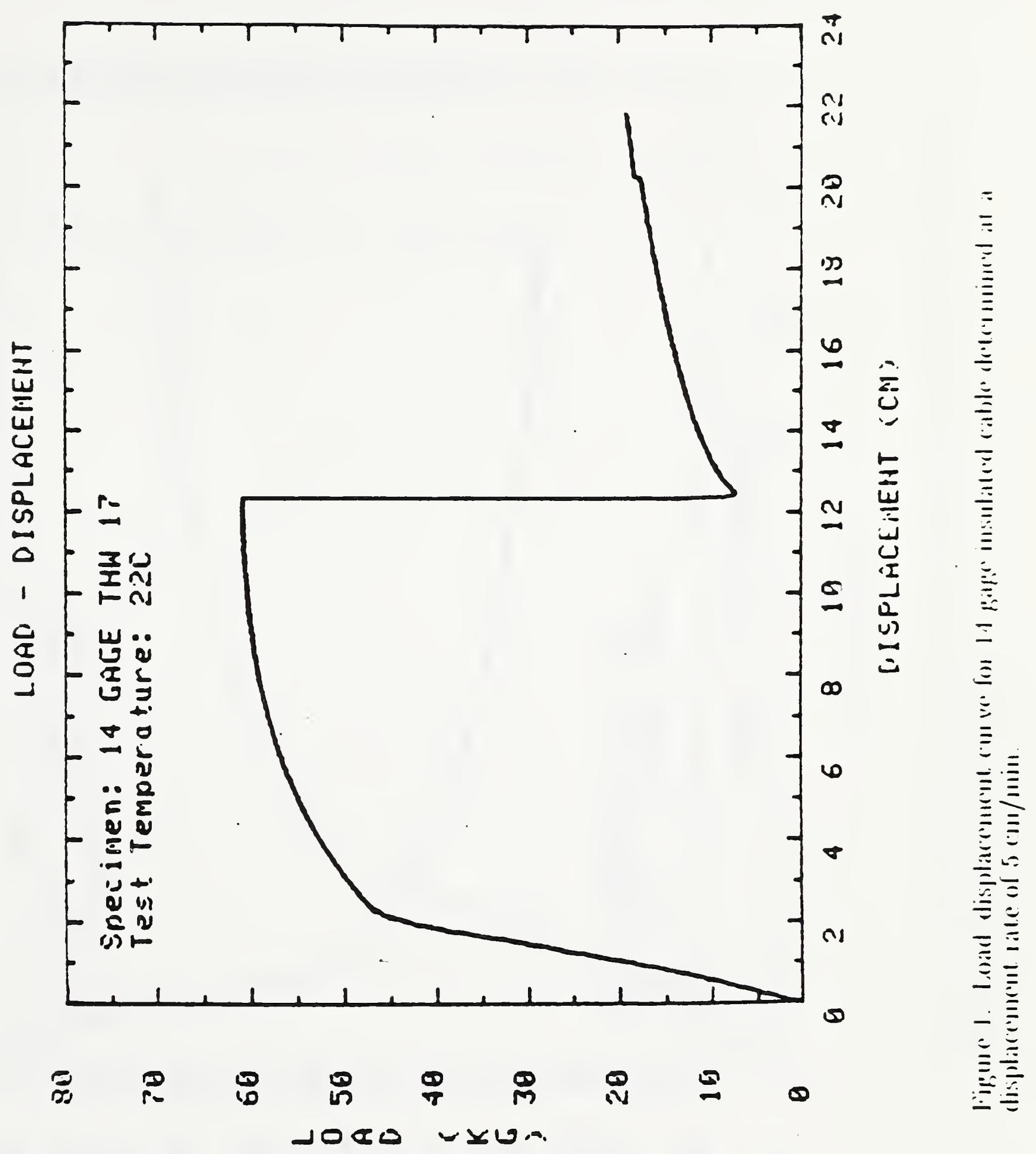




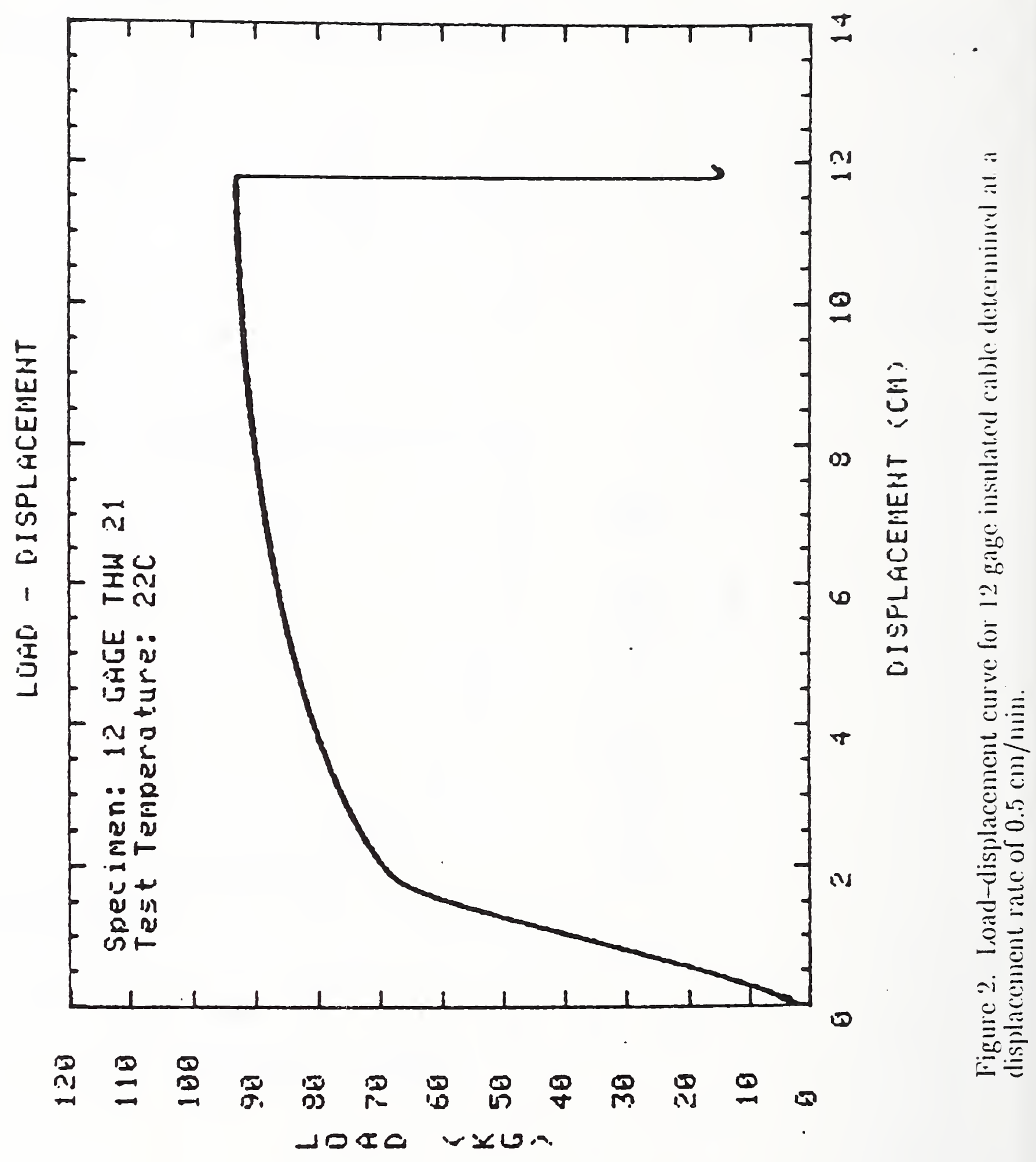




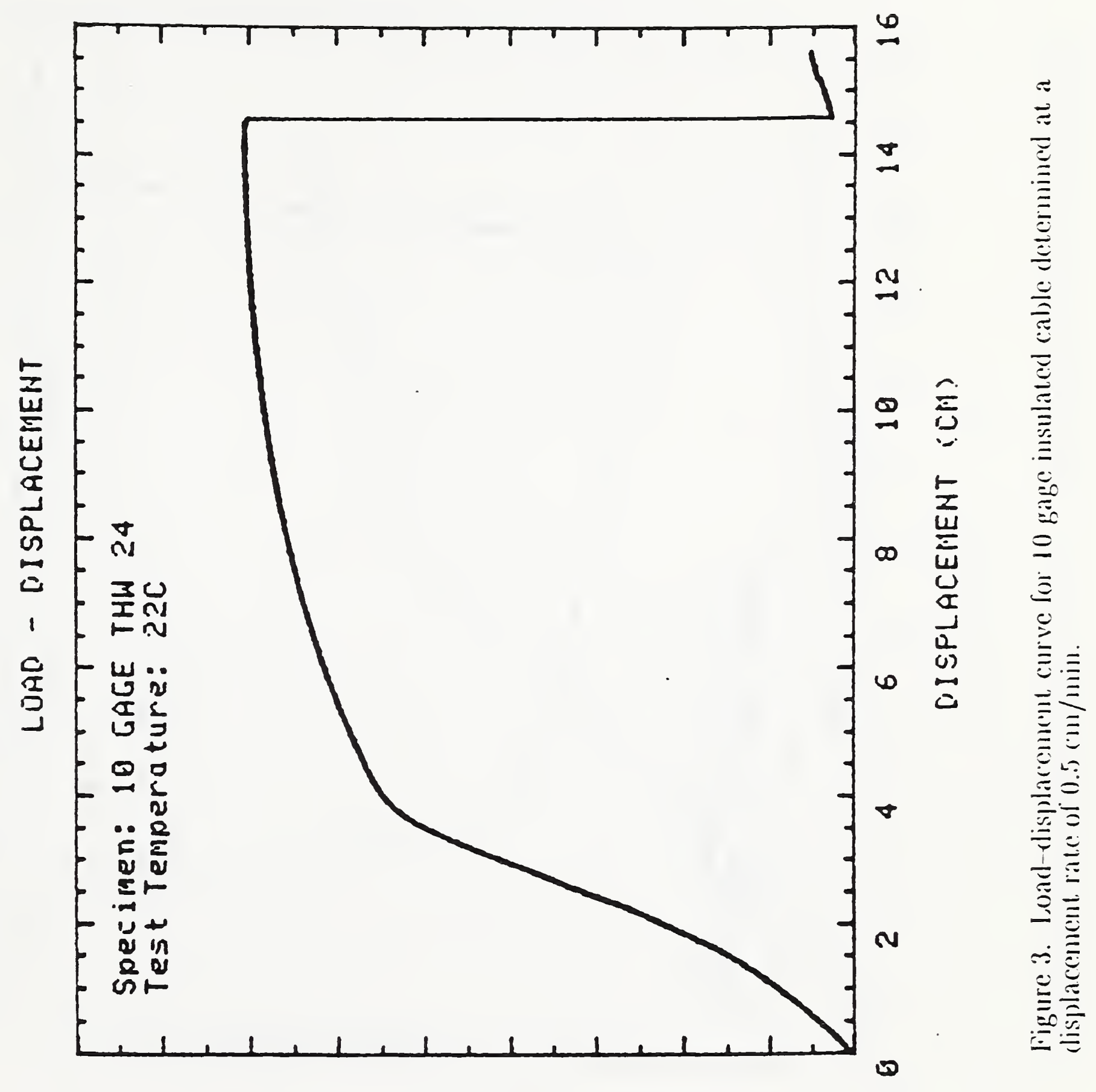

I 


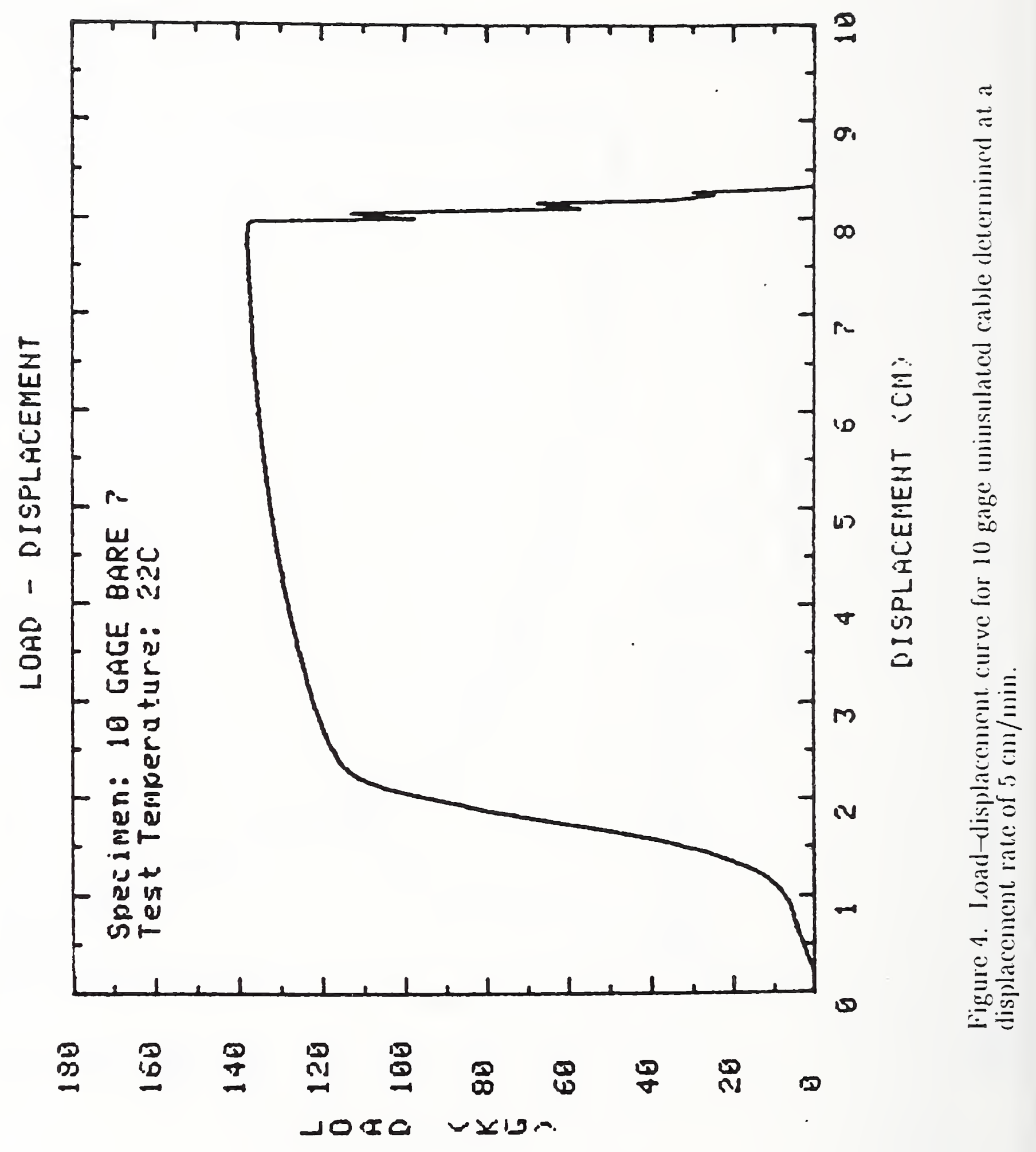




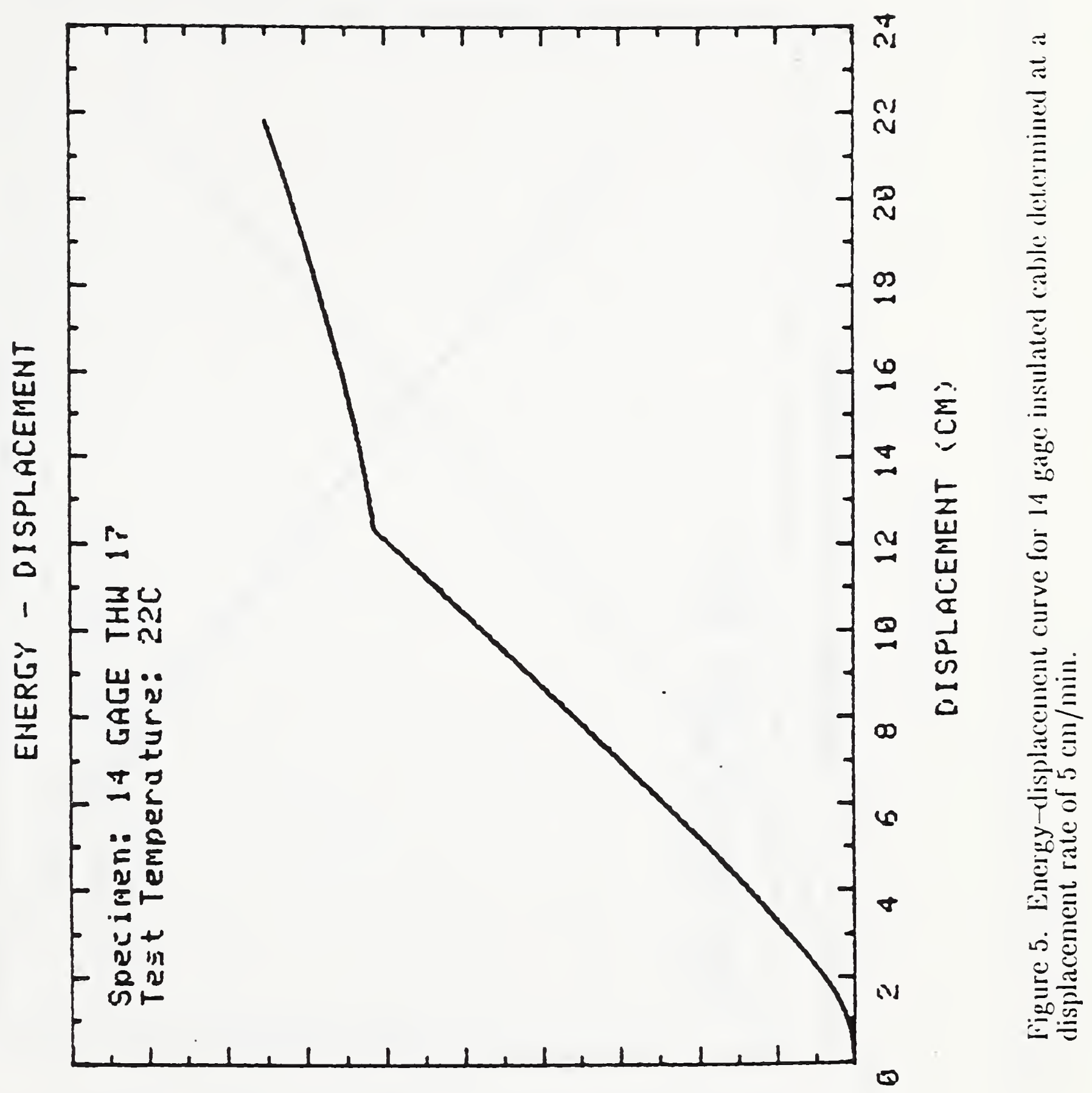

量苟

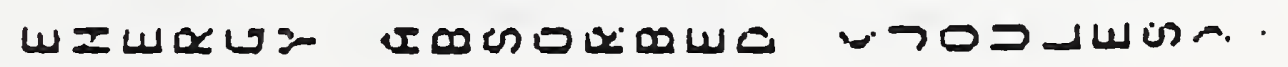




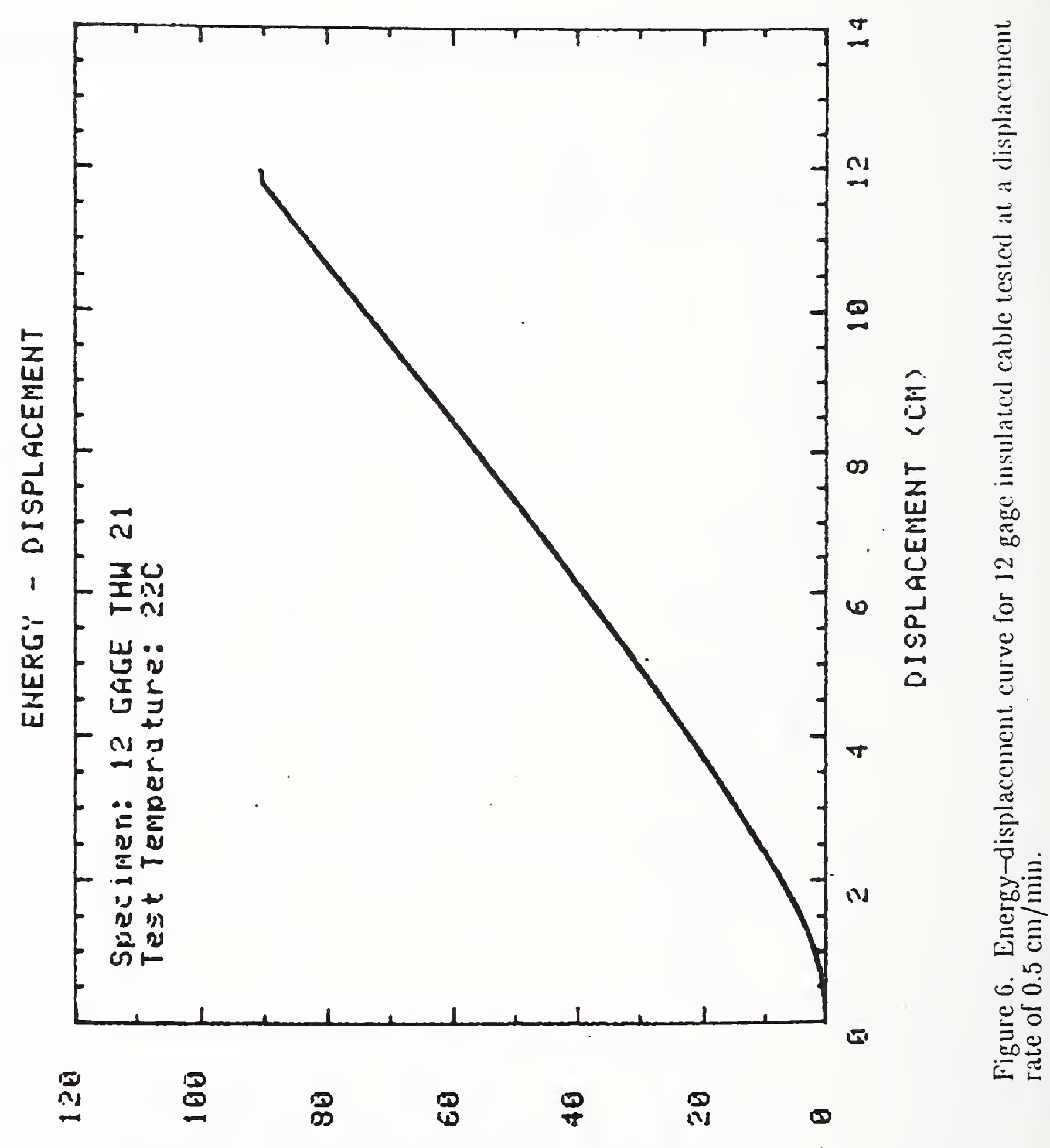

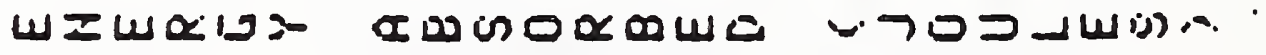




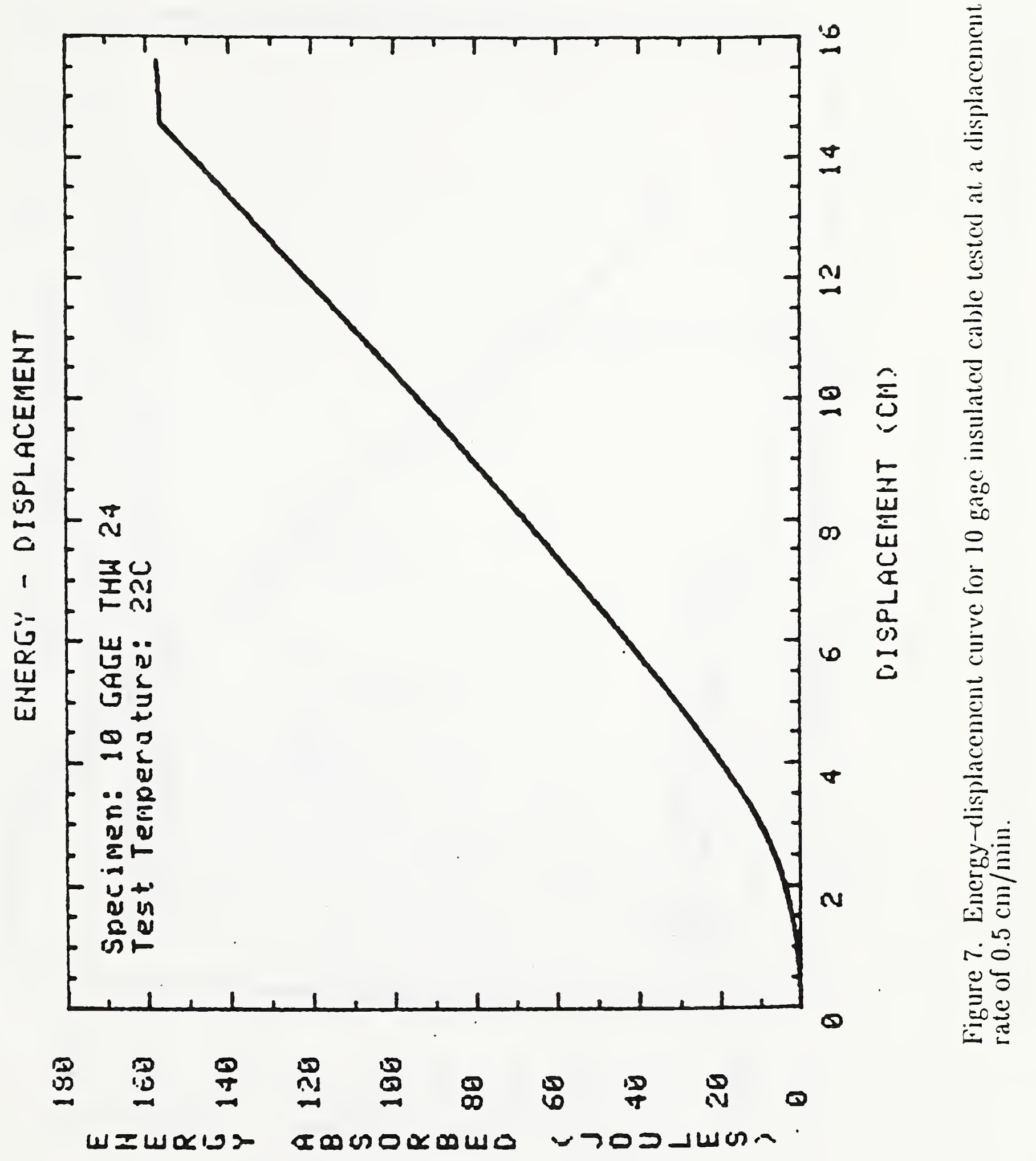




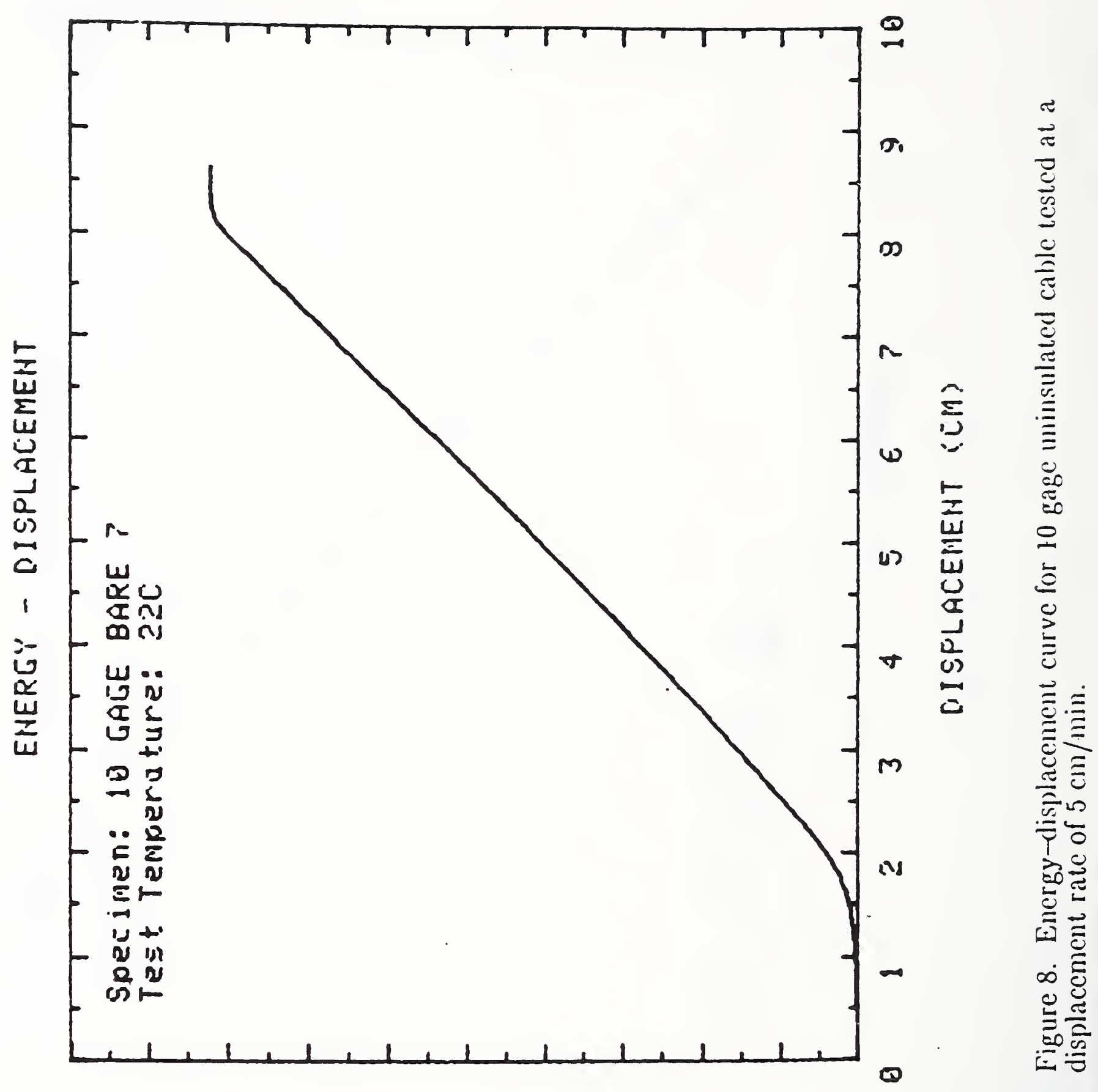

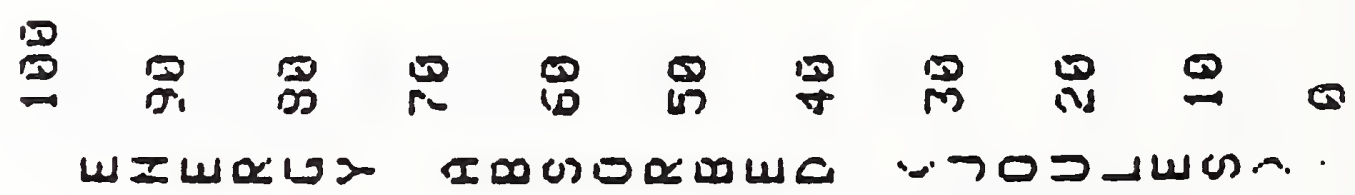




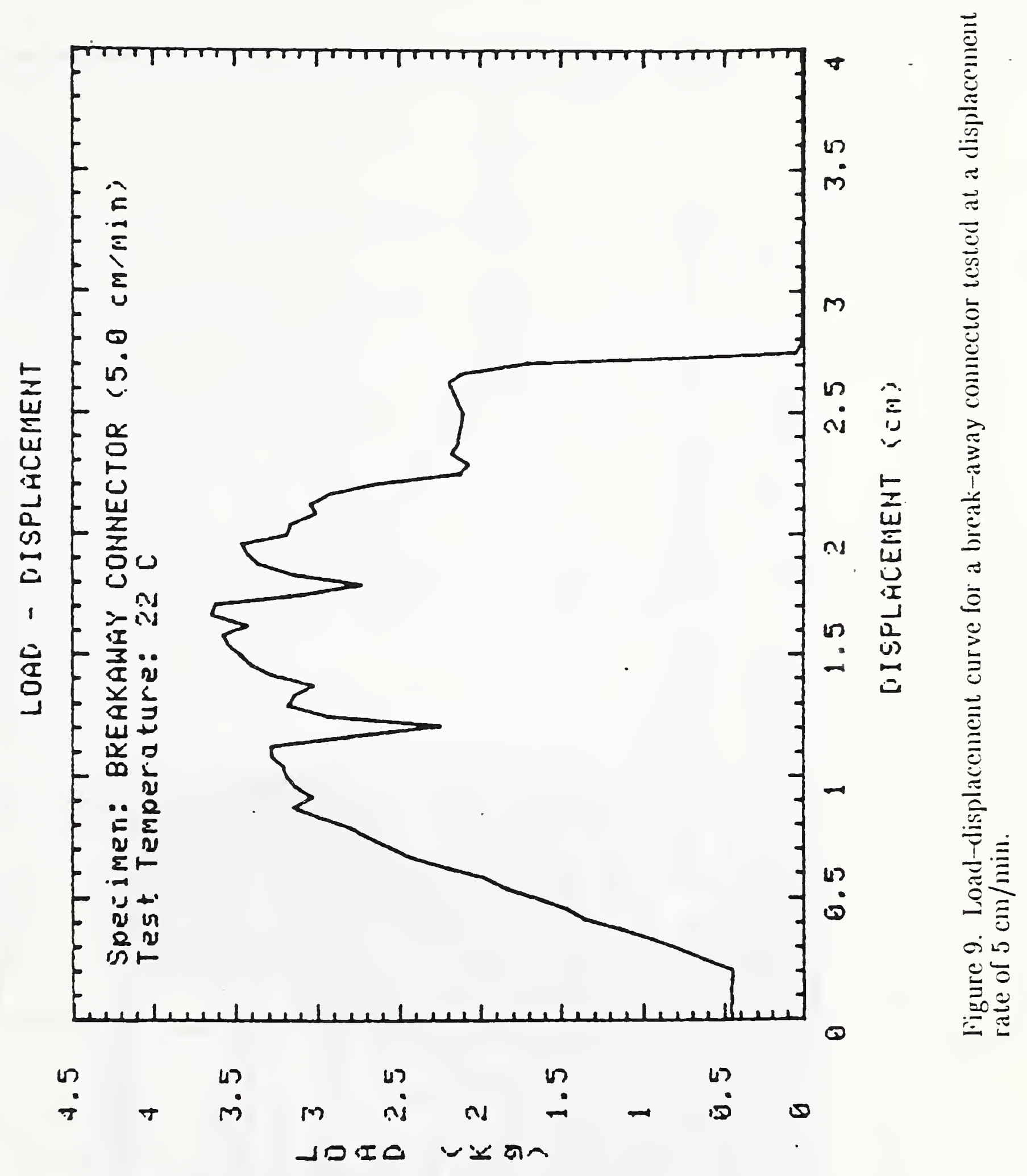




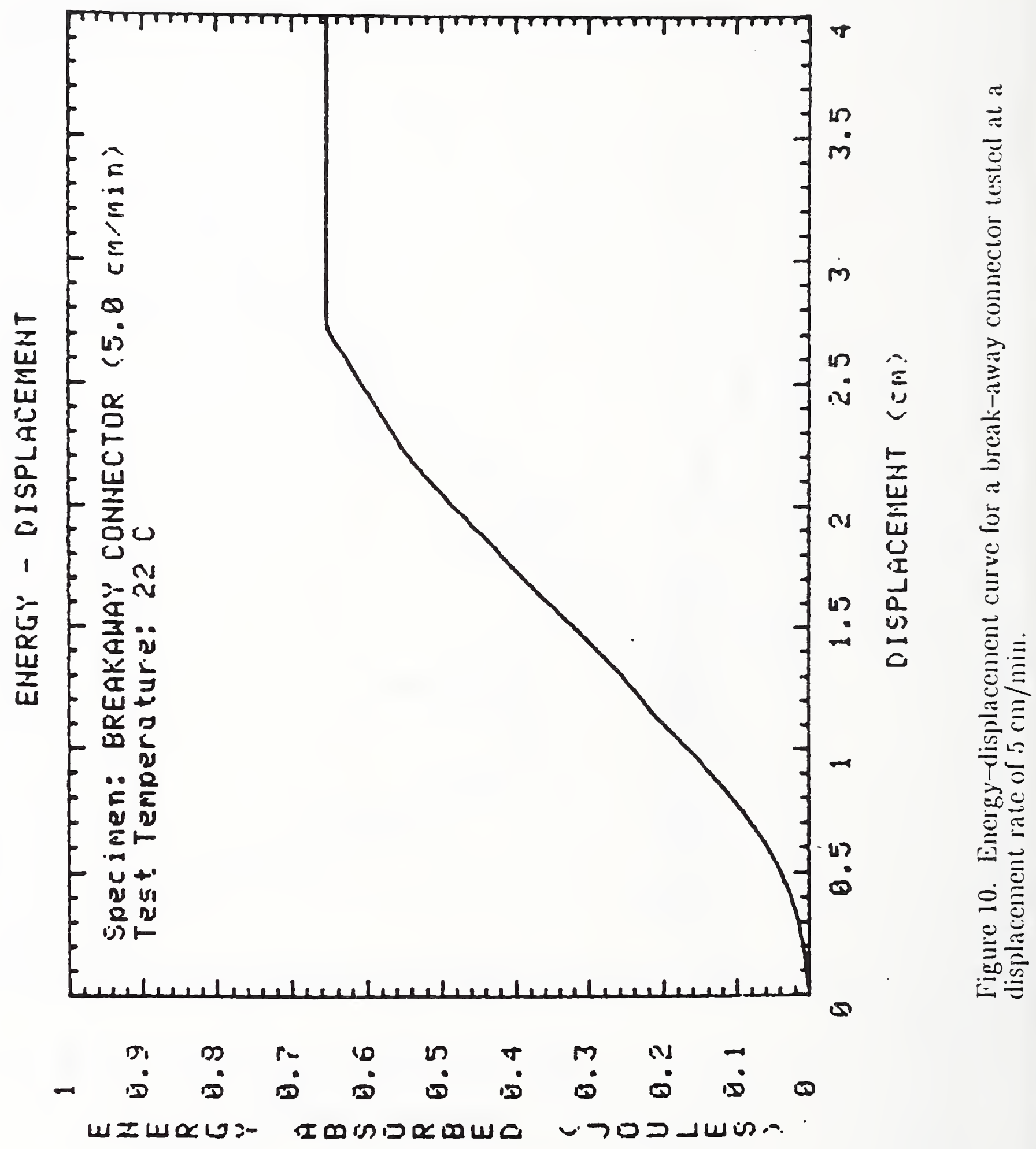



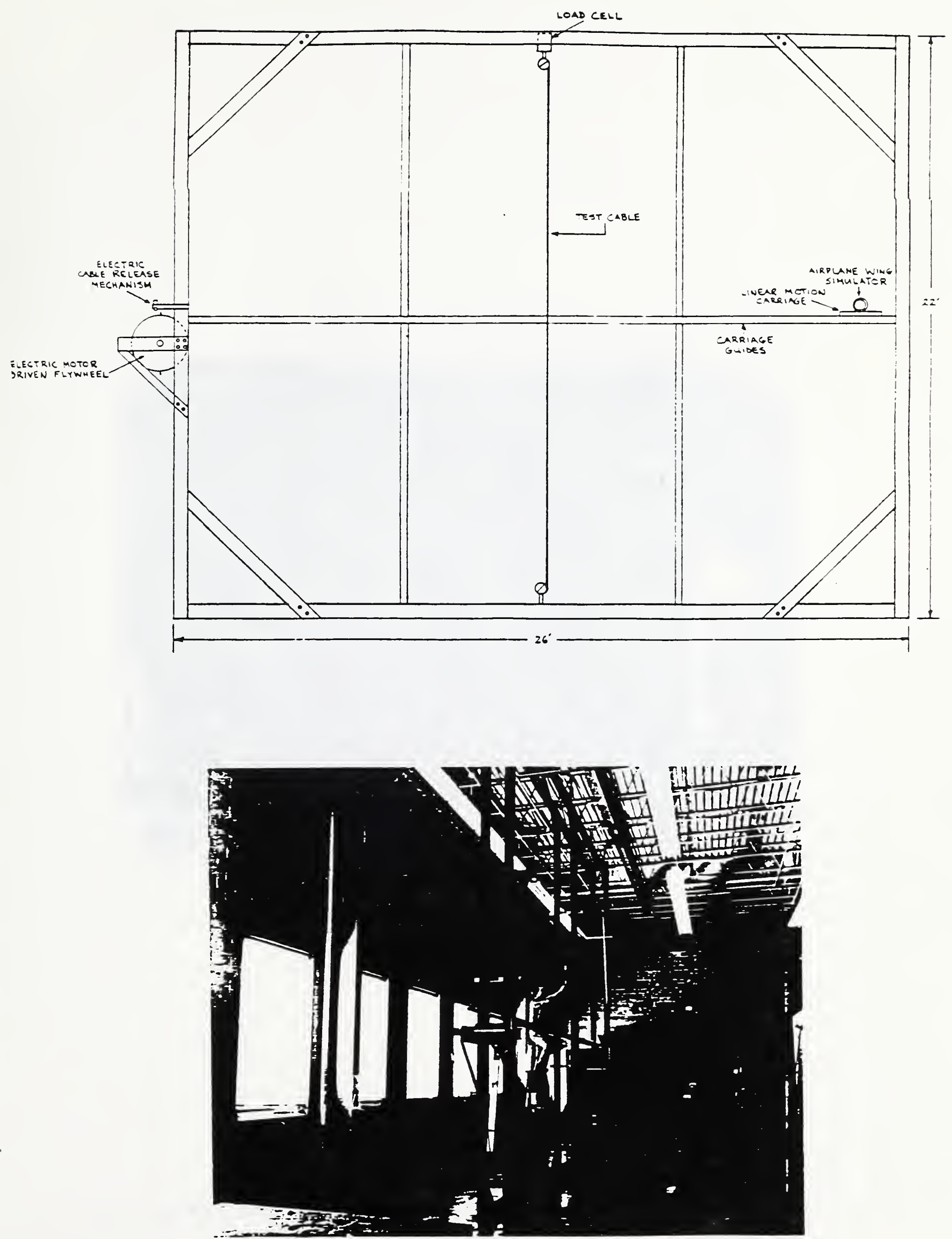

Figure 11. The dynamic test apparatus showing a test cable being placed in the grips. A high speed camera can be secn on a tripod to the right of the test apparatus. 


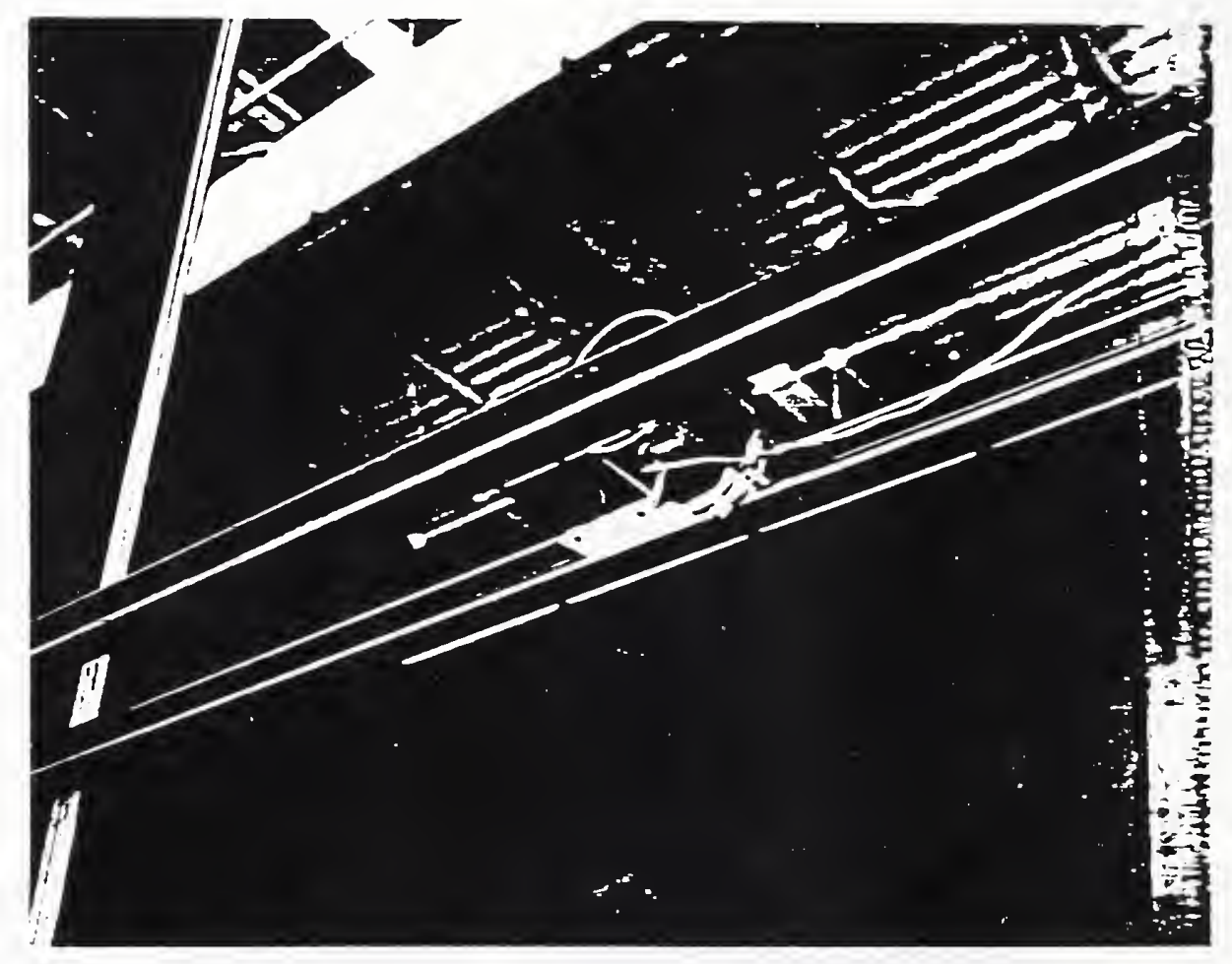

Figure 12. The impactor positioned in the guide rails prior to a trot. 


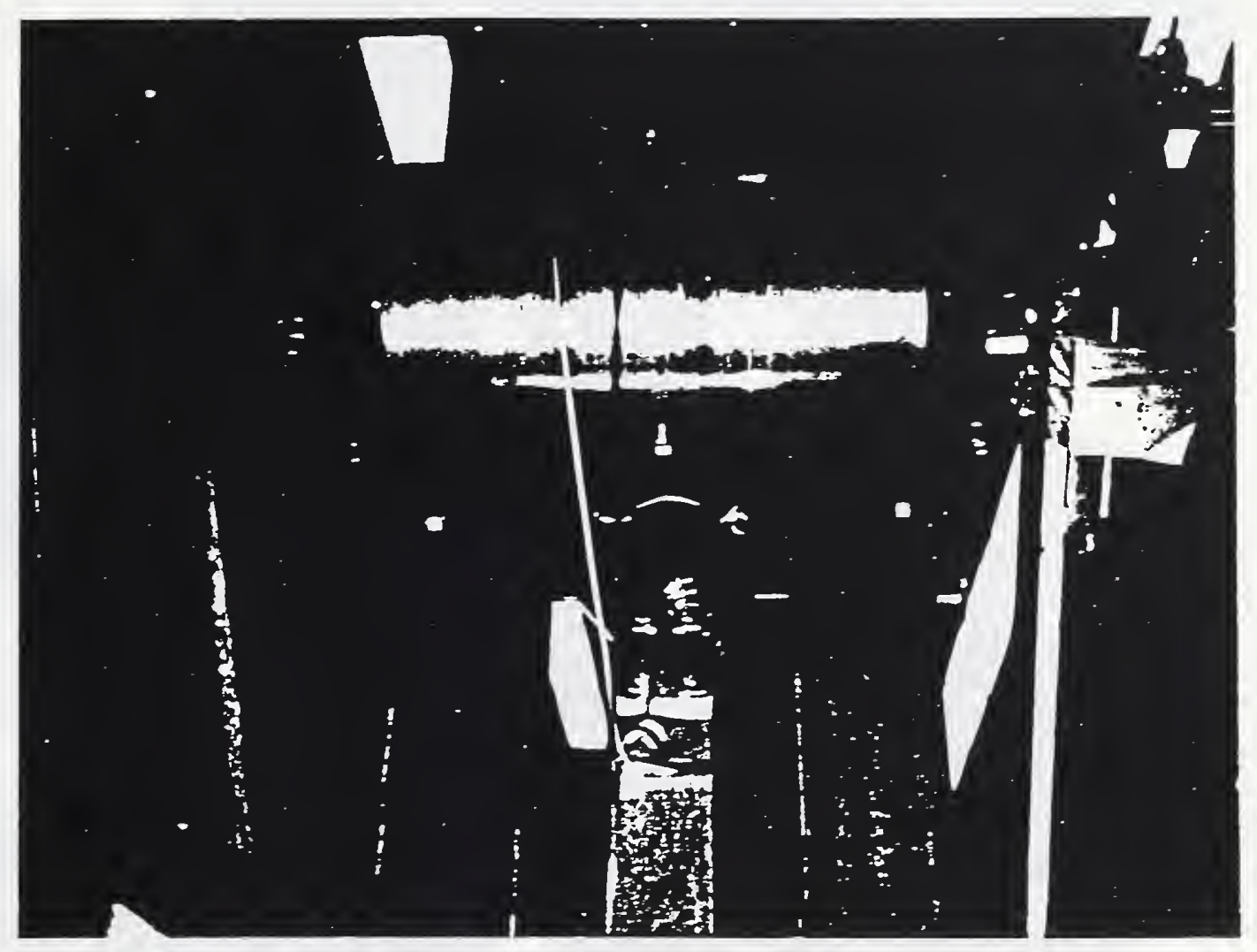

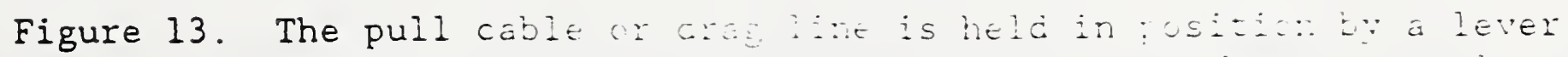

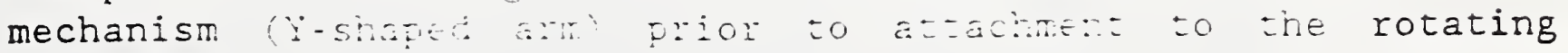
flywheel. 


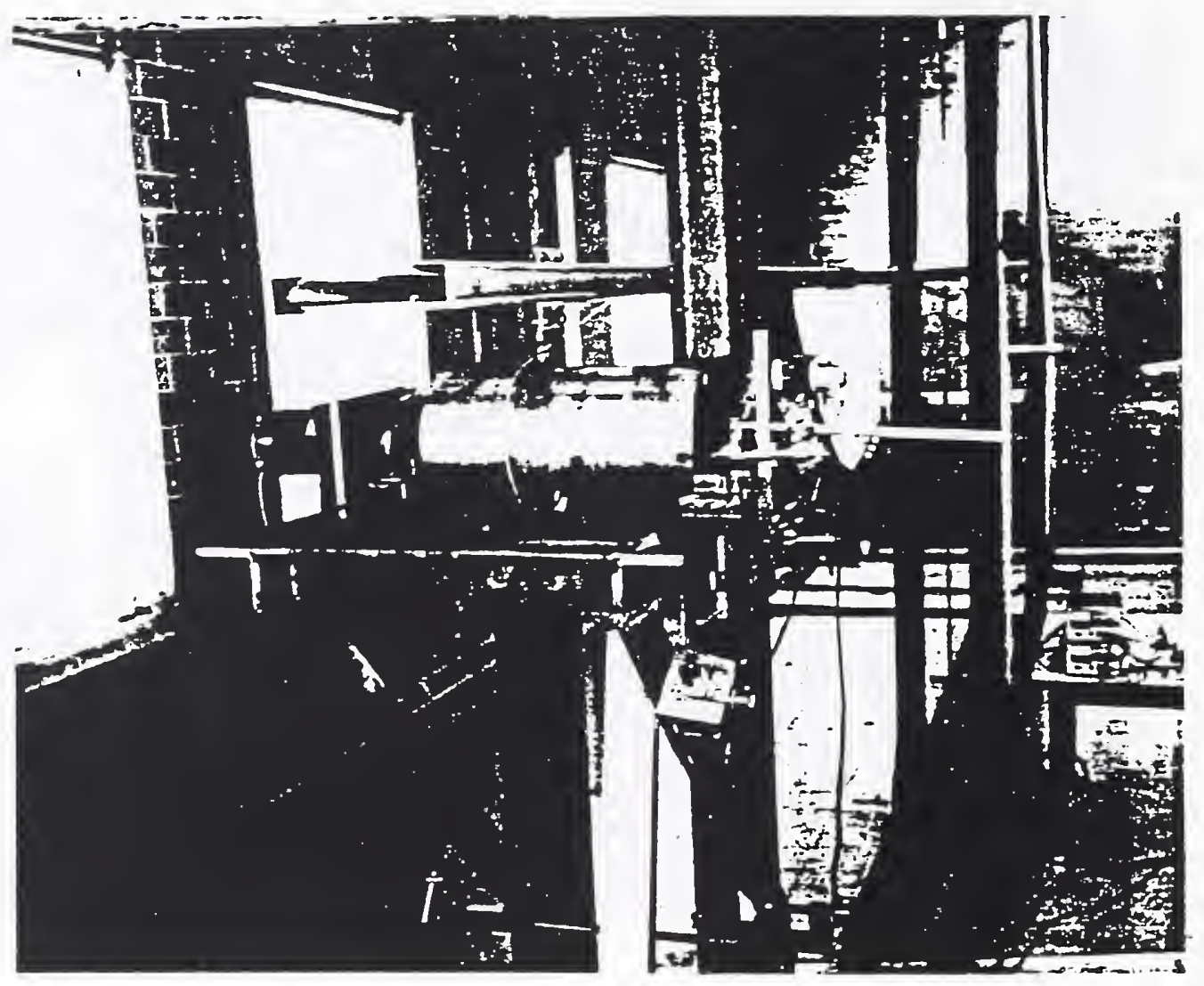

Figure 14. The flywheel is the cylincrical object in the center of the photograph. The photodiode device fo: monitoring the flywheel rotation frequency is mounted to the right of the fl.....heel. 


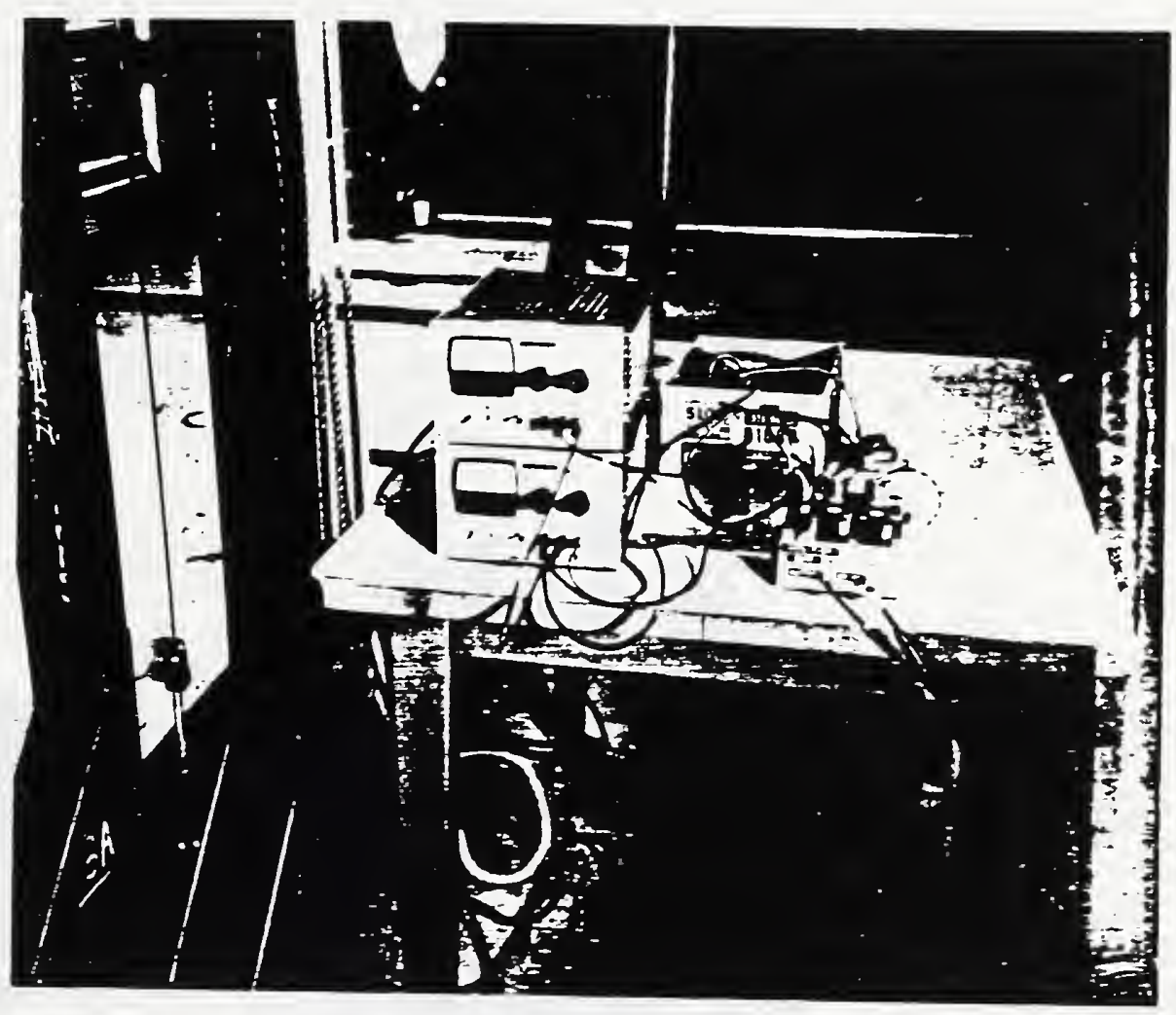

Figure 15. The bridge-amplifier system used to condition the strain signals from the grip connecting rods. A test cable, split capstan grip, and connecting rod can be seen on the left between the two uprights of the test apparatus. 


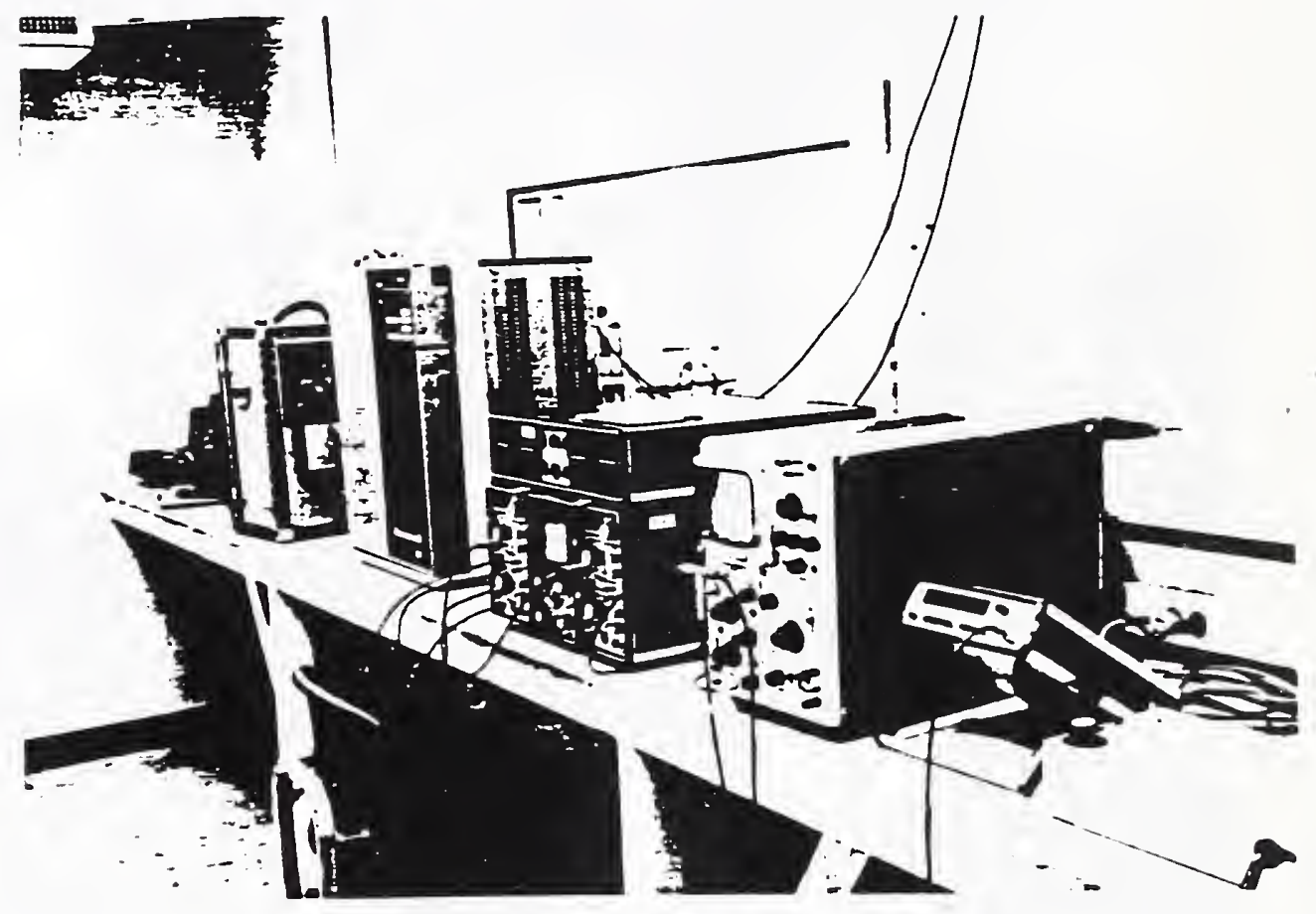

Figure 16. Electronic equipment used for the dynamic test. 
TOP PULL ROD CALIBRATION (JAN 1987)
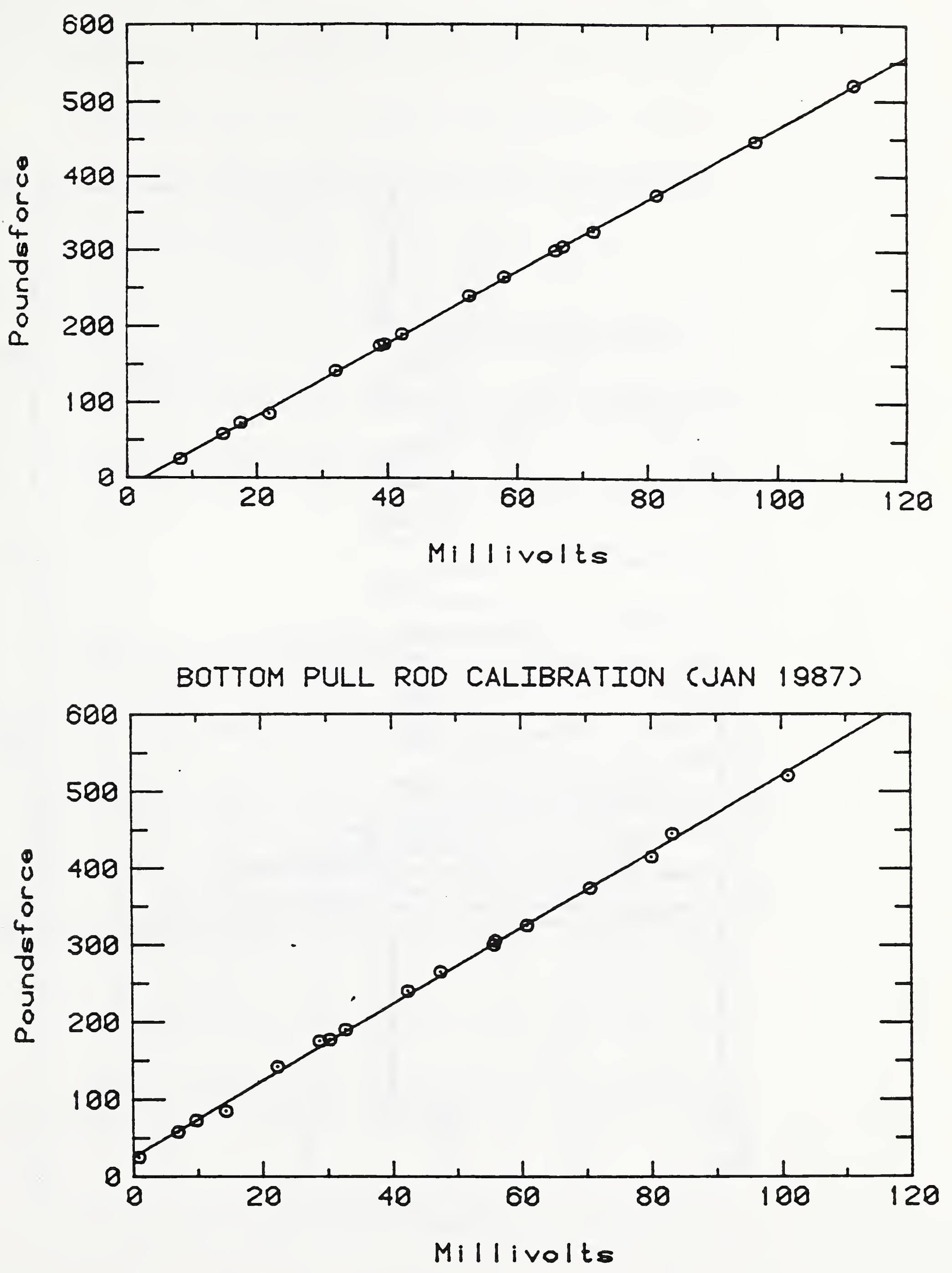

Figure 17. Correlation between voltage level from strain gage conditioncrs and actual load. 


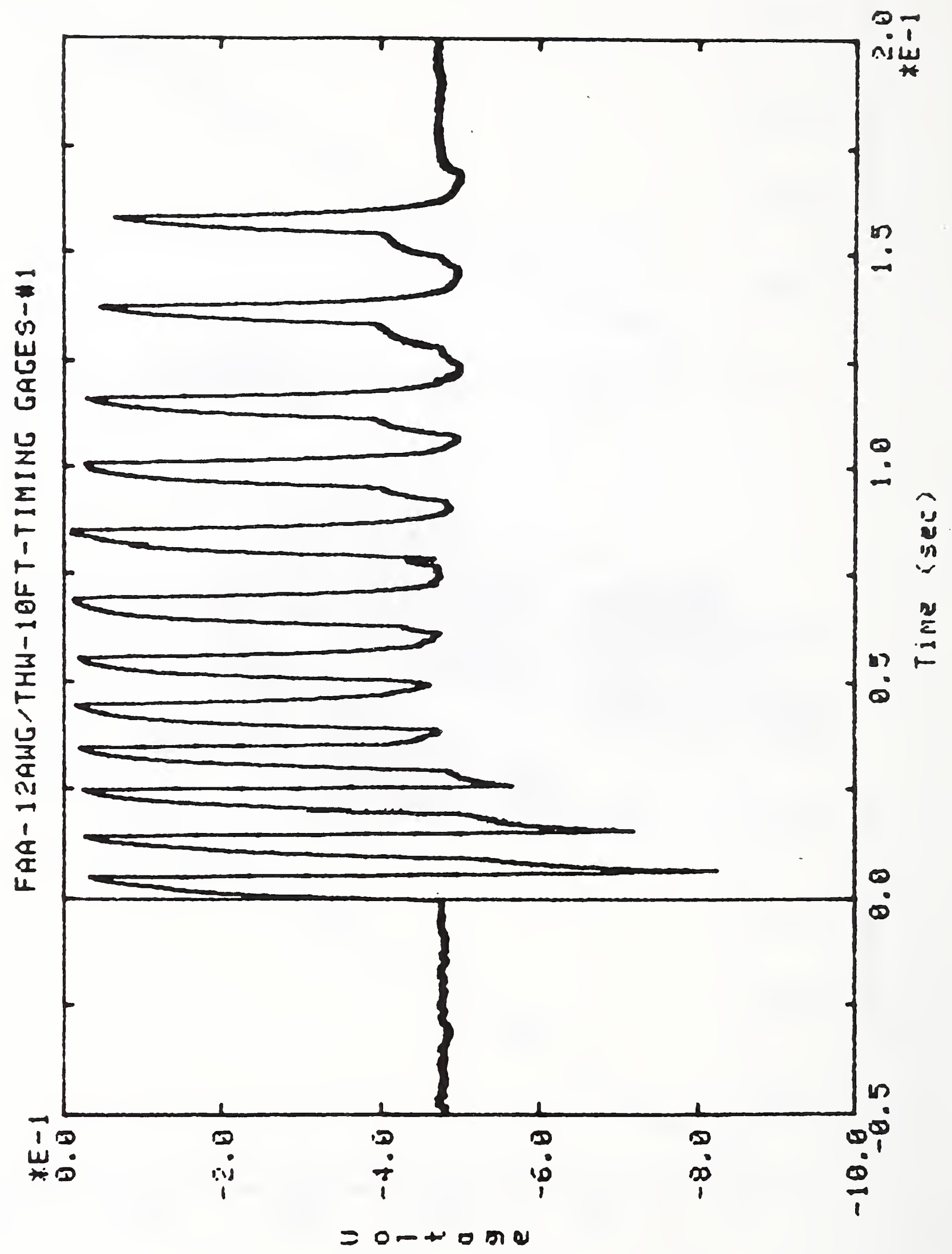



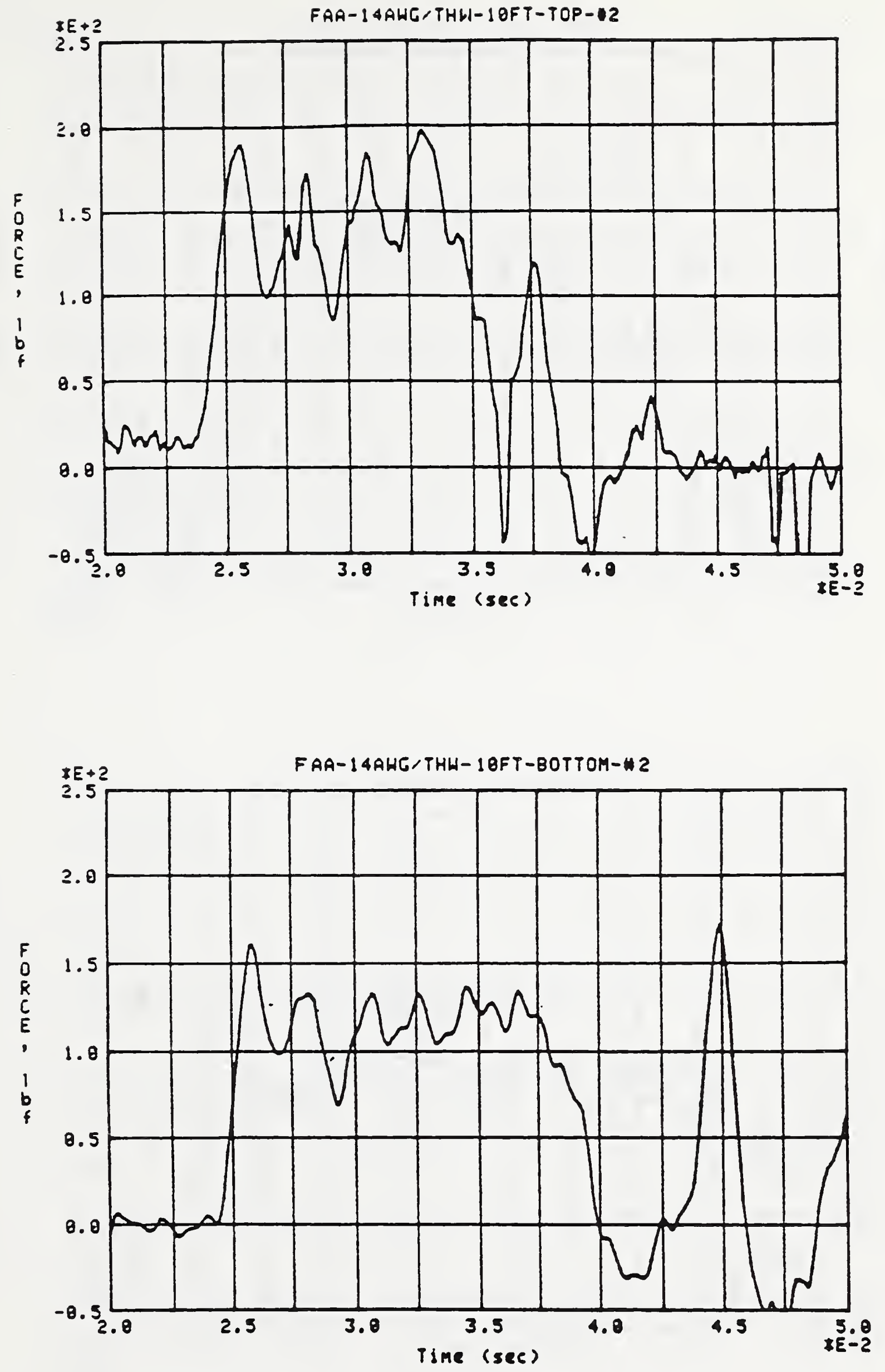

Figure 19. Load-time records for a $10 \mathrm{ft}$ long, 14 gage, insulated cable. 

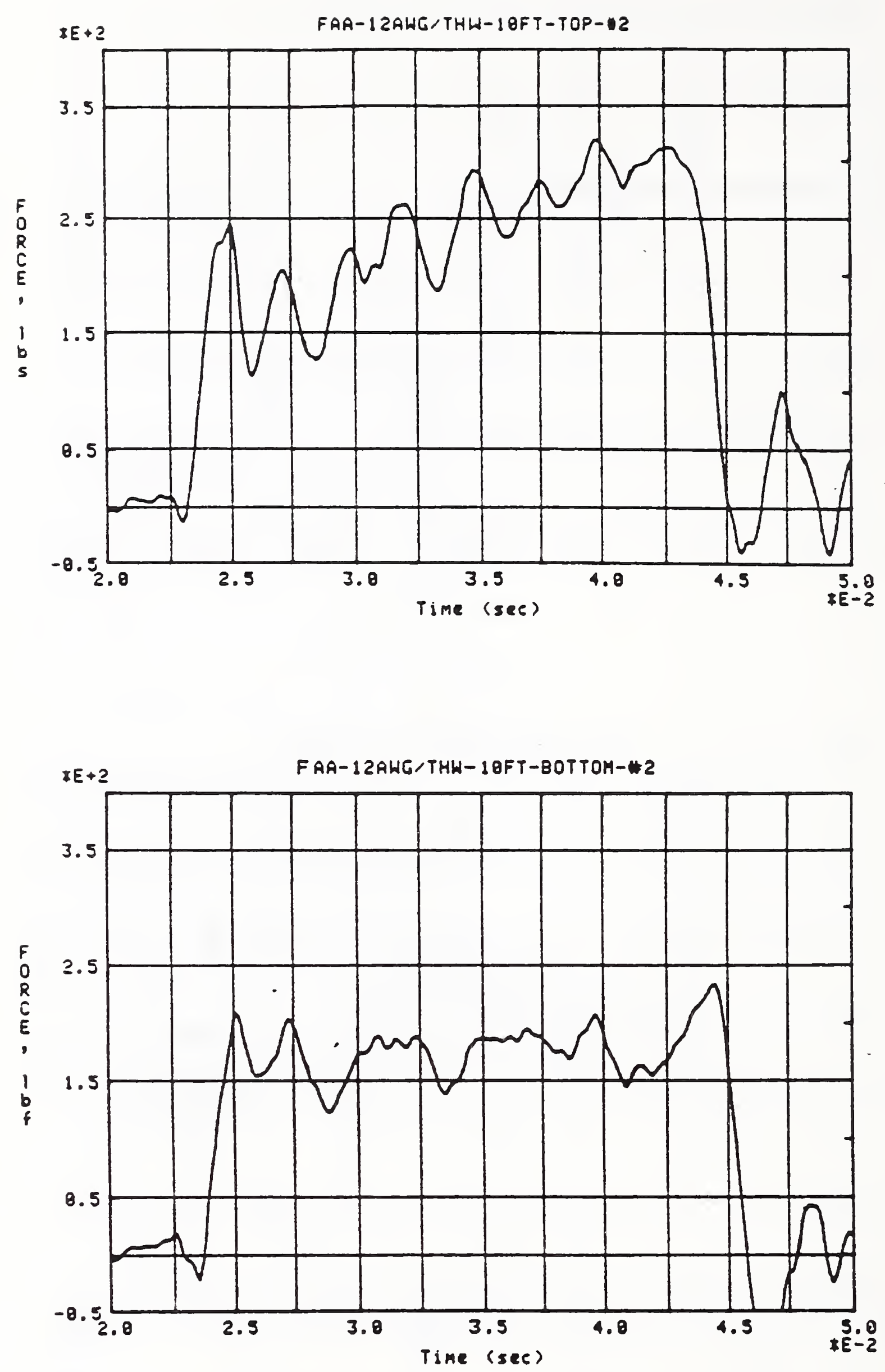

Figure 20. Load-time records for a $10 \mathrm{ft}$ long, 12 gage, insulated cable. 

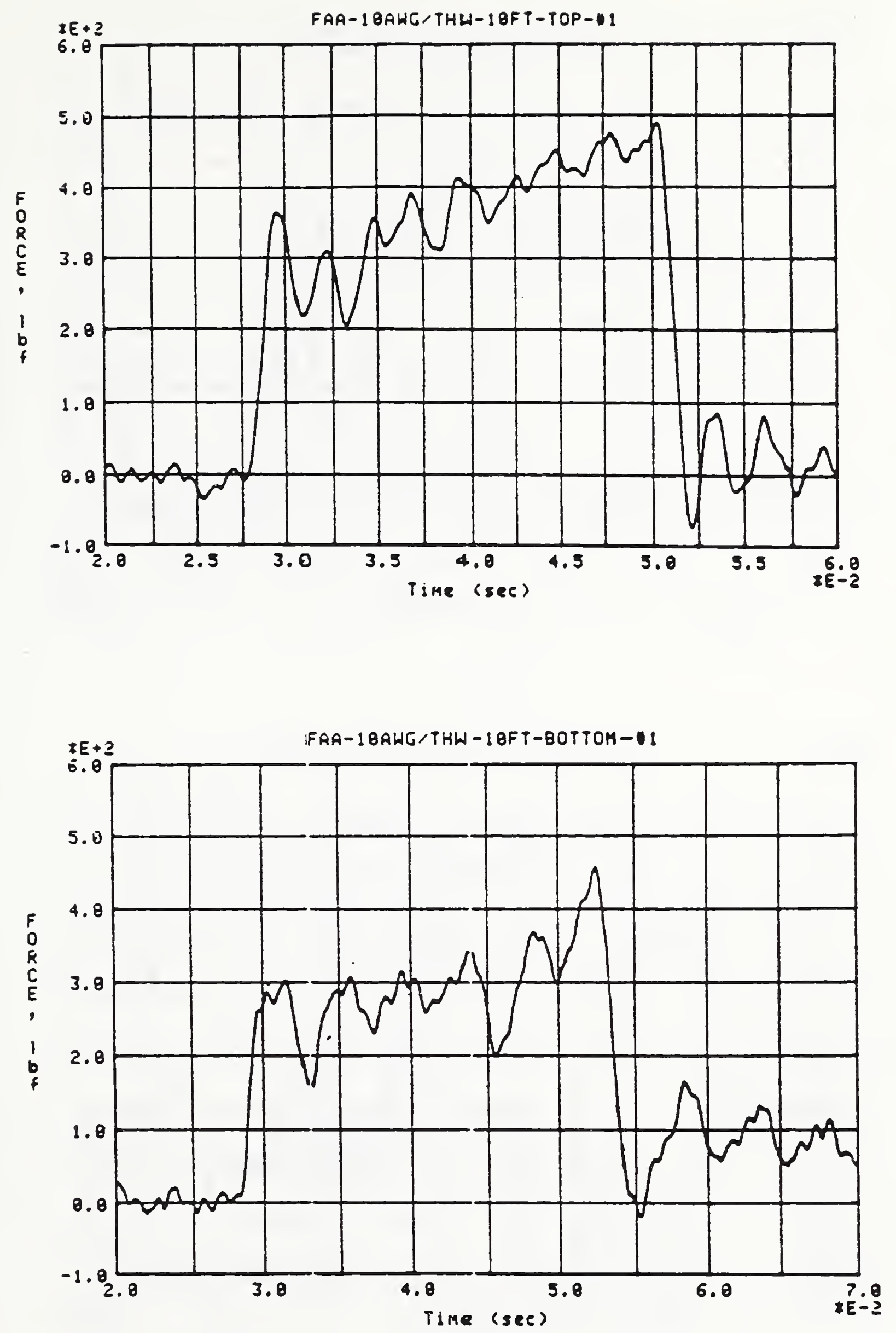

Figure 21. Load-time records for a $10 \mathrm{ft}$ long, 10 gage, insulated cable. 

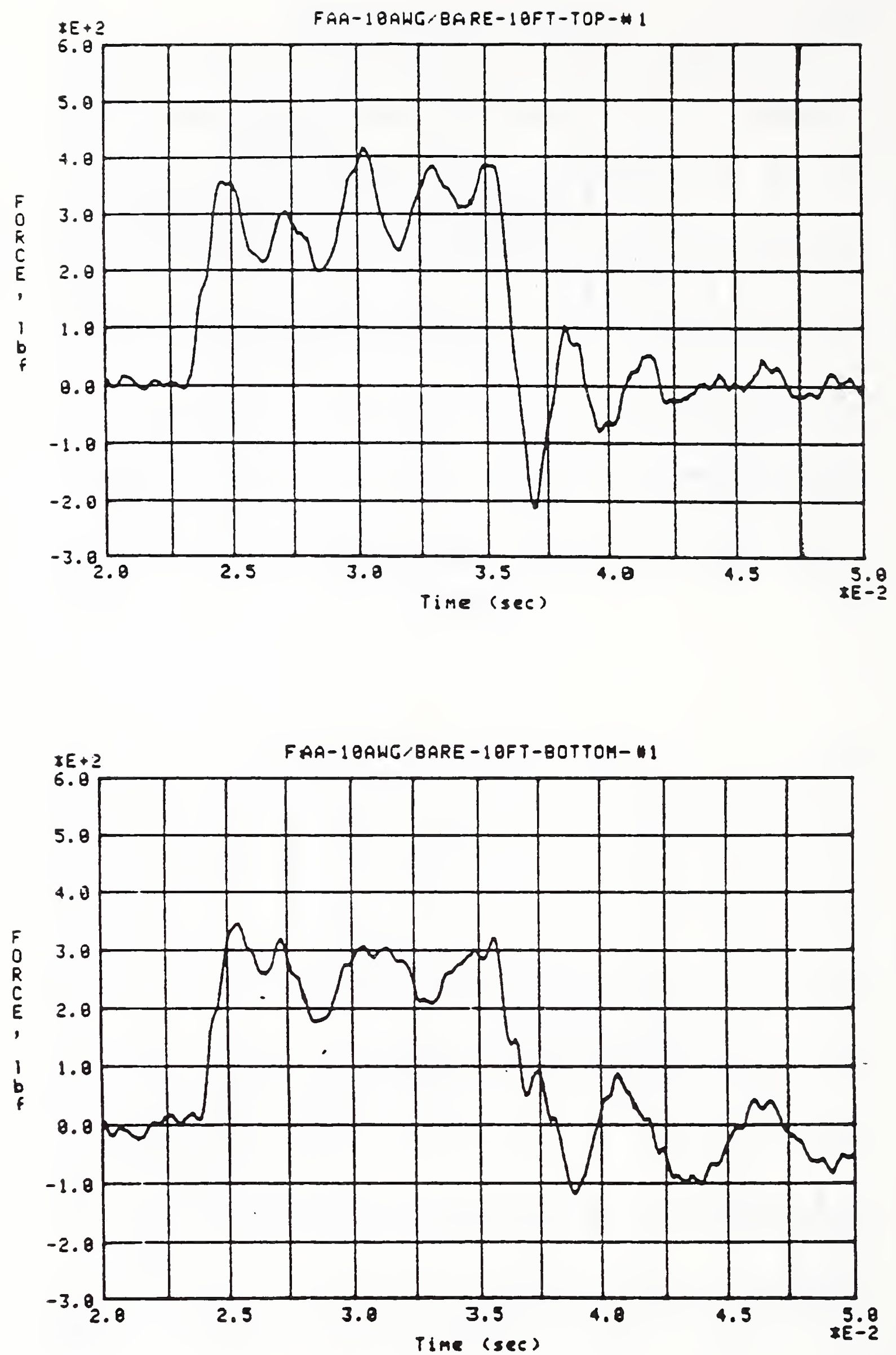

Figure 22. Load-time records for a $10 \mathrm{ft}$ long, 10 gage, uninsulated cable. 
CABLE, 14 AYC/THY, $20 \mathrm{FT}$

TOP GRIP

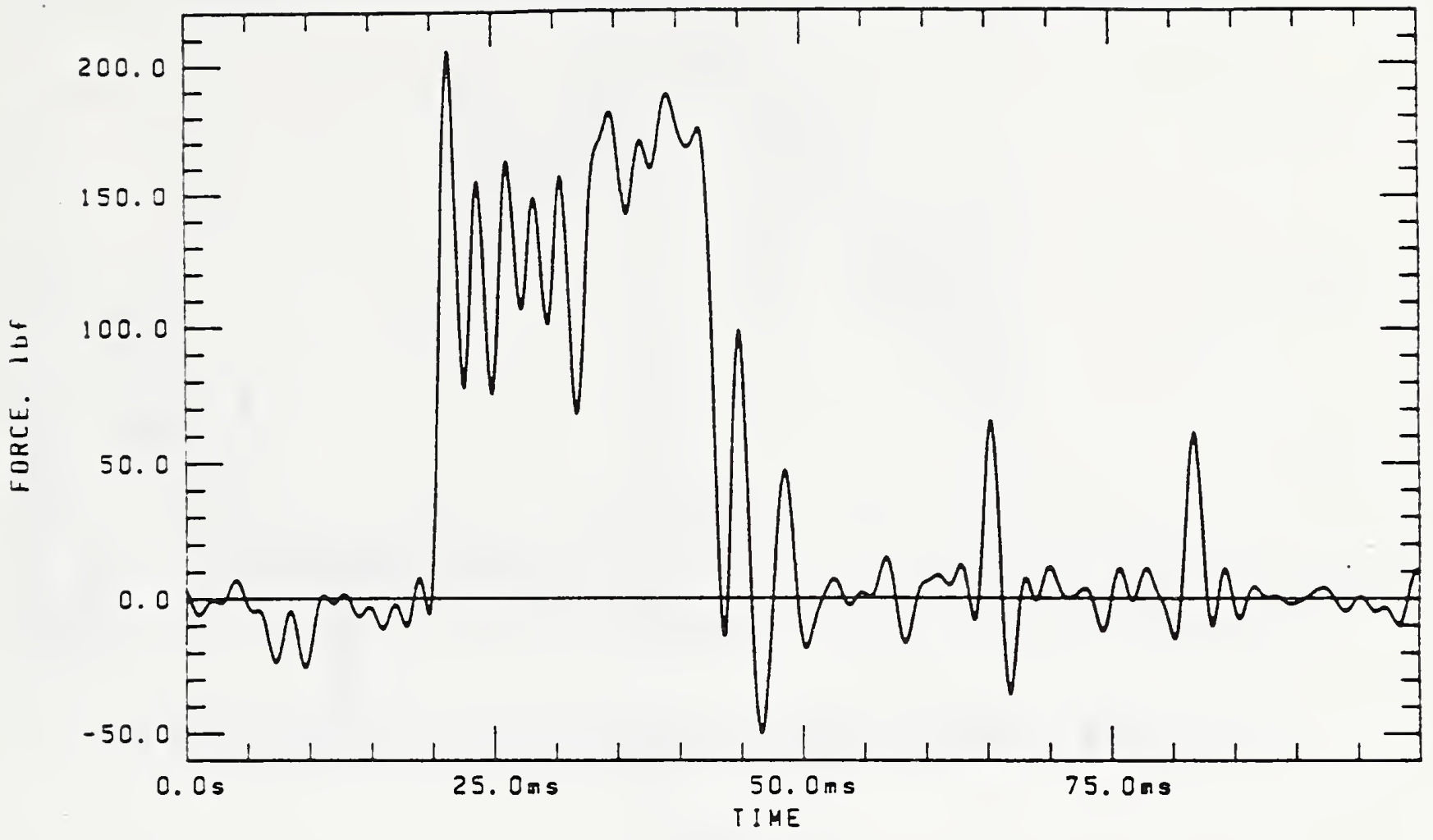

TEST $\# 4$

CABLE: 14 AYC/THW. $20 \mathrm{FT}$

BOTTOM GRIP

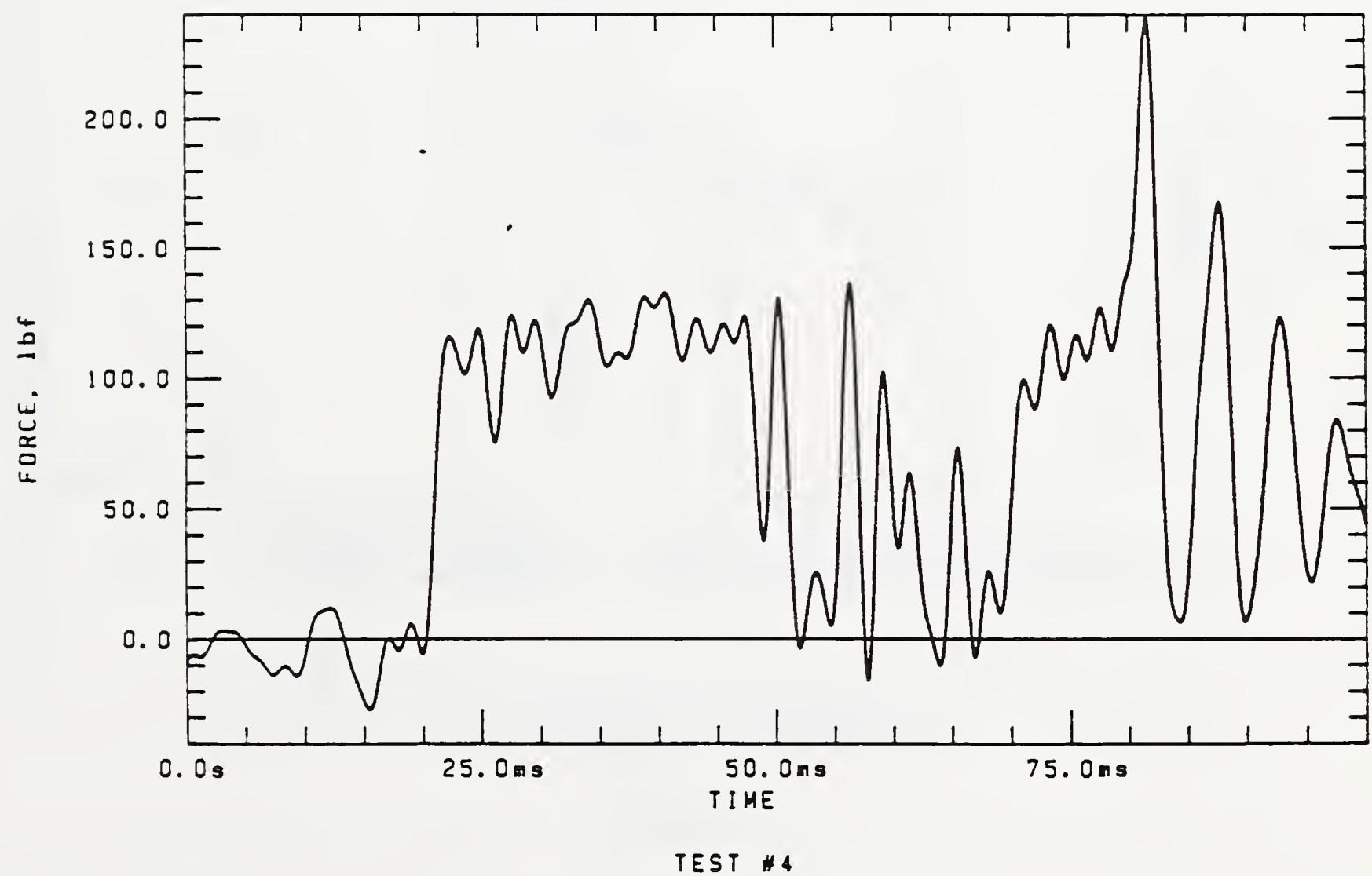

Figure 23. Load-time records for a $20 \mathrm{ft}$ long, 14 gage, insulated cable. 
TOP CRIP

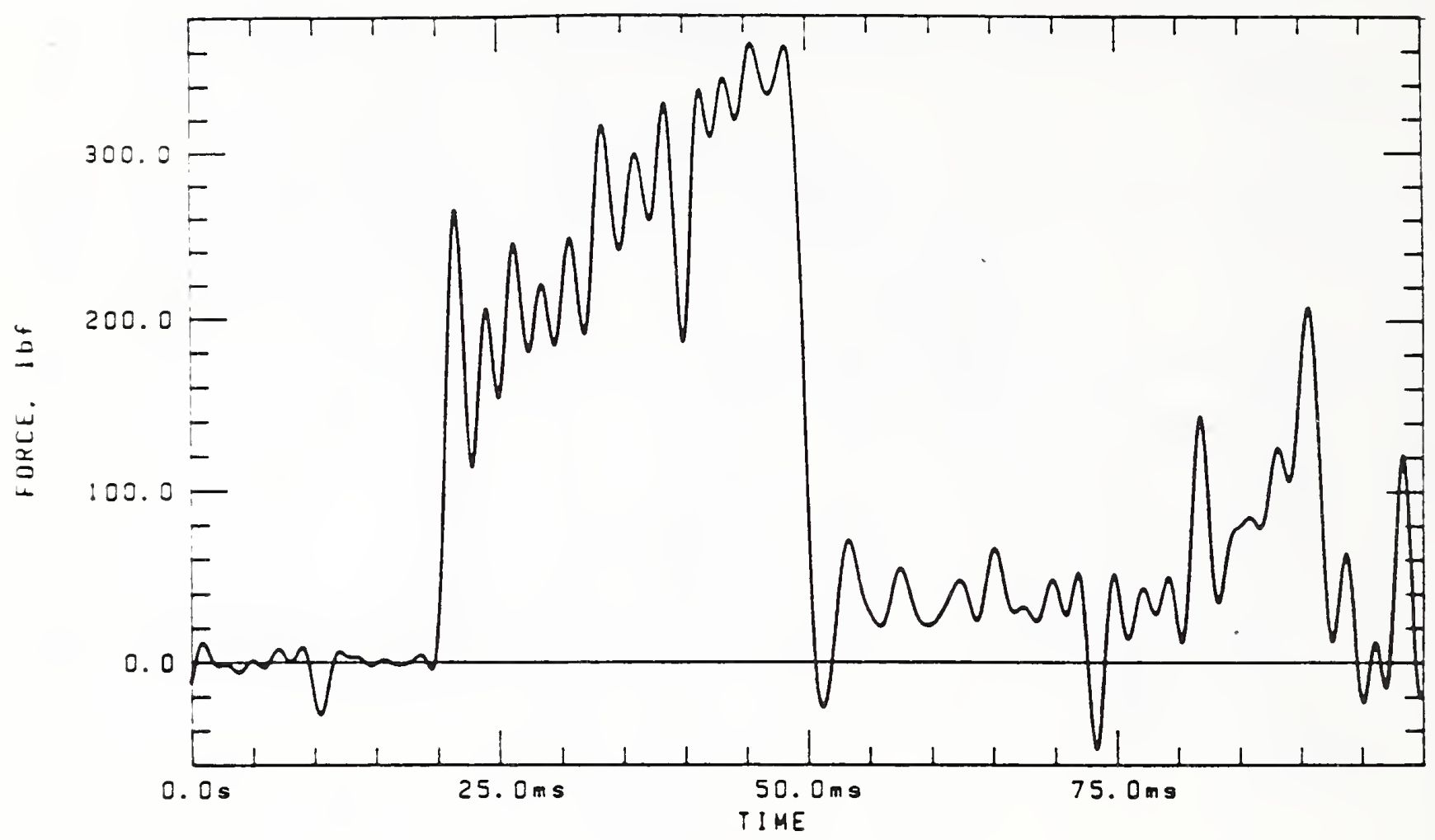

TEST 3

CABLE: 12 AWG/THW. ZO FT

BOTTOM GRIP

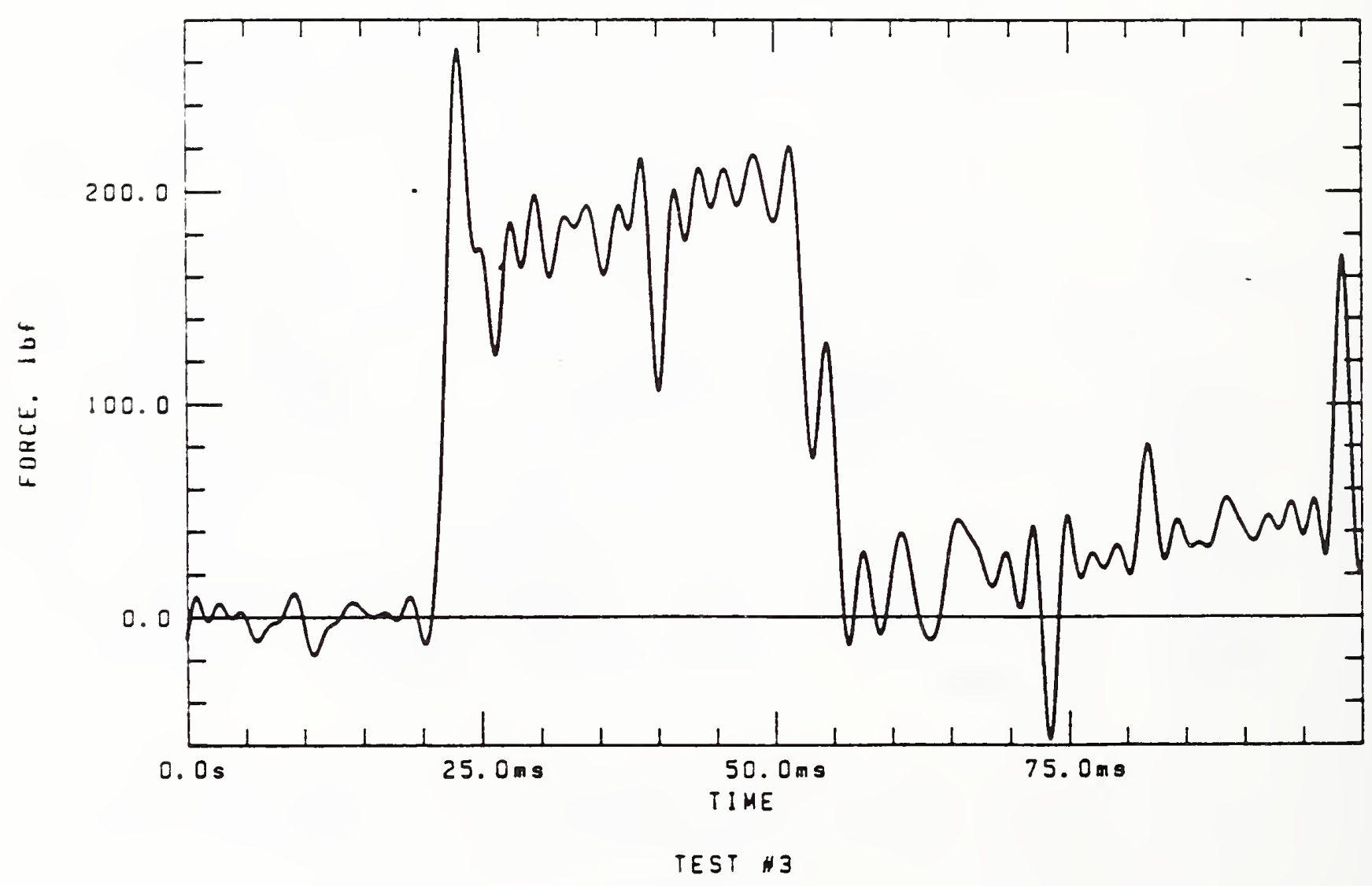

Figure 24. Load-time records for a $20 \mathrm{ft}$ long, 12 gage, insulated cable. 
CABLE, IO AYO/THY, 20 FT

TOP CRIP

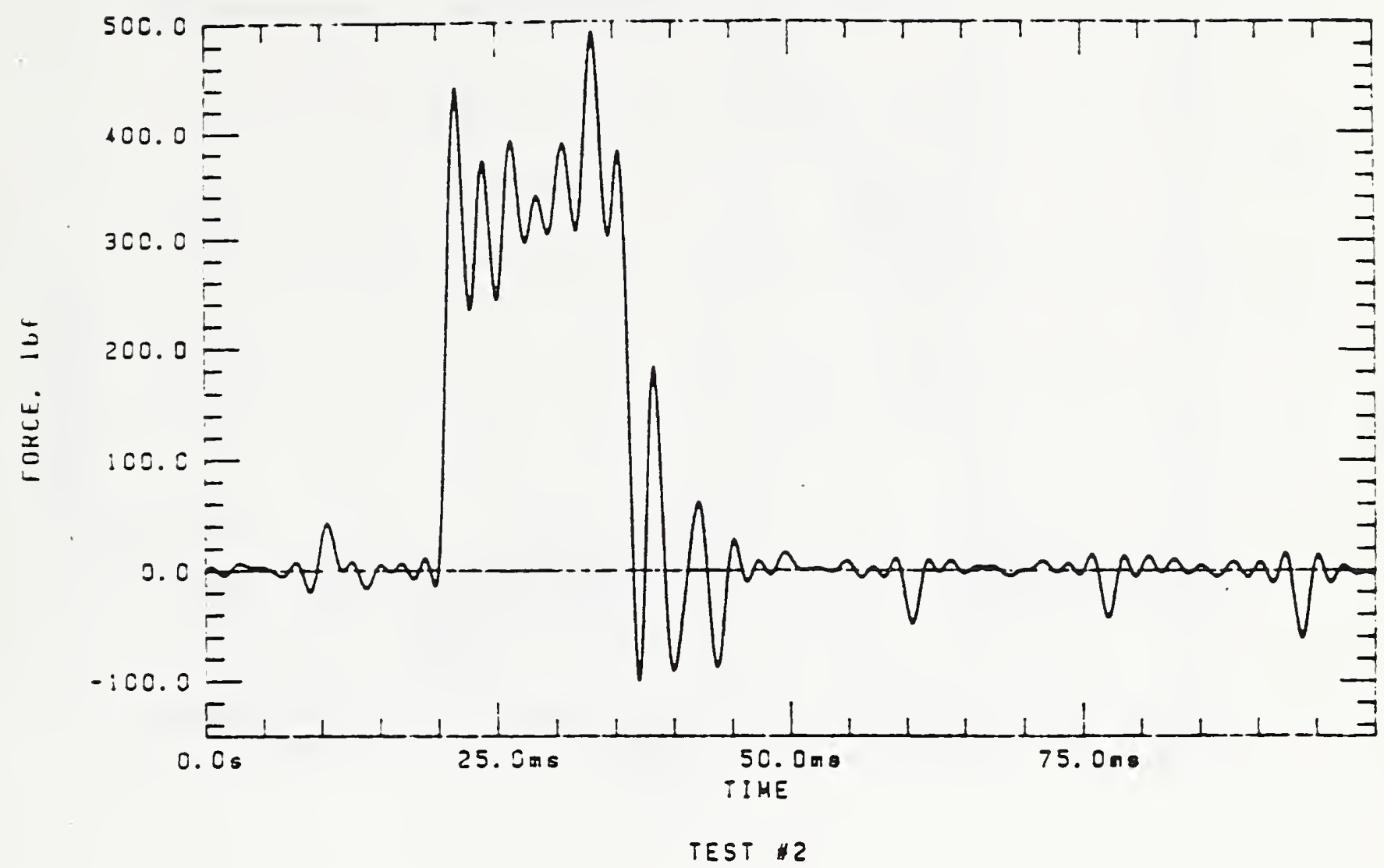

CABLE, IC AYC/THY, $20 \mathrm{FT}$

BOTTOM GRIP

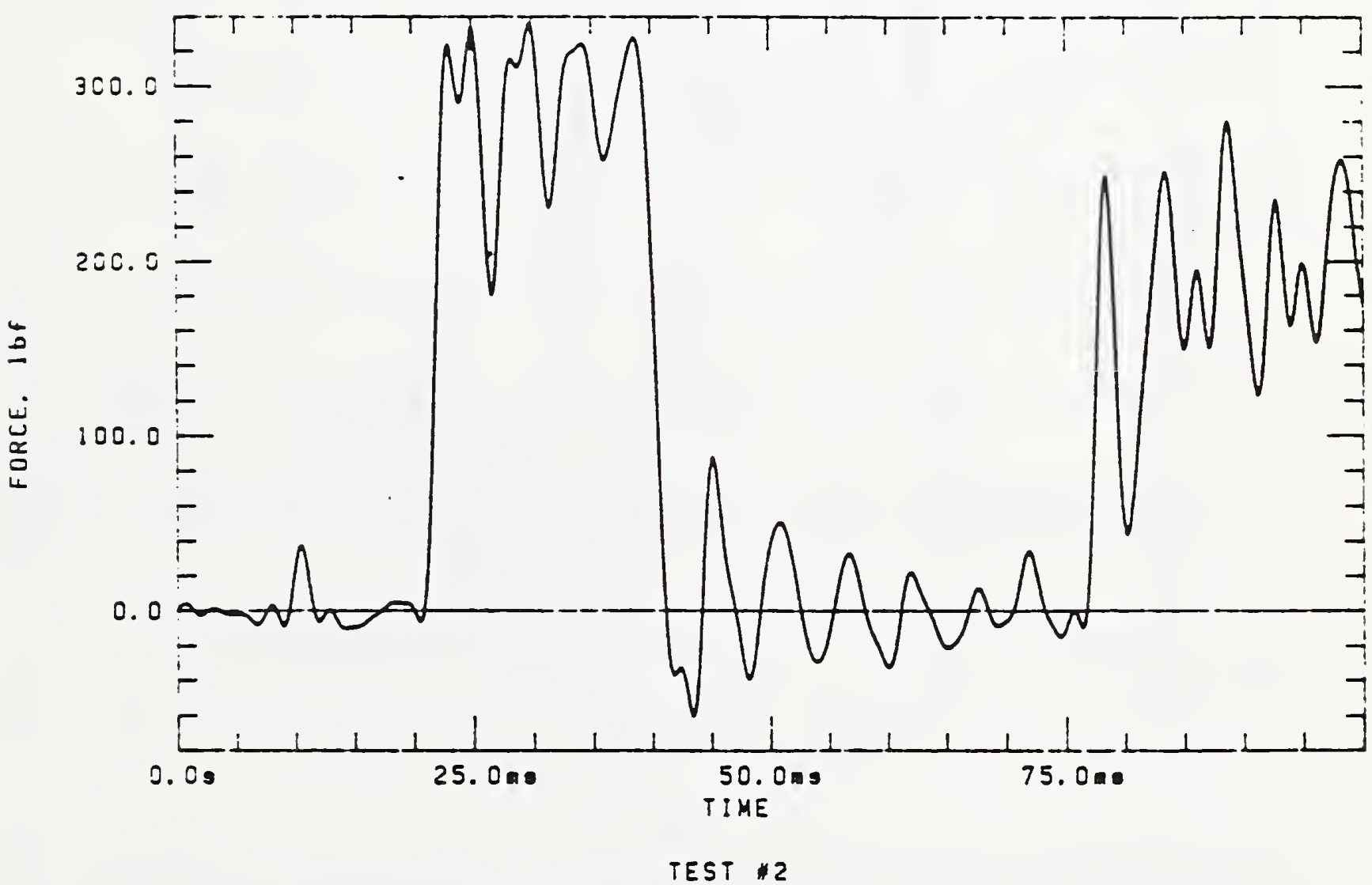

Figure 25. Load-time records for a $20 \mathrm{ft}$. long, 10 gage insulated cable. 
10 AWG/BARE. $20 \mathrm{FT}$

TOP GRIP

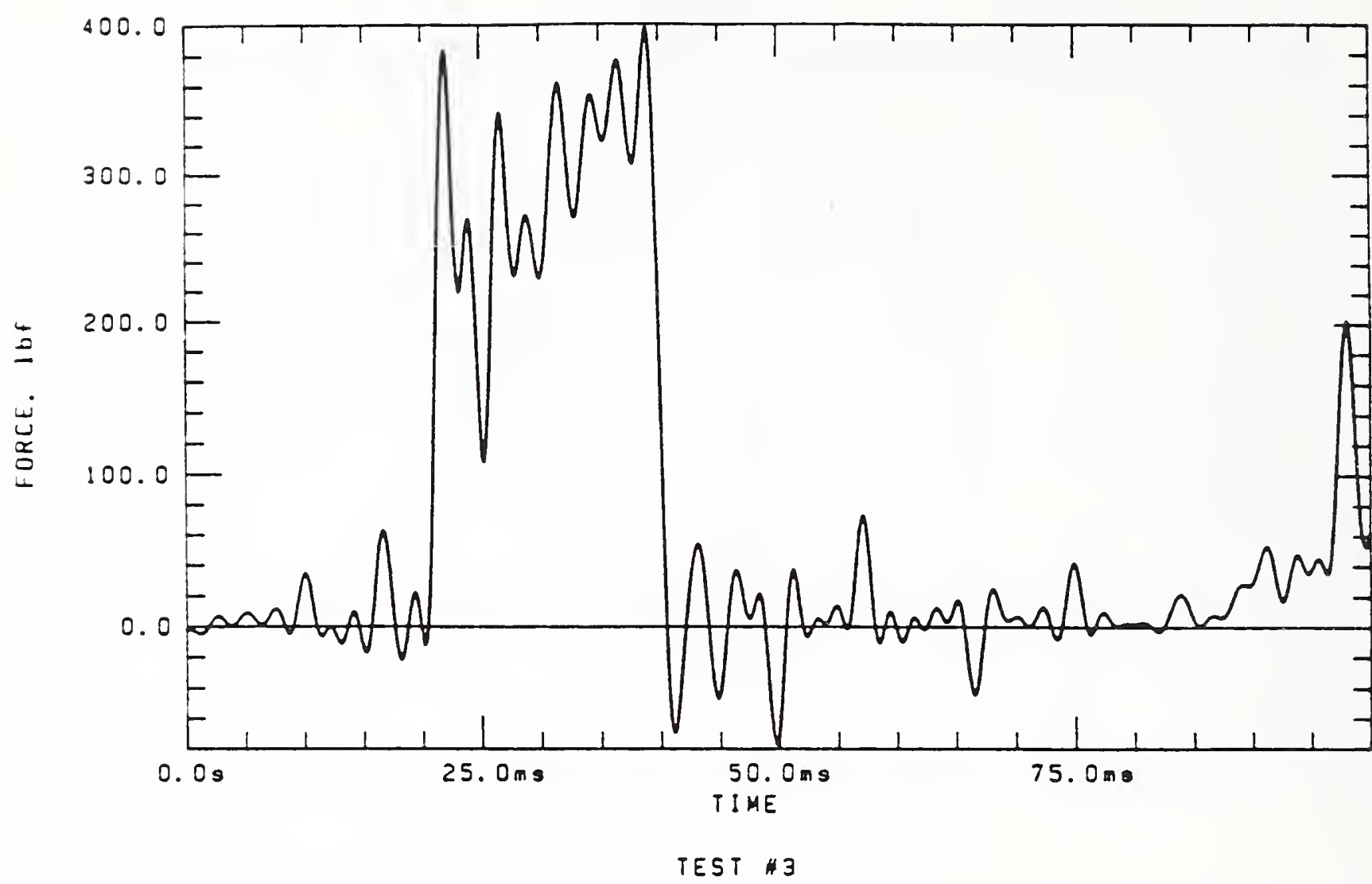

10 A VOIBARE, $20 \mathrm{FT}$

BOTTOM GRIP

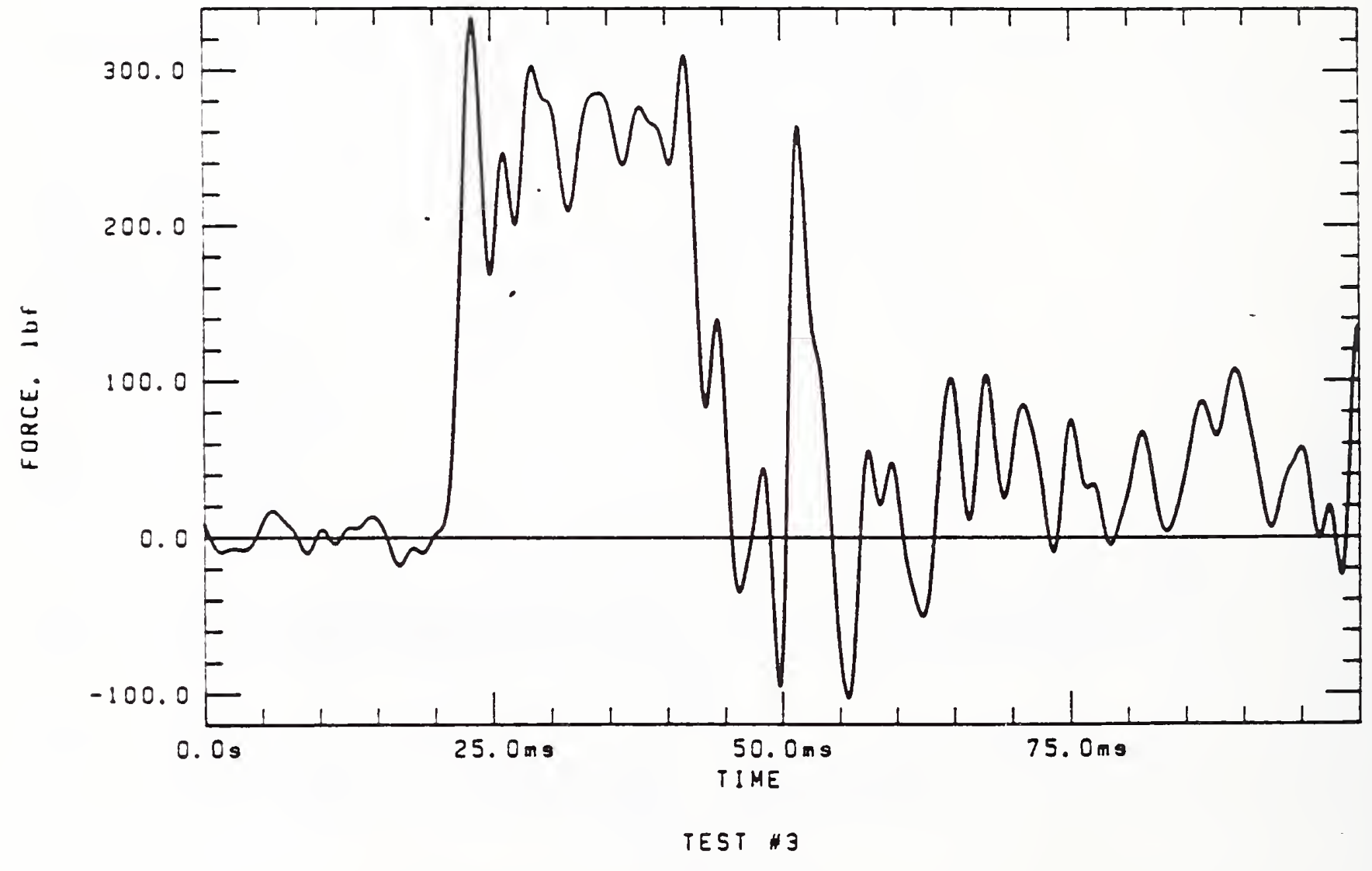

Figure 26. Load-time records for a $20 \mathrm{ft}$. long, 10 gage, uninsulated cable. 

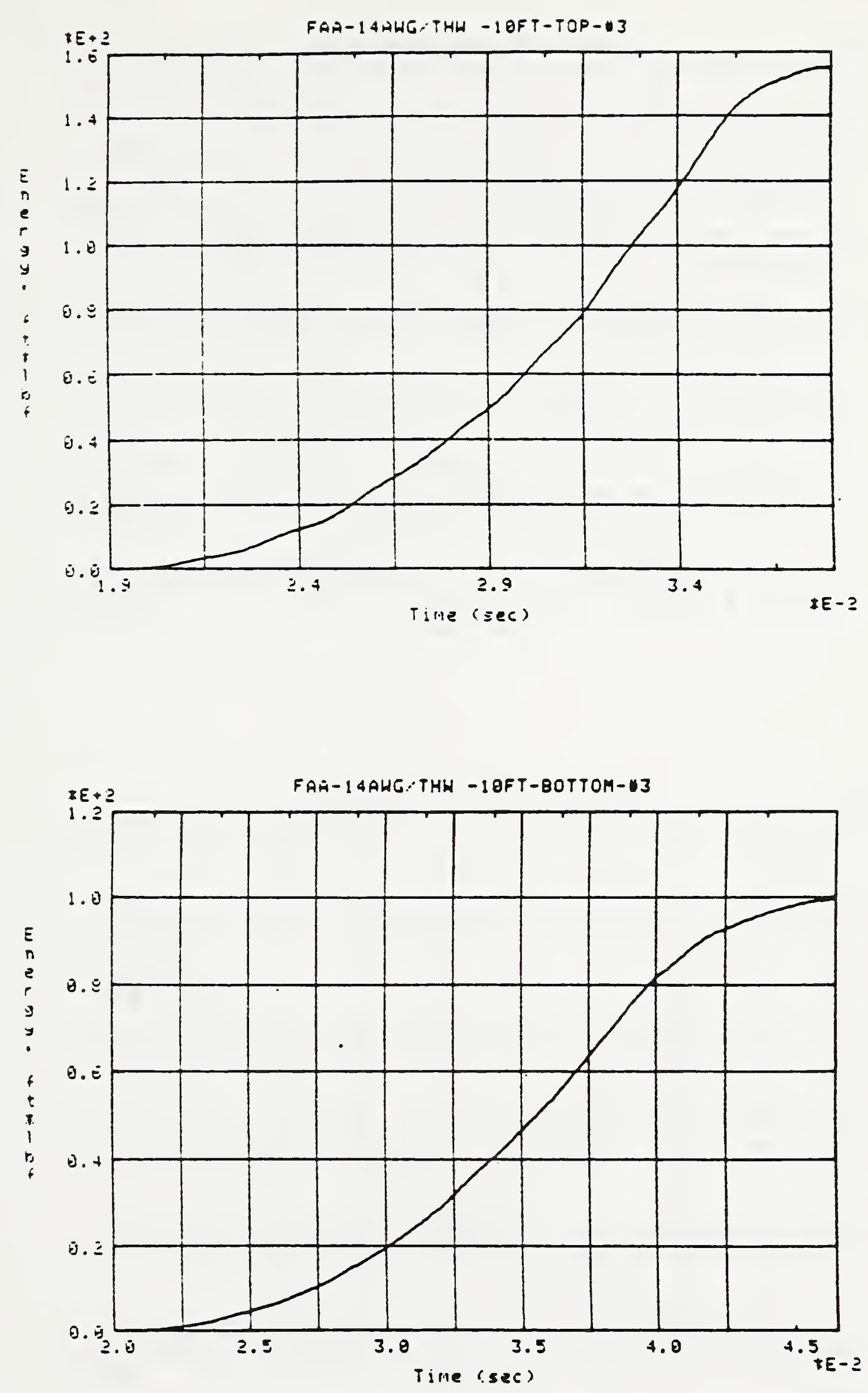

Figure 27. Energy-time records for a $10 \mathrm{ft}$ long 14 gage, insulated cable. 

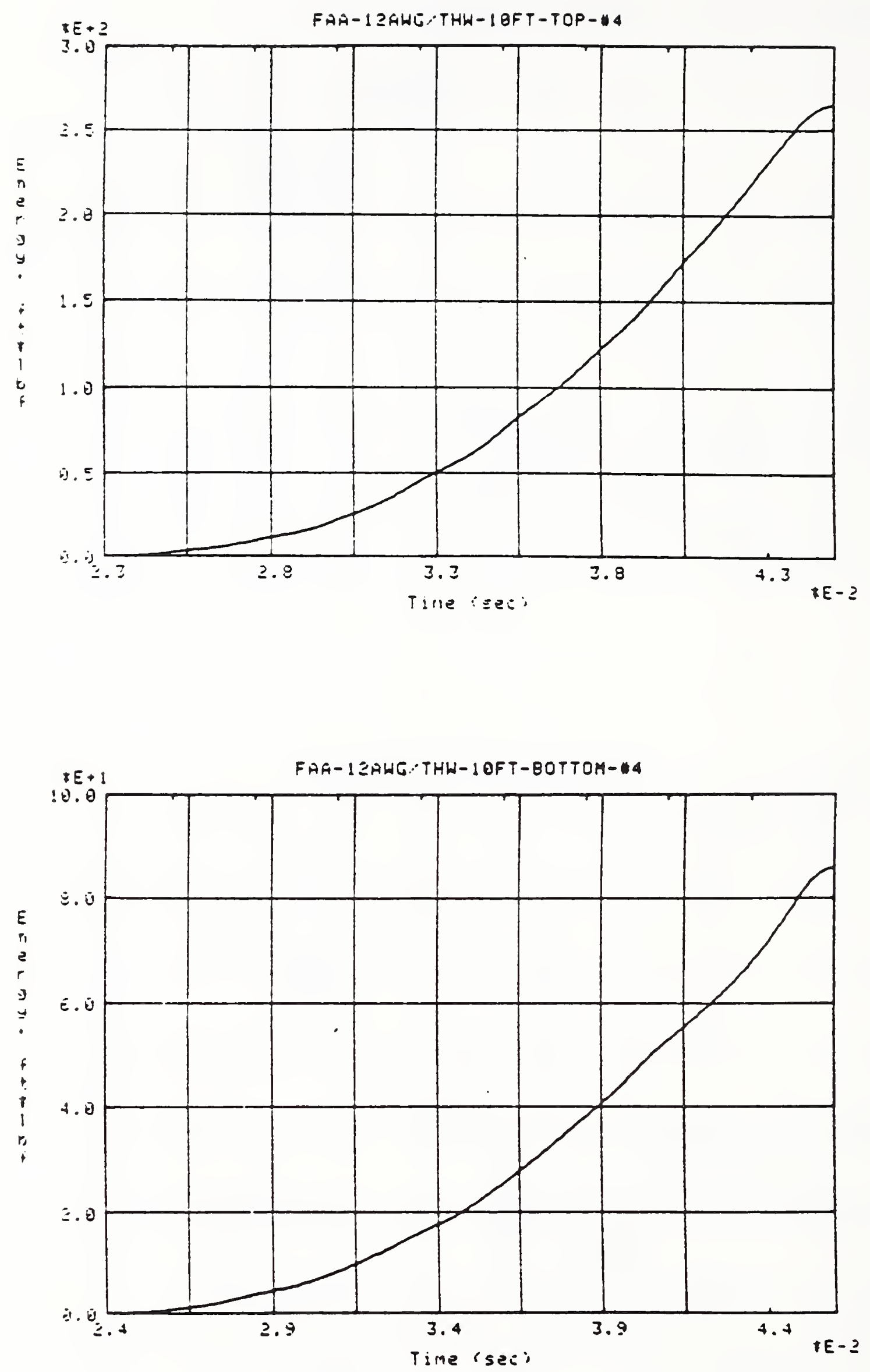

Figure 28 . Energy-time records for a $10 \mathrm{ft}$ long, 12 gage, insulated cable. 

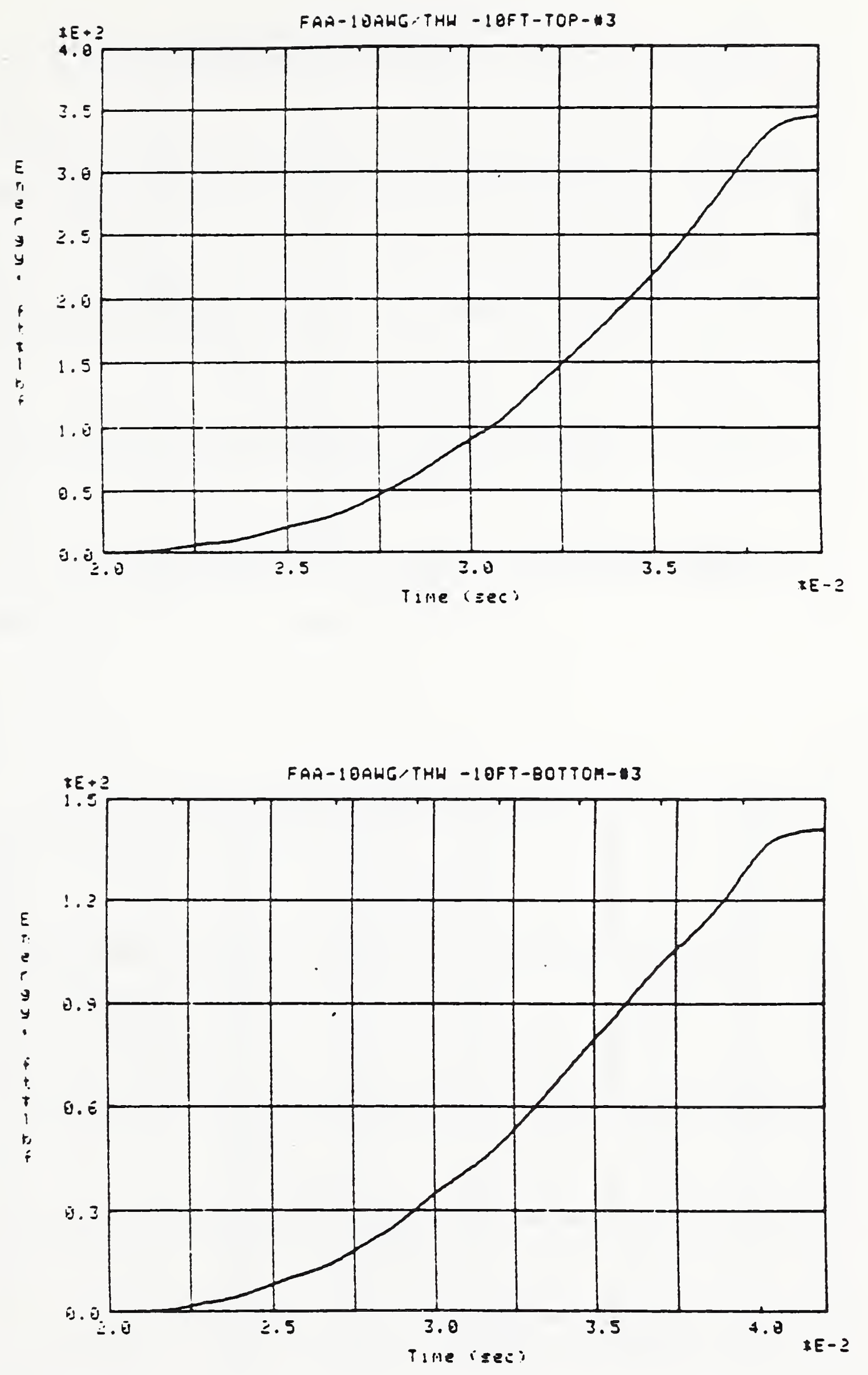

Figure 29. Energy-time records for a $10 \mathrm{ft}$ long, 10 gage, insulated cable. 

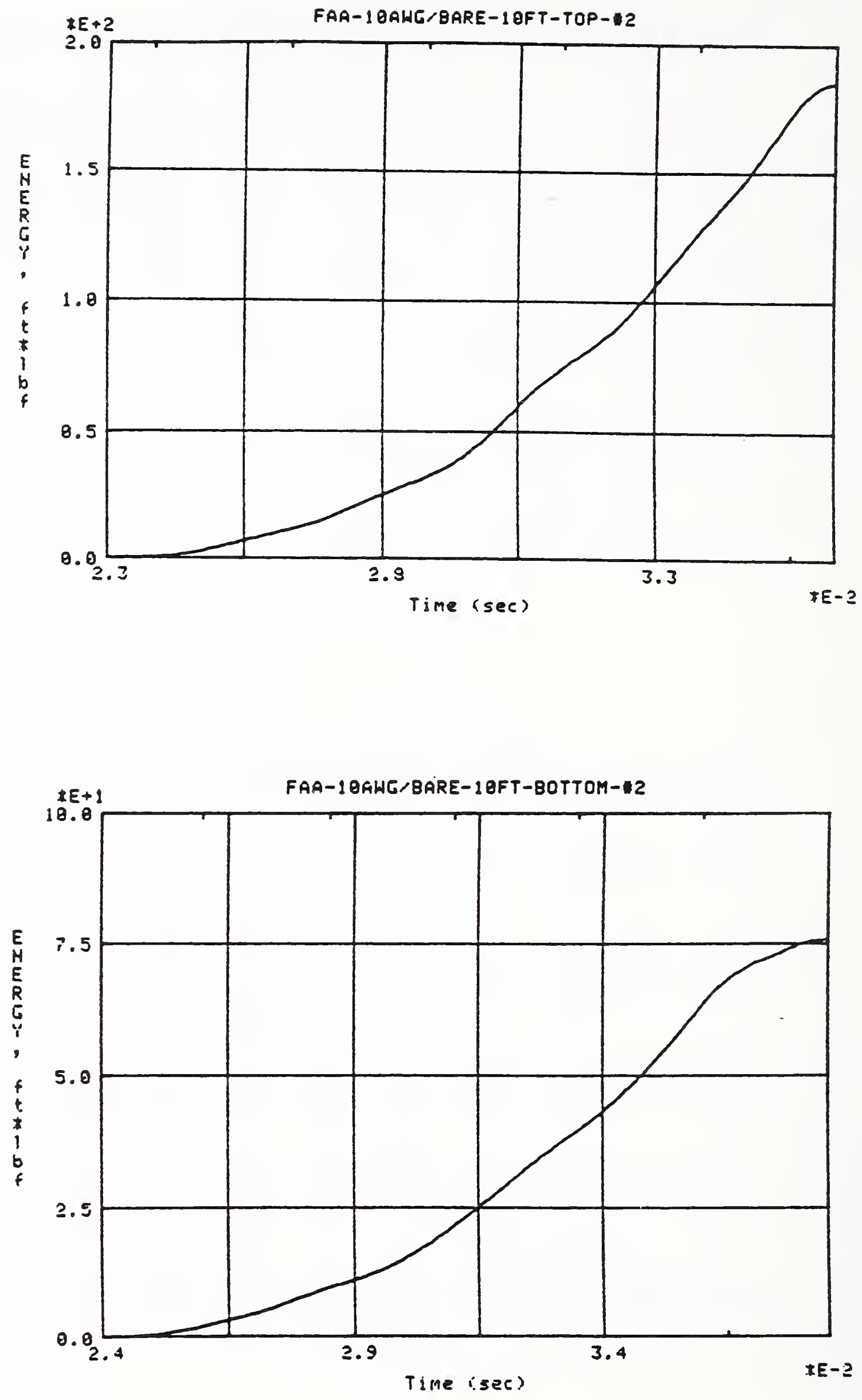

Figure 30. Energy-time records for a $10 \mathrm{ft}$ long, 10 gage, uninsulated cable. 

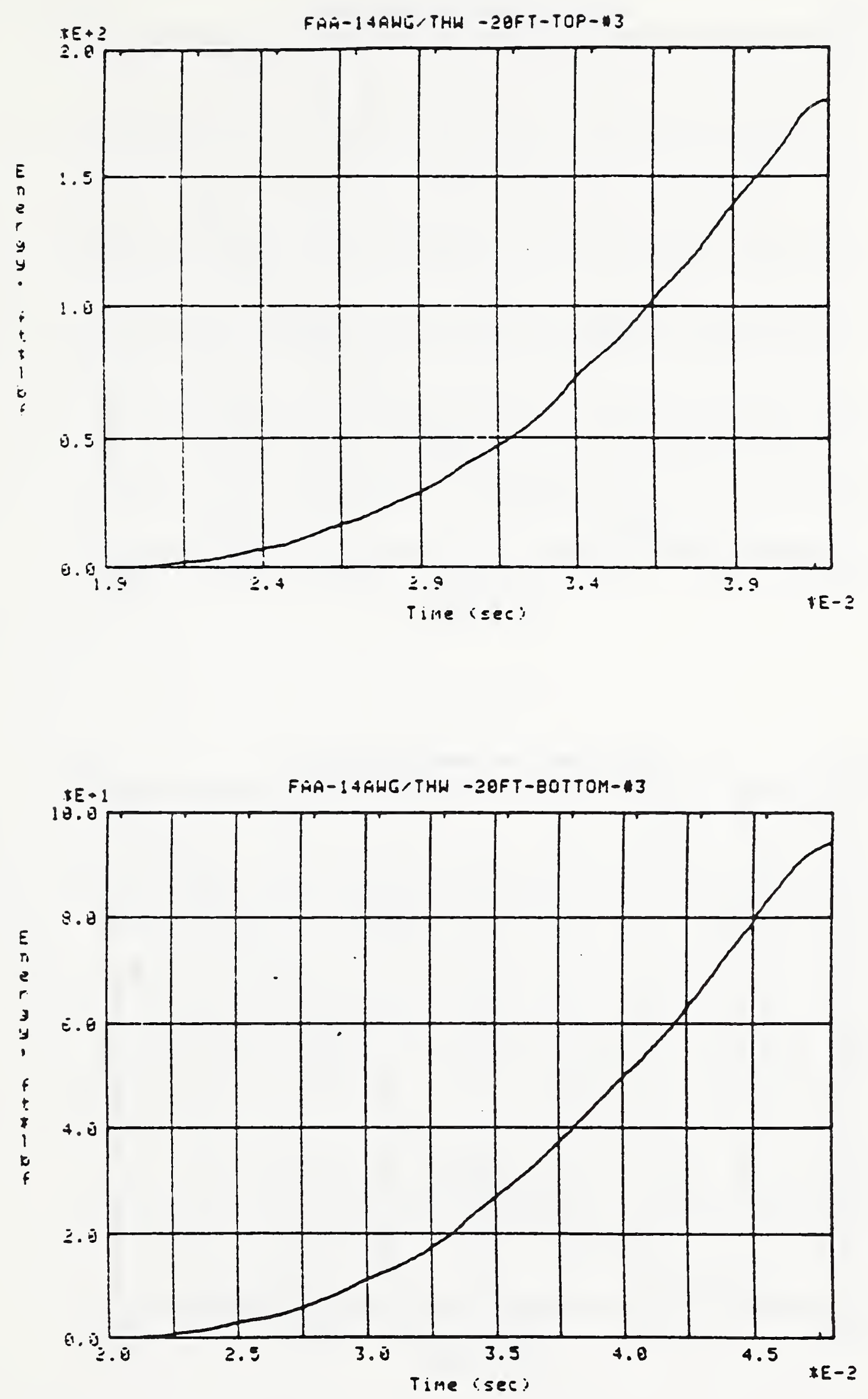

Figure 31 . Energy-time records for a $20 \mathrm{ft}$ long, 14 gage, insulated cable. 

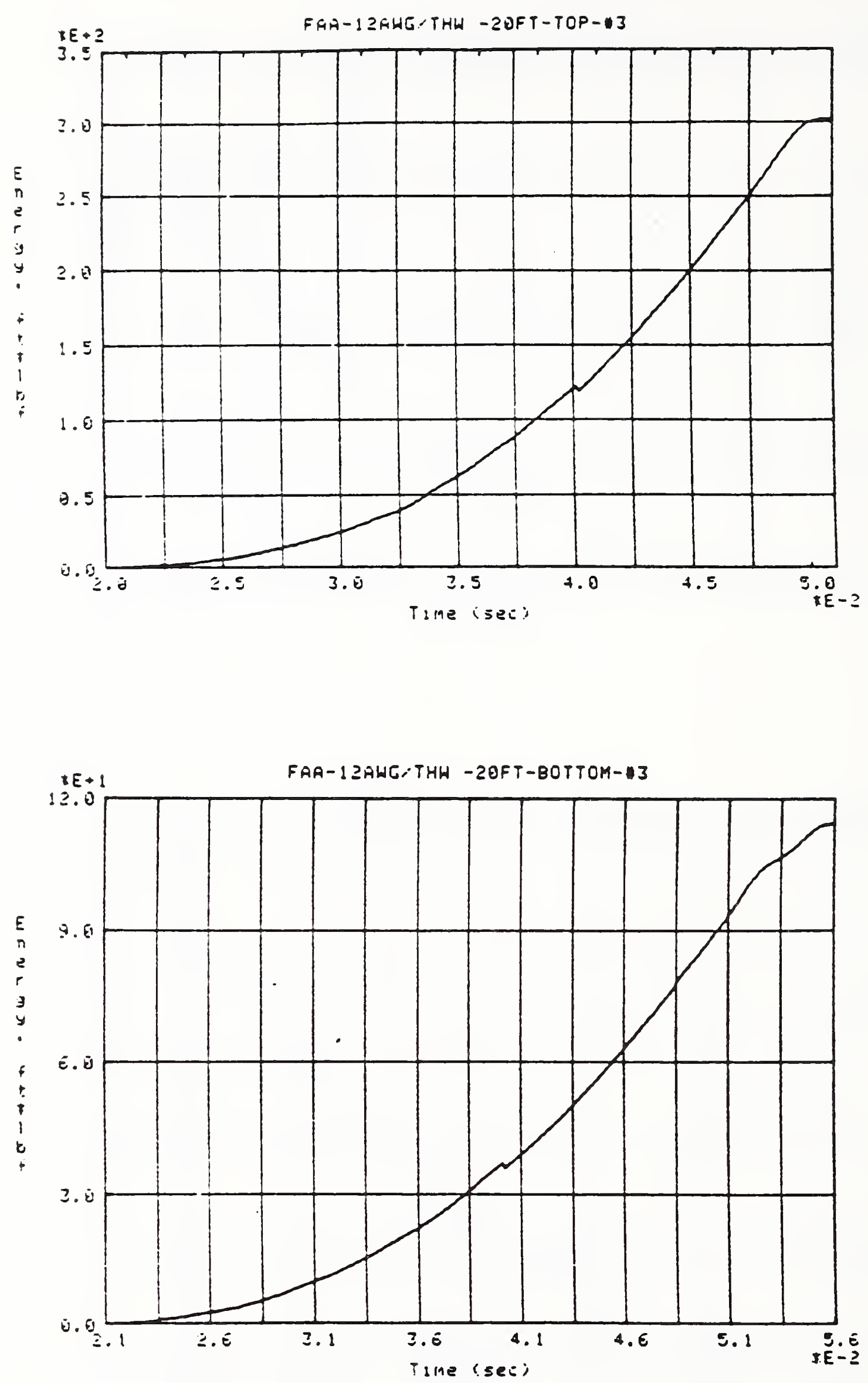

Figure 32. Energy-time records for a $20 \mathrm{ft}$ long, 12 gage, insulated cable. 

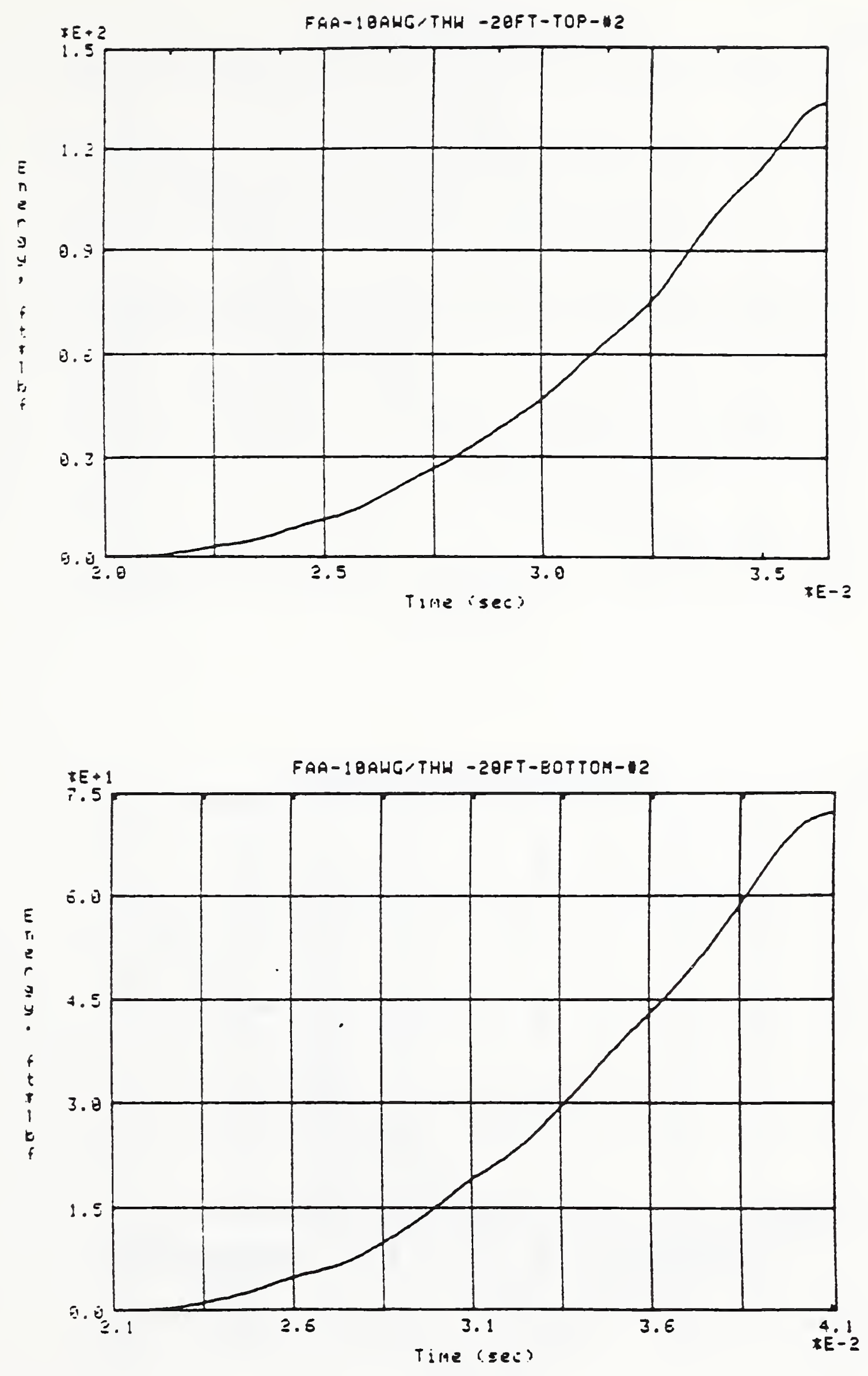

Figure 33. Energy-time records for a $20 \mathrm{ft}$ long, 10 gage, insulated cable. 

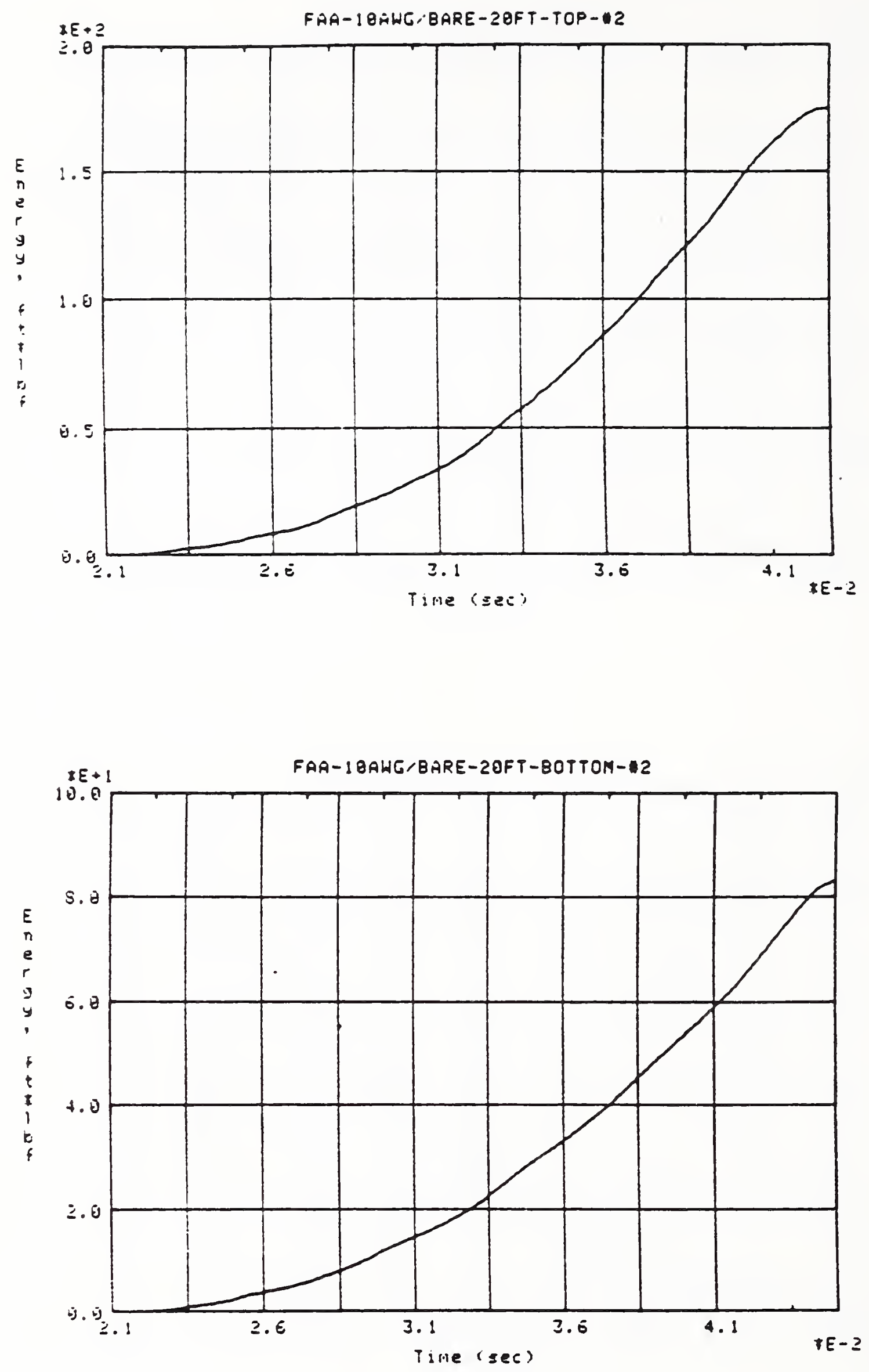

Figure 34. Energy-time records for a $20 \mathrm{ft}$ long, 10 gage, uninsulated cable. 

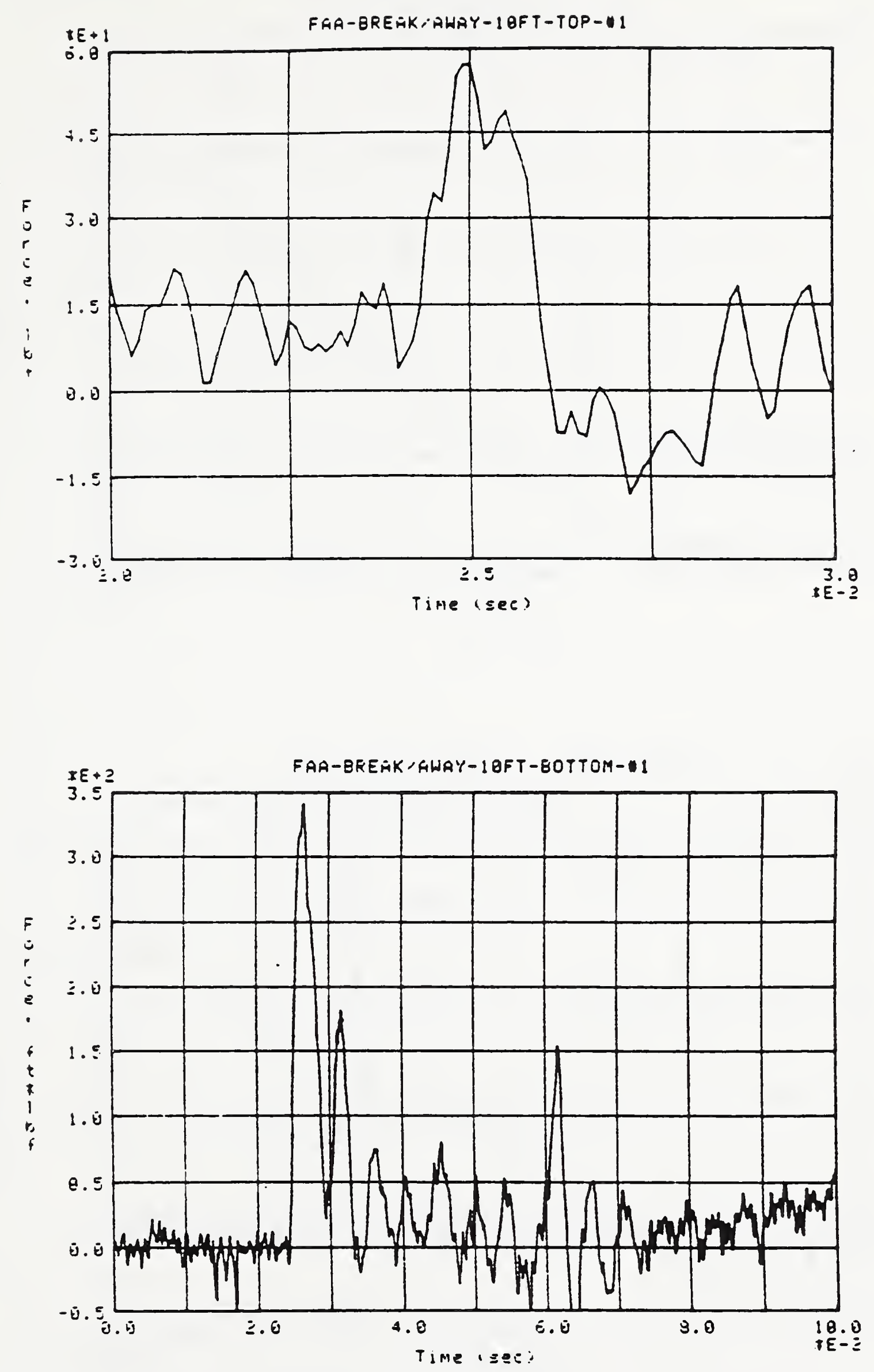

Figure 35. Load-time records for a $10 \mathrm{ft}$ long cable with one break-away connector located $8.5 \mathrm{ft}$. above lower grip, i.e., at midpoint of cable above impact point. 

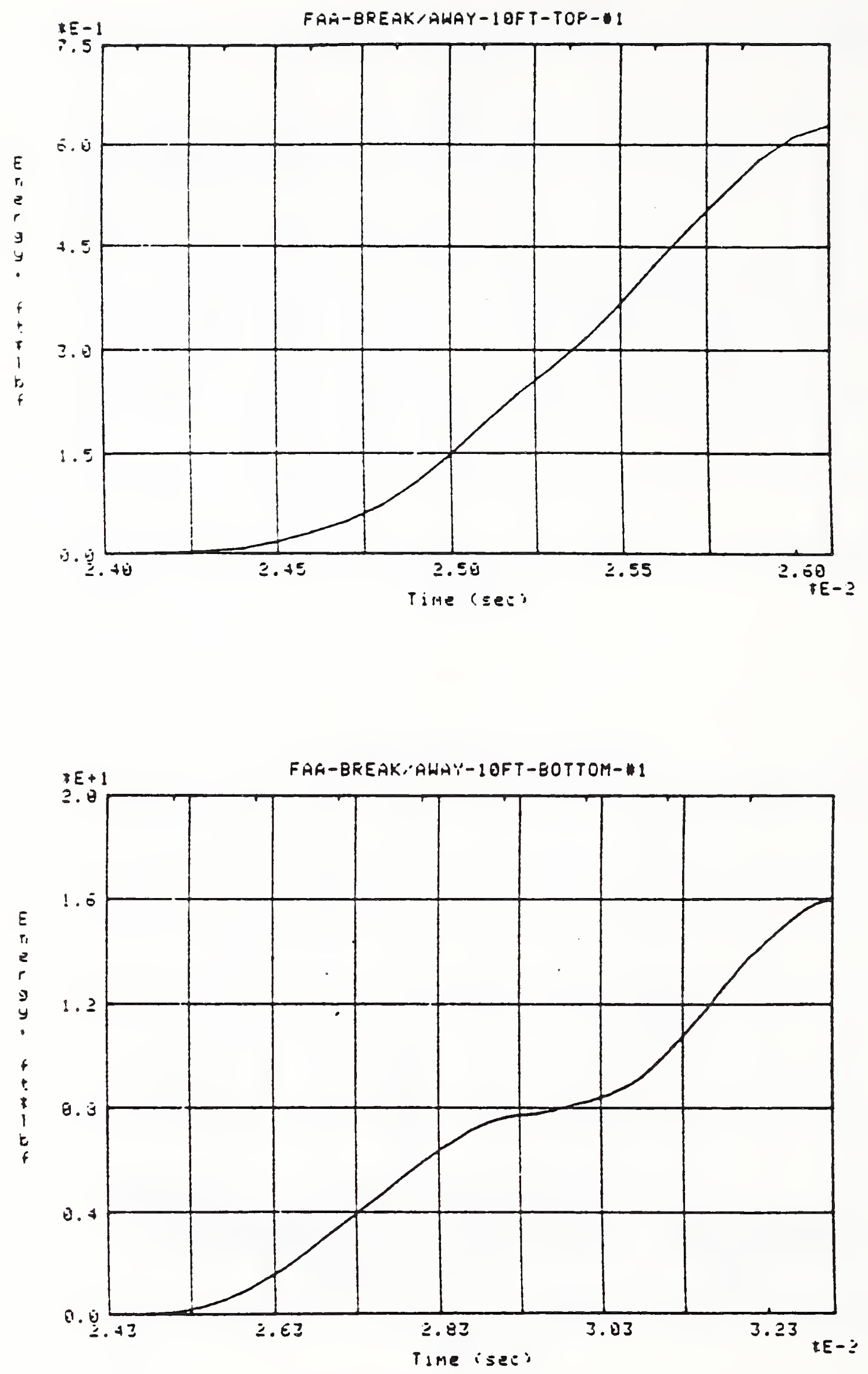

Figure 36. Energy-time records for test shown in Figure 35. 
BREAK-AYAY CONNECTOR. 20 FT CABLE

TOP GRIP

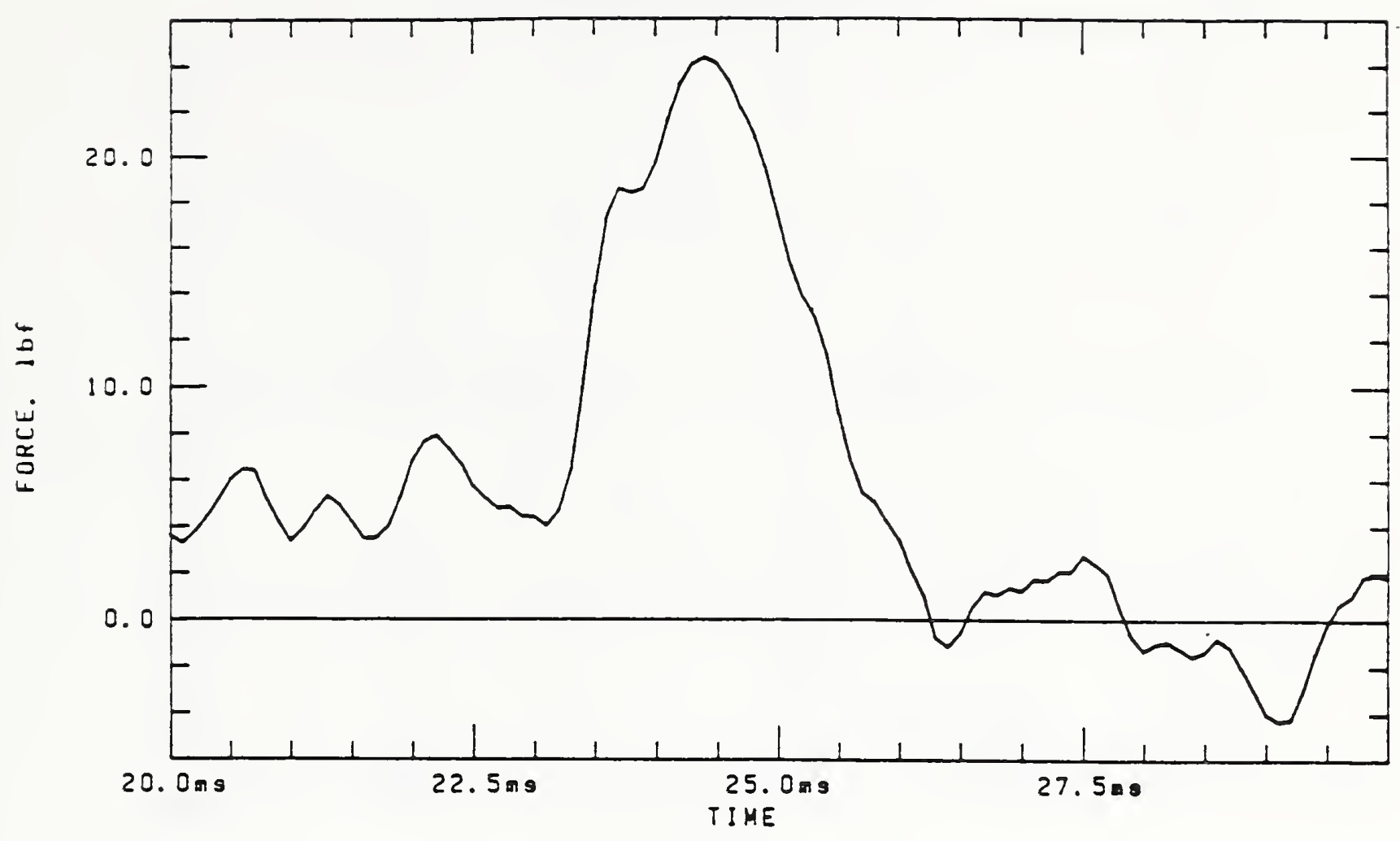

TEST 2

BREAK-AYAY CONNECTOR. 20 FT CABLE

BOTTOM GRIP

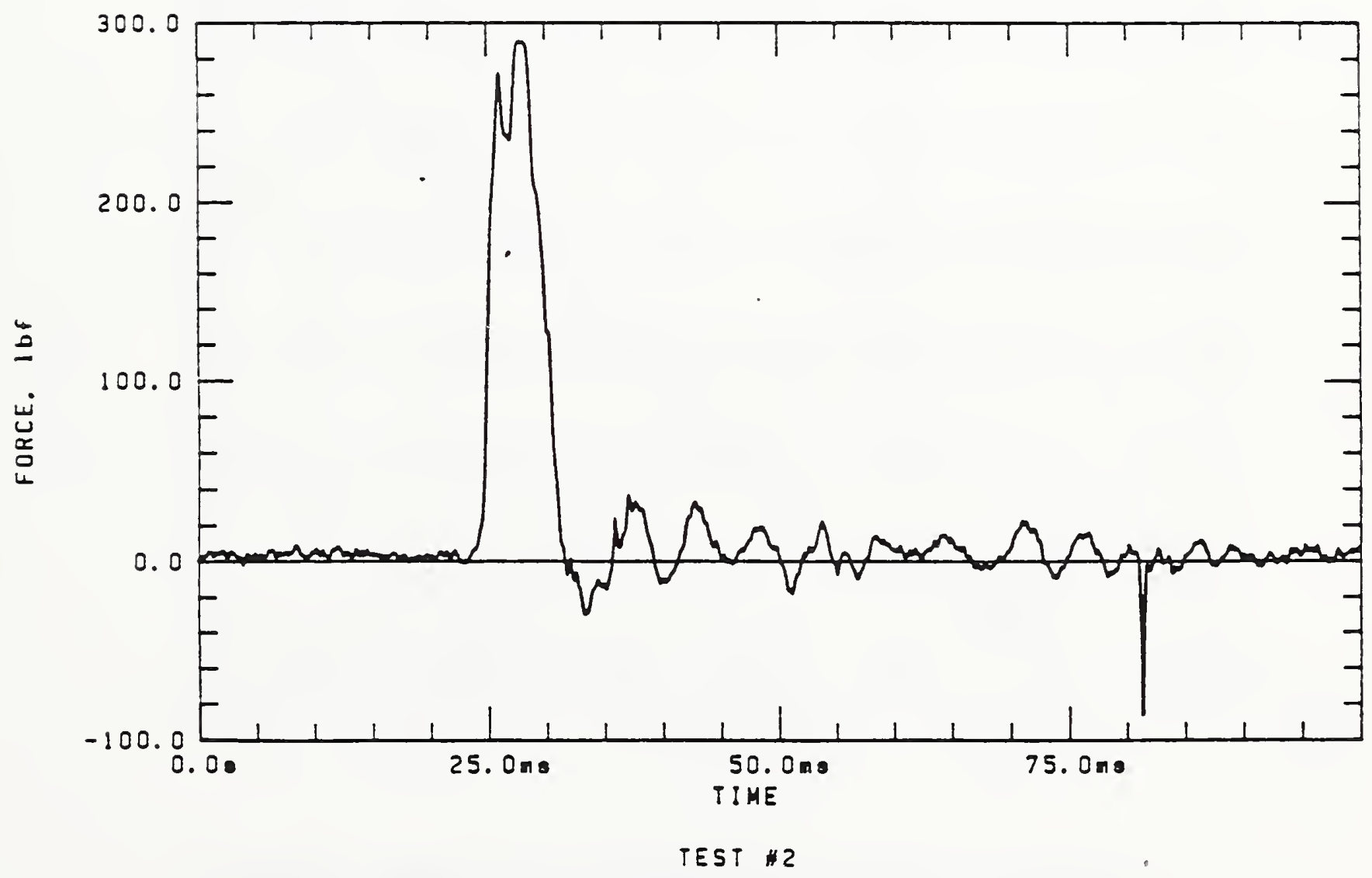

Figure 37. Load-time records for $20 \mathrm{ft}$ cable with one break-away connector located at midpoint of upper portion of cable. 

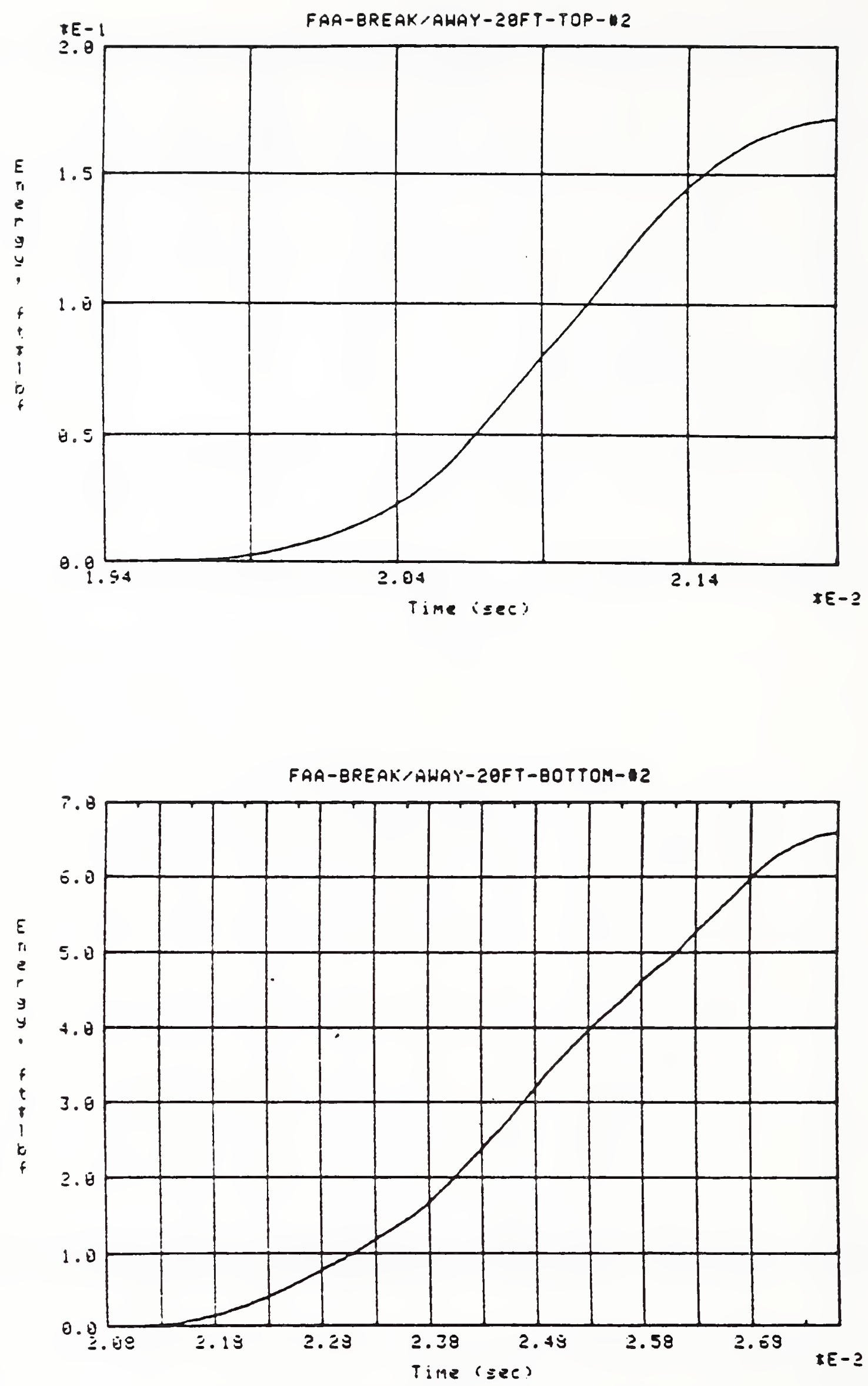

Figure 38. Energy-time records for test shown in Figure 37. 
2 BREAK-AYAY CONNECTORS, 2 FT SPAN, 20 FT CABLE

TOP GRIP

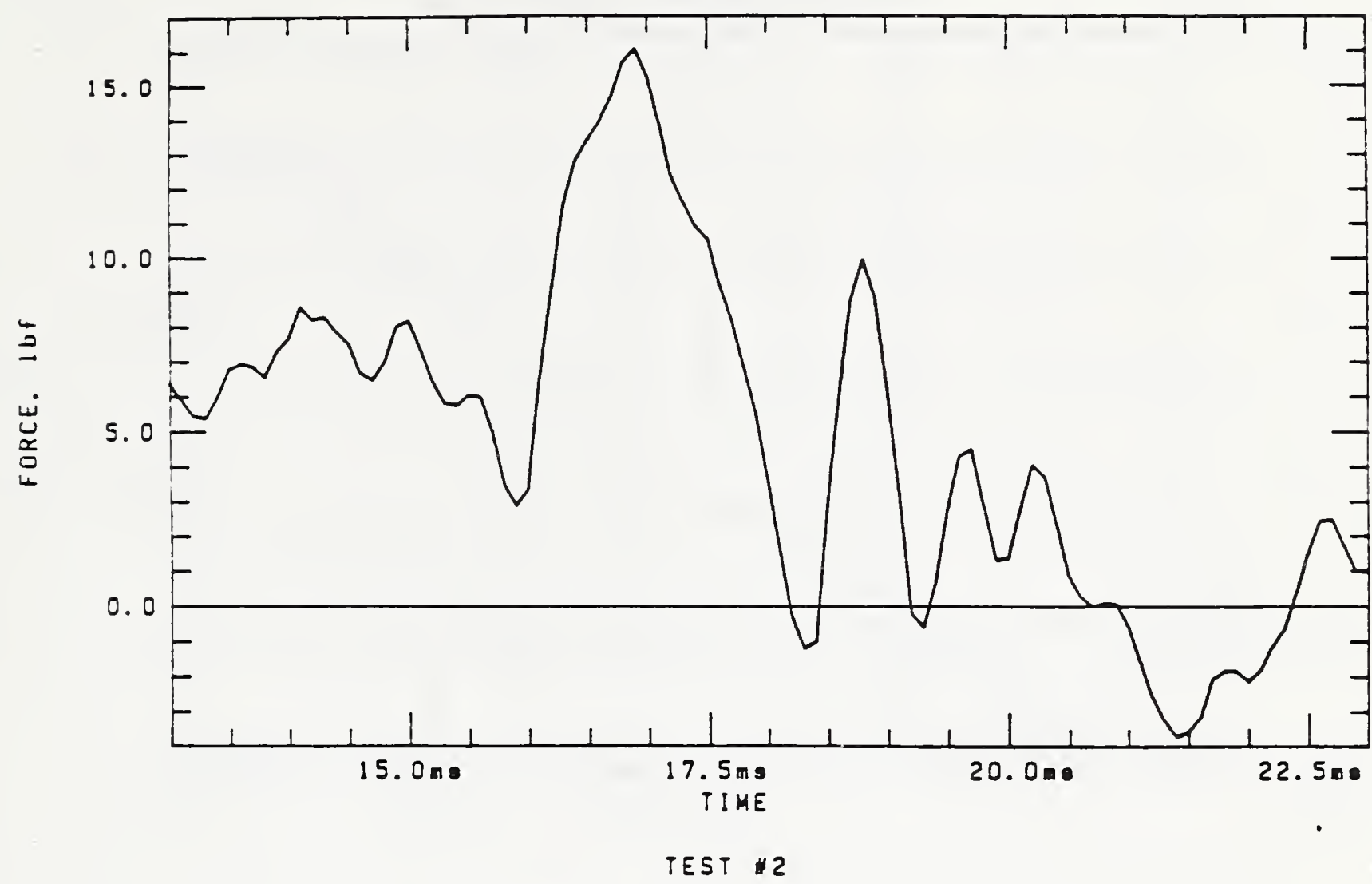

2 BREAK-AYAY CONNECTORS. 2 FT SPAN, 20 FT CABLE

BOTTOM CRIP

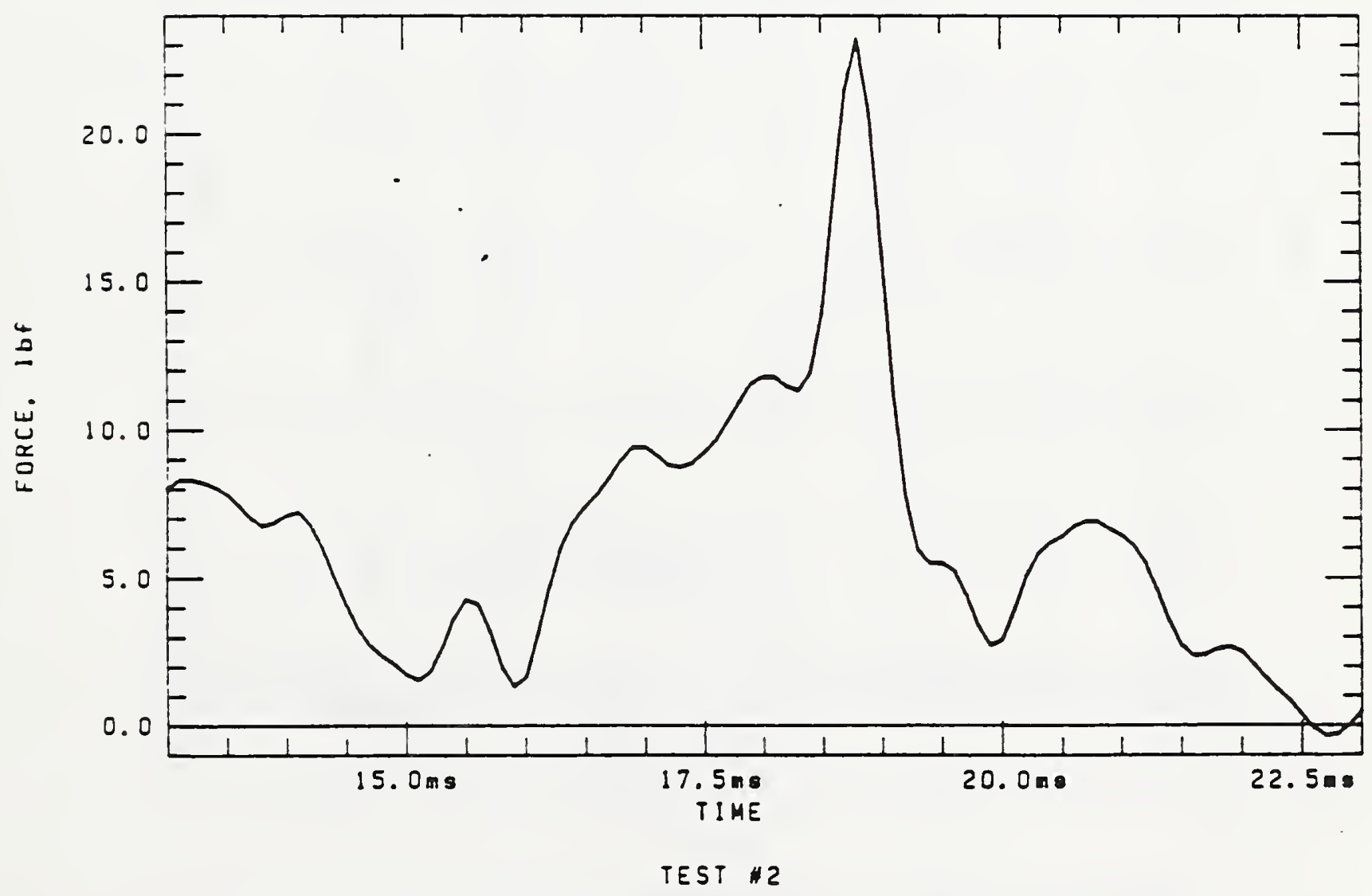

Figure 39. Load-time records for cable tested with break-away connectors located $1 \mathrm{ft}$ above and $1 \mathrm{ft}$ below impact point, i.e., $2 \mathrm{ft}$ span. 

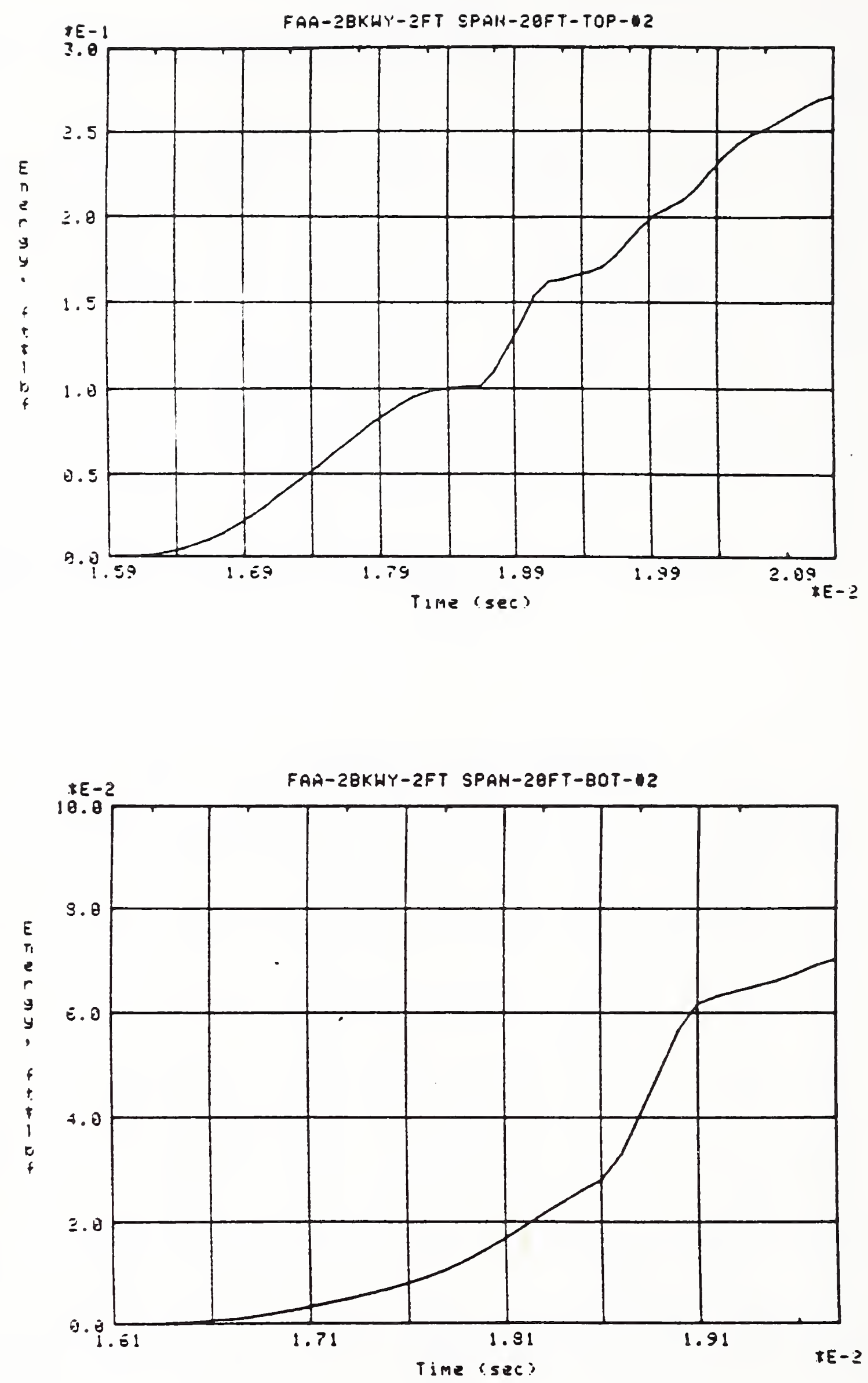

Figure 40. Energy-time records for test shown in Figure 39. 
2 BREAK-AYAY CONNECTORS. 18 FT SPAN, 20 FT CABLE

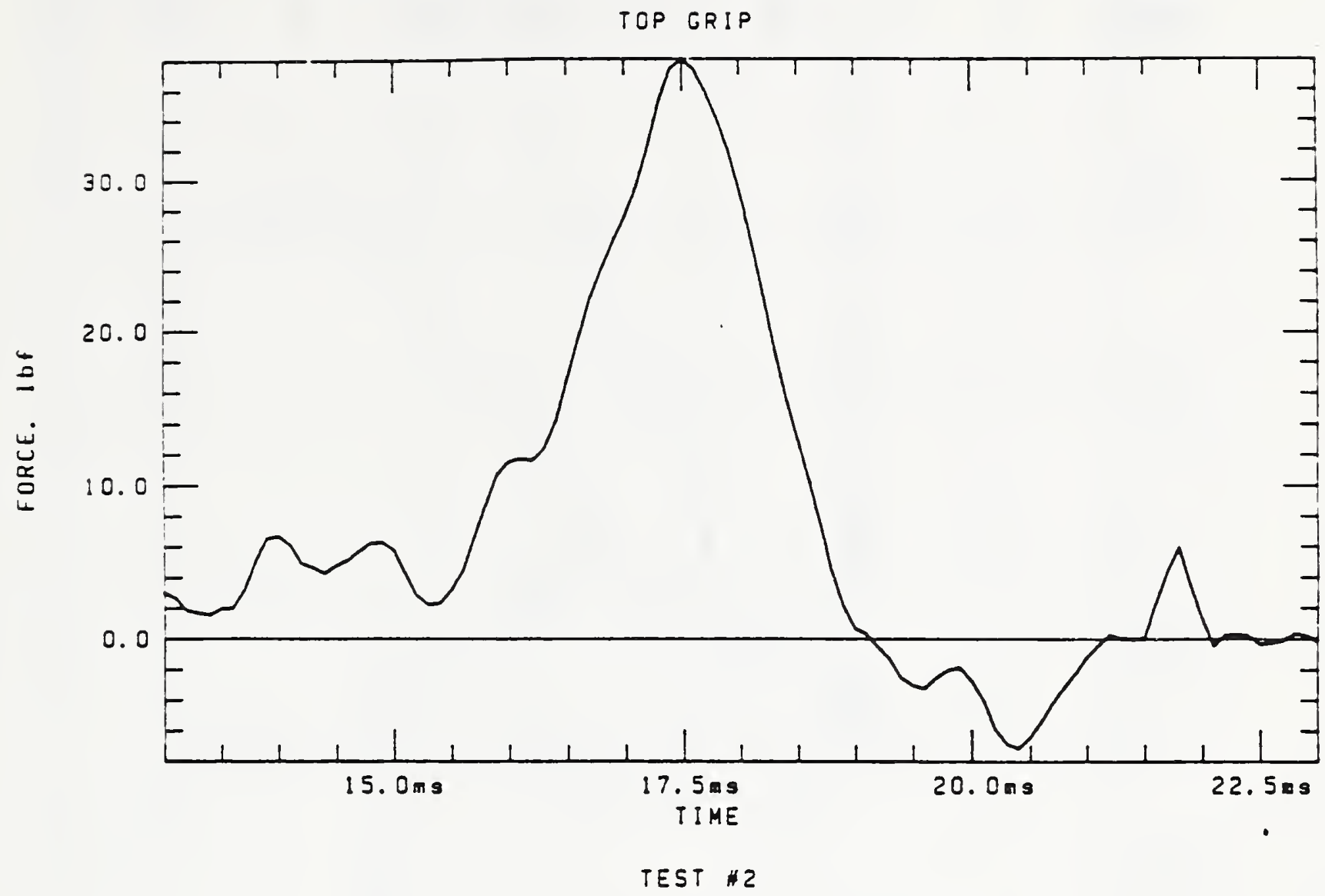

2 BREAK-AYAY CONNECTORS. 18 FT SPAN. 20 FT CABLE

BOTTOM GRIP

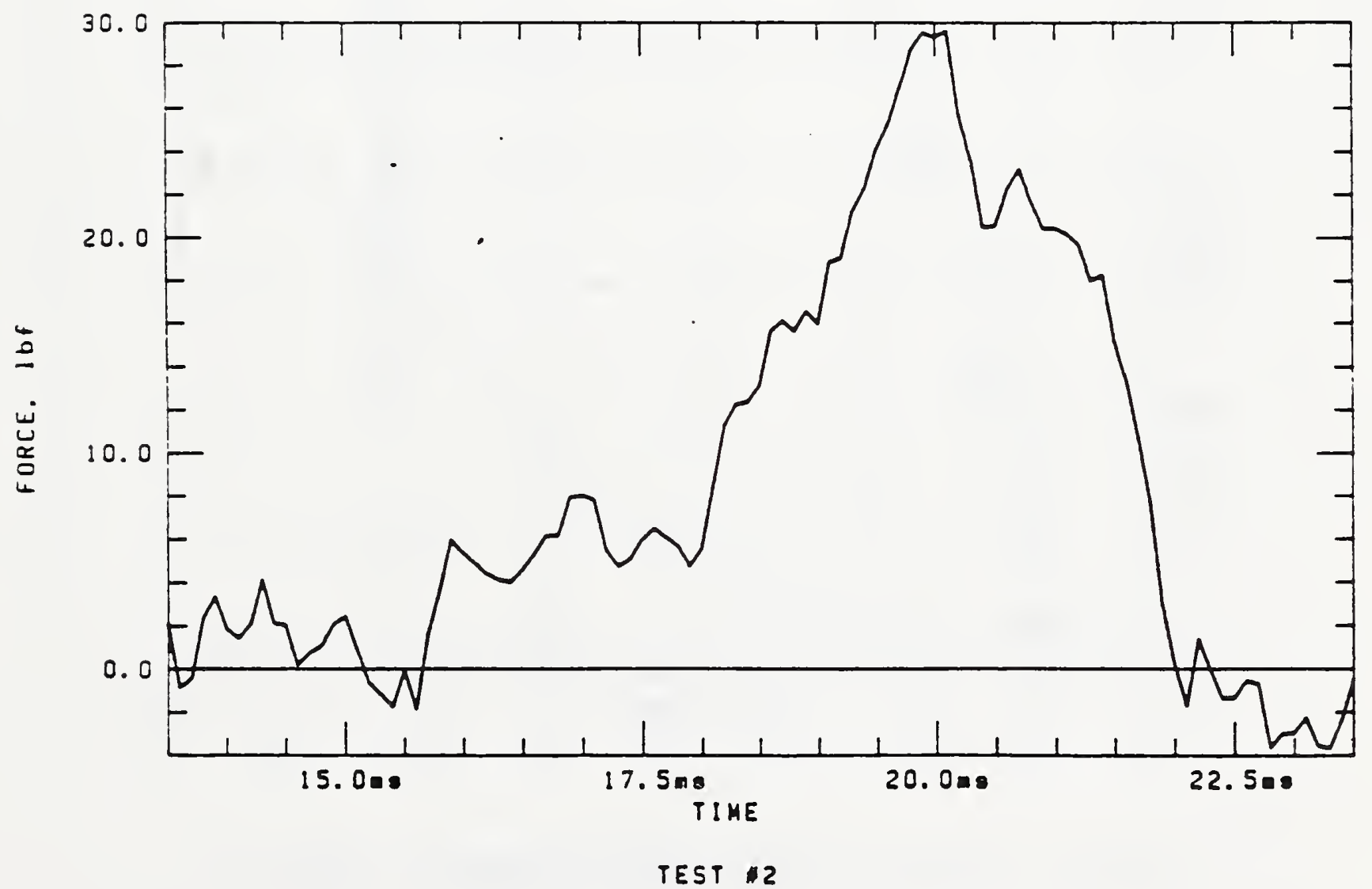

Figure 41. Load-time records for cable tested with break-away connectors located $1 \mathrm{ft}$ above bottom grip and $1 \mathrm{ft}$ bclow top grip, i.e., is ft span. 

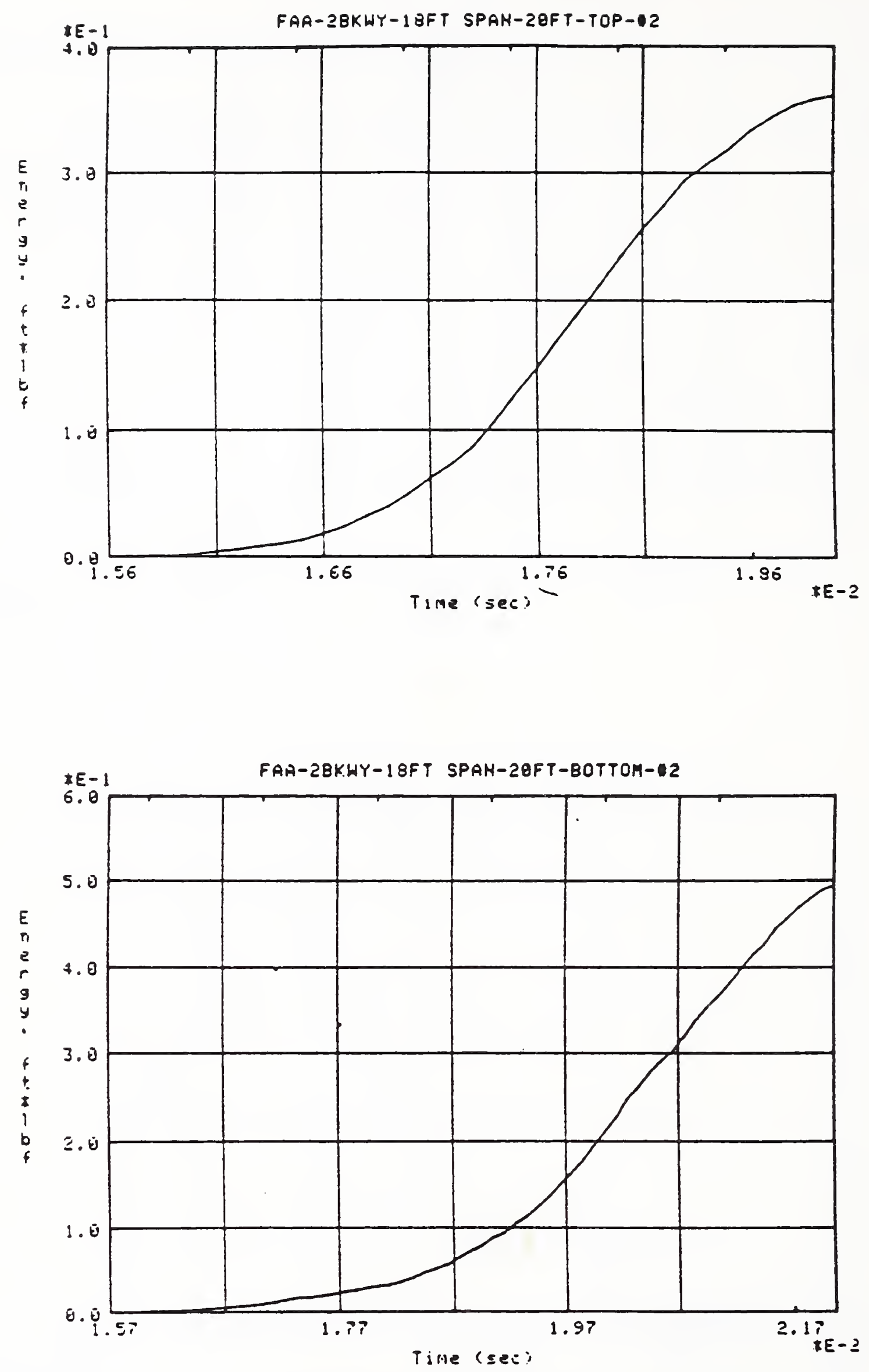

Figure 42. Energy-time records for test shown in Figure 41. 


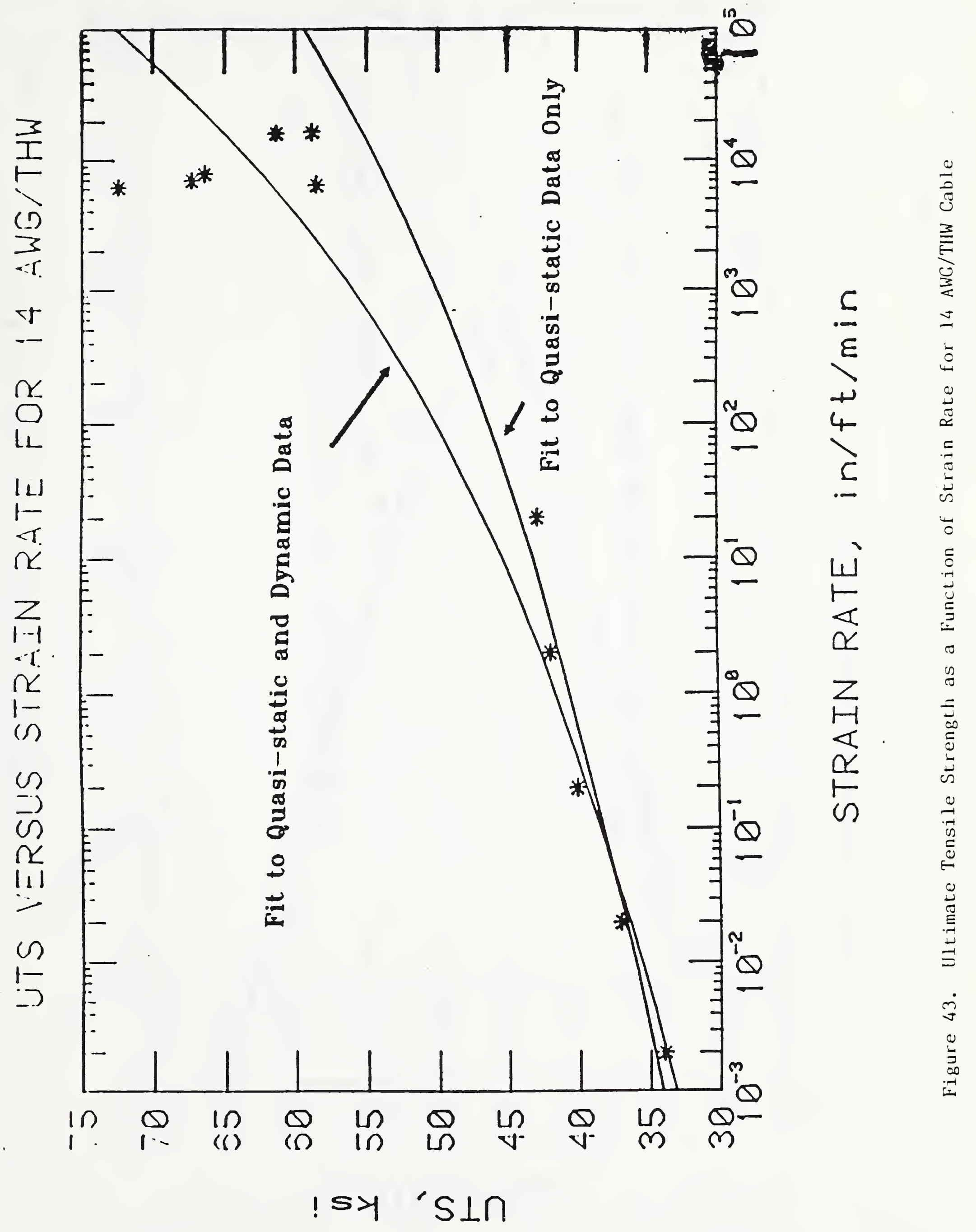




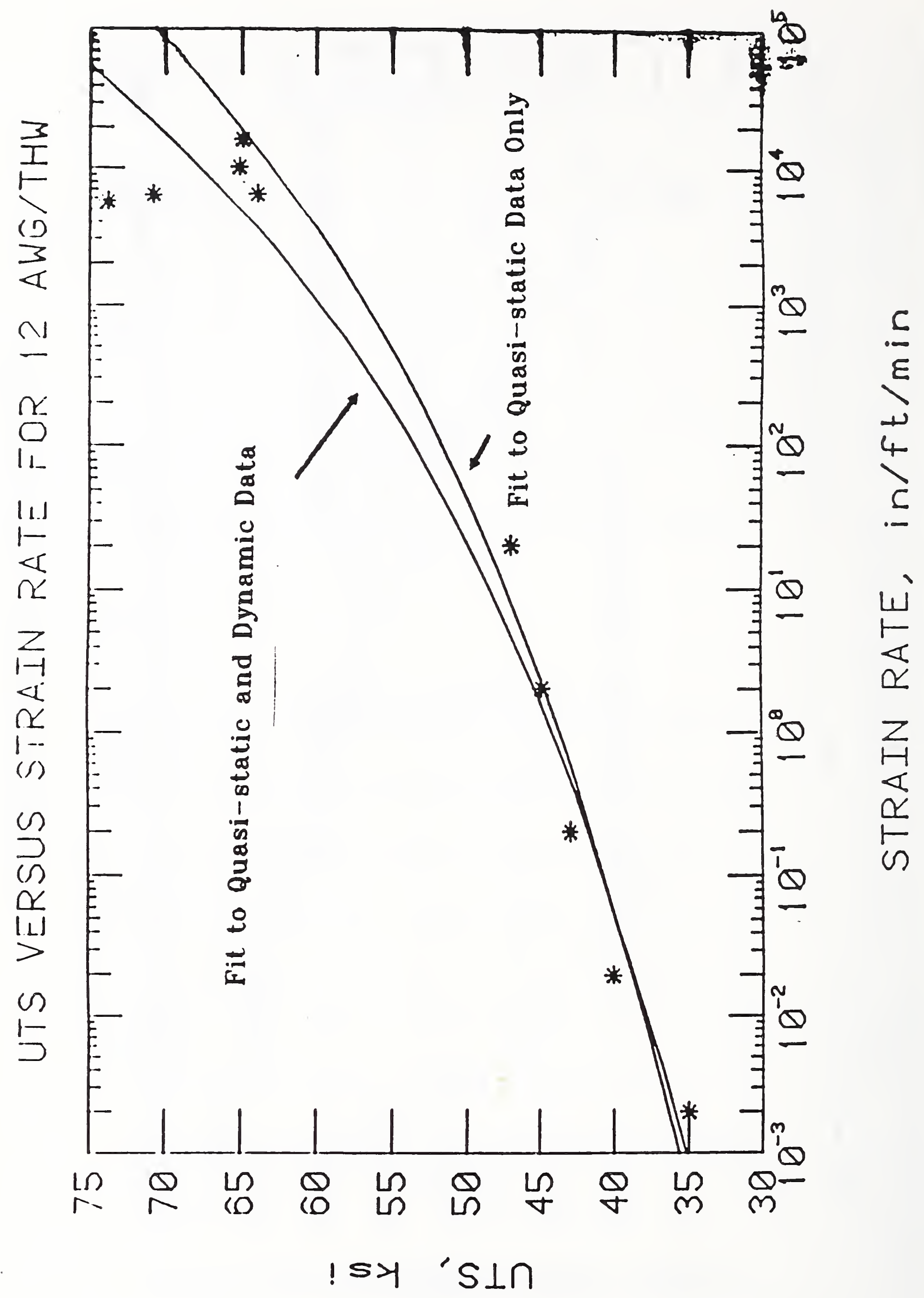




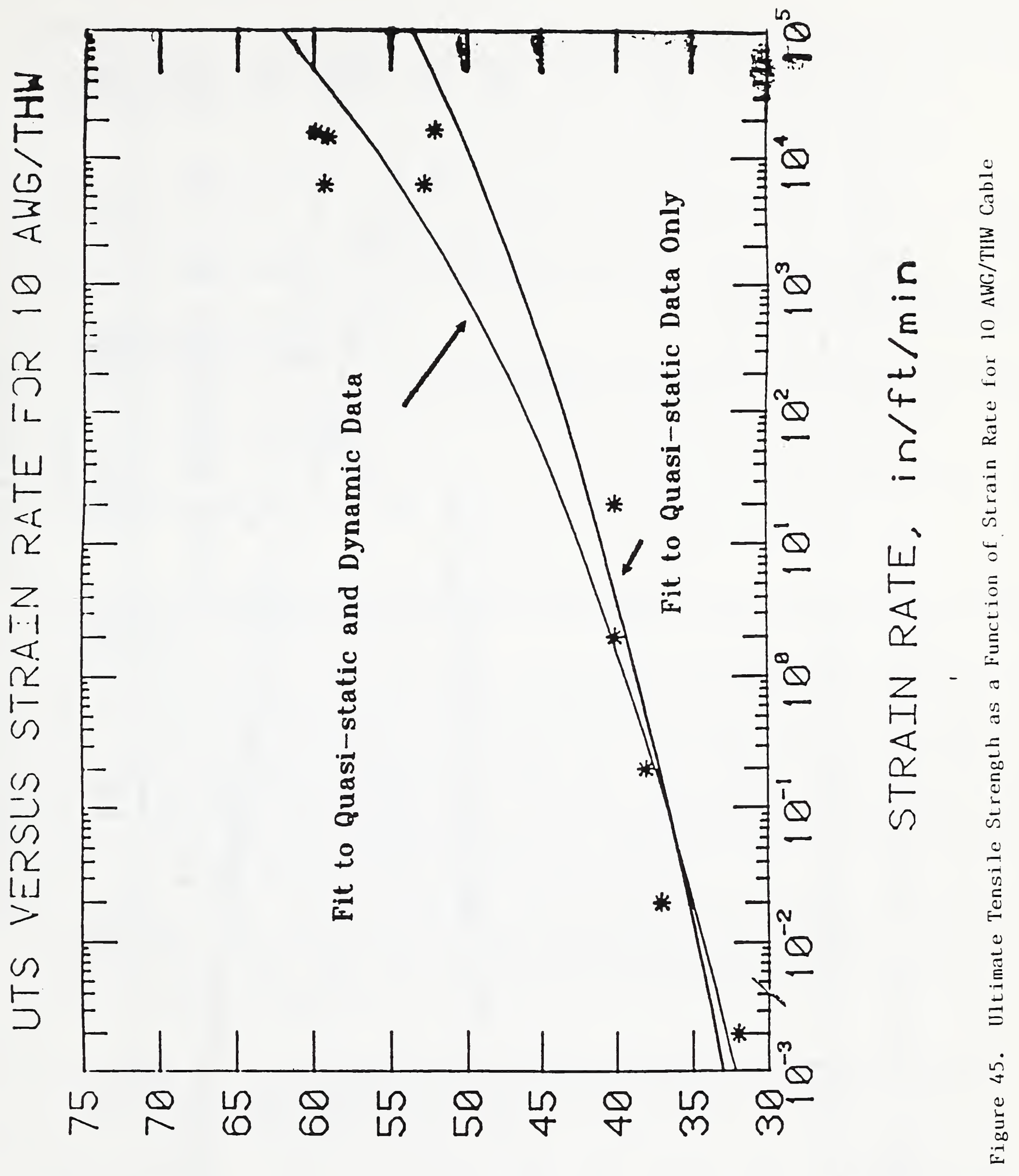

ISY ' $S \perp \cap$ 


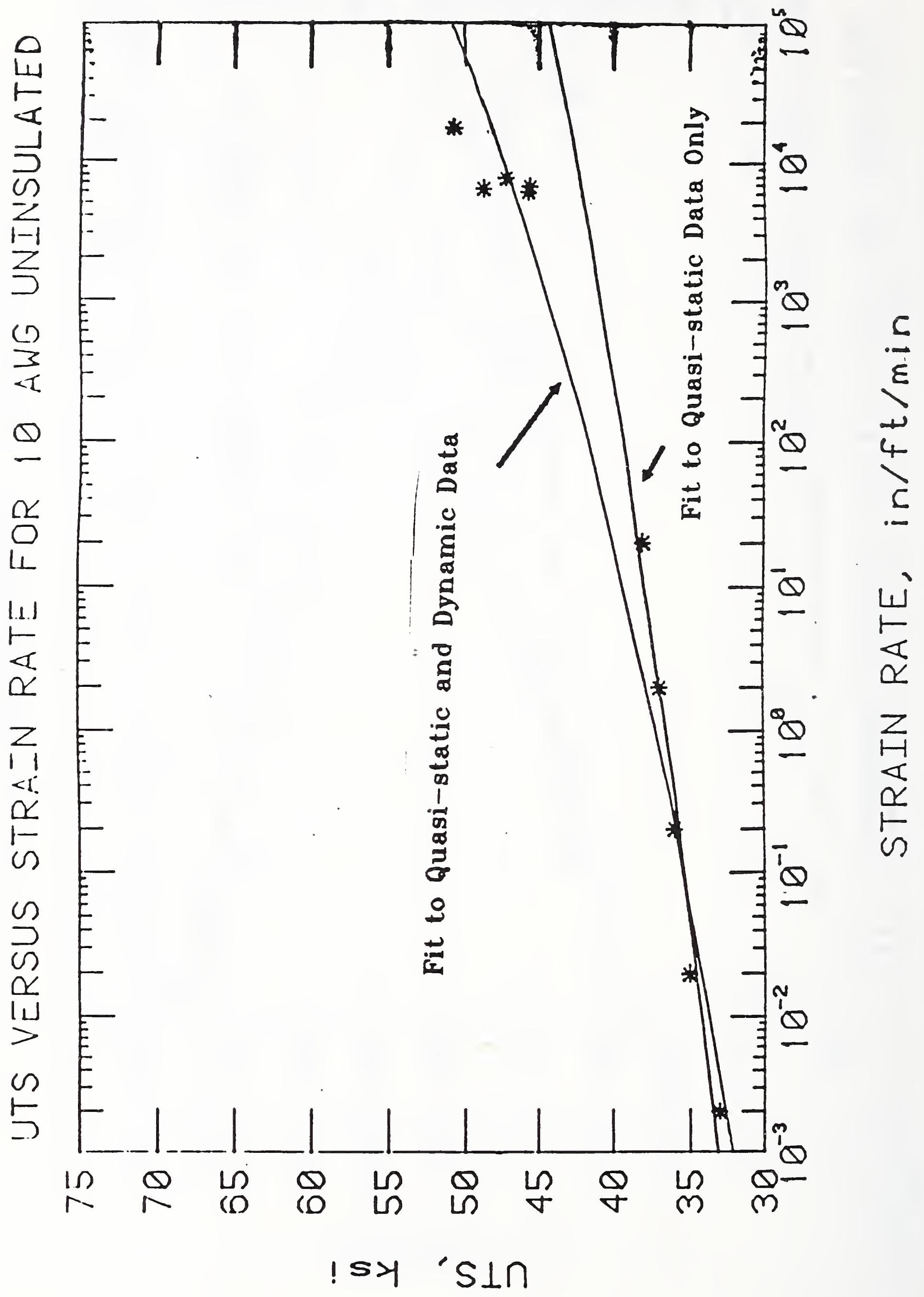




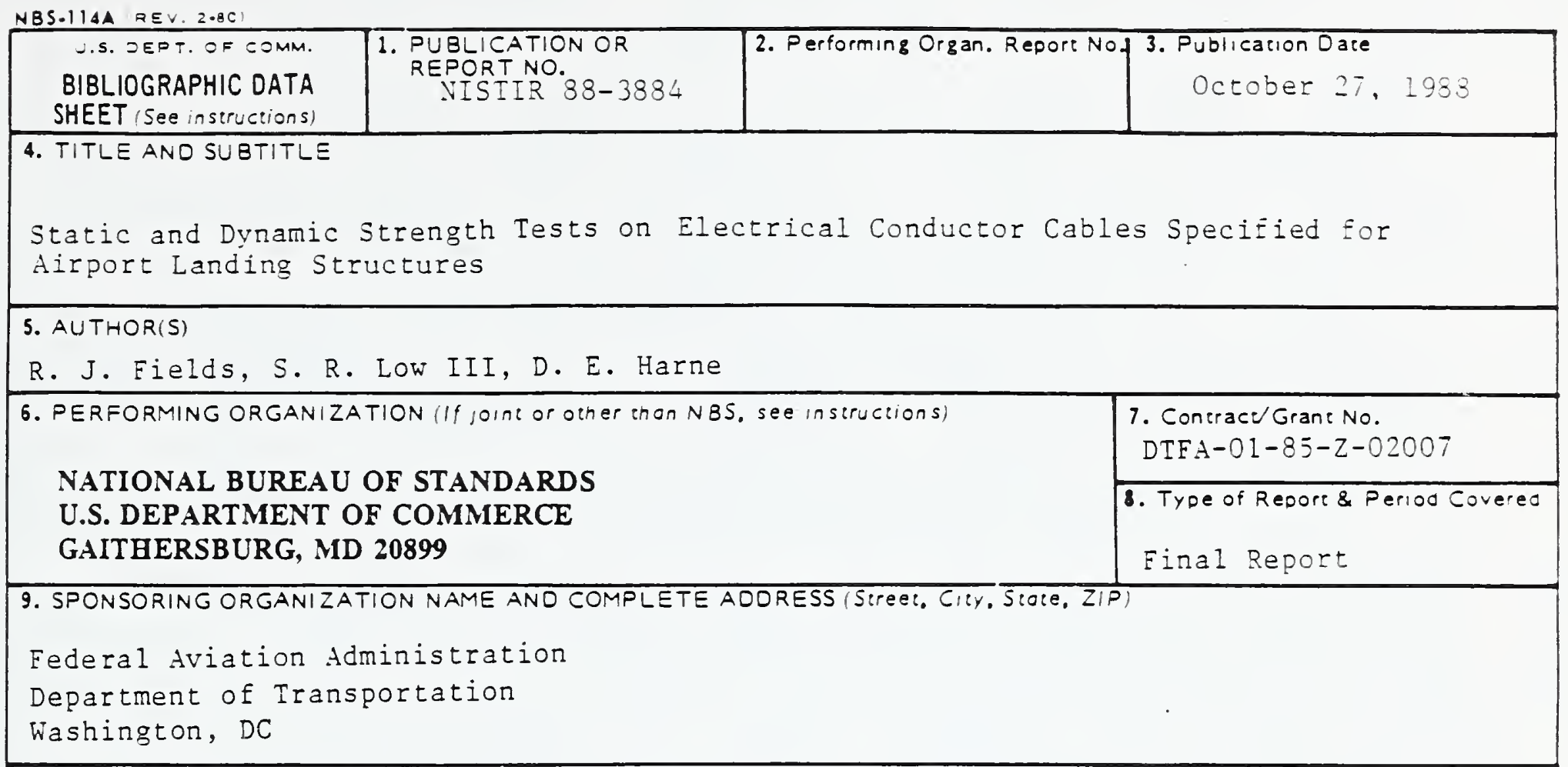

10. SUPPLEMENTARY NOTES

-- Document describes a comouter program; SF-185. FIPS Software Summary, is attached.

11. ABSTRACT (A 200-word or less factual summary of most significant informotion. If document includes a significant bloliogrodhy or literoture survey. mention it here)

This is a final report covering a series of static and dynamic tests on electrical conductors specified for use in landing aids on airport runways carried out by the Federal Aviation Administration. The structures are intended to be frangible so that they will break up readily if impacted, thus minimizing damage to the impacting aircraft. While the structures are frangible, they contain electrical cables which. due to the requirement of electrical conduction, are not frangible. In an actual impact, these cables do not break readily and tend to wrap around the aircraft. The tests authorized by the FAA were carried out to assess the force required to break through various types of FAA specified cables by a simulated aircraft impact. Furthermore, the effectiveness of using break-away connectors was evaluated to determine iz they would reduce the total load on an impacting aircraft.

In order to correctly design the dynamic test apparatus, it was necessary to know che approximate, expected load levels and cable elongations at fracture. Therefore a serieg of quasi-static tests were performed on the cables and break-away connectors. This report describes these quasi-static tests as well as the construction and application of the dynamic test apparatus.

12. KEY WORDS(Six to iwelve entries; alphobetical order: capltalize only proder names; and sedarate key words by semicolons) airport landing aids; break-away connector; cables; copperwire; dynamic strength tests; frangible structures; static strength

13. AVAILABILITY

XX Unlimited

- For Official Distribution. Do Not Release to NTIS

- Order From Suderintendent of Documents, U.S. Government Printing Office. Washington, O.C. 20402 .

EXt Order From National Technical Information Service (NTIS), Springfield, VA. 22161

14. NO. OF PRINTEO PAGES

81

15. Price

AO5 
$\cdots$

$-$ 

